\title{
AEROSPIKE THRUST VECTORING SLOT-TYPE COMPOUND NOZZLE
}

\author{
A Thesis \\ Presented to the \\ Faculty of California Polytechnic State University, \\ San Luis Obispo
}

In Partial Fulfillment

of the Requirements for the Degree

Master of Science in Mechanical Engineering

by

William Scott Case

June 2010 
(C) 2010

William Scott Case

ALL RIGHTS RESERVED 


\section{COMMITTEE MEMBERSHIP}

TITLE:

AUTHOR:

DATE SUBMITTED:

COMMITTEE CHAIR:

COMMITTEE MEMBER:

COMMITTEE MEMBER:
Aerospike Thrust Vectoring Compound Slot-Type Nozzle

William Scott Case

June 2010

William R. Murray, Professor of Mechanical

Engineering

Russel V. Westphal, Professor of Mechanical Engineering

Saeed Niku, Professor of Mechanical Engineering 


\section{ABSTRACT \\ Aerospike Thrust Vectoring Slot-Type Compound Nozzle William Scott Case}

A study of thrust vectoring techniques of annular aerospike nozzles was conducted. Cold-flow blow-down testing along with solid modeling and rapid prototyping technology were used to investigate the effects of slot size, placement, geometry and orientation. The use of slot-type compound nozzles proved to be a feasible approach to thrust vectoring. Previous methods of thrust vectoring have proved to be difficult to implement in a cost effective manner or have had limited effectiveness or durability.

Keywords: Thrust Vectoring, Aerospike, Compound Nozzle. 


\section{ACKNOWLEDGMENTS}

To my Parents for all their love and support and without whom none of this would be possible.

To Dr. Murray and Dr. Carpenter for all their help and guidance as well as the opportunity to take part in this project.

To my teammates Stan Beebe and Nick Rohlik for their assistance with the laboratory work and reports.

To Mr. Gerhardt for his assistance with set up and instruction of the test facilities.

To all my friends that helped push and support me to complete my degree. 


\section{Table of Contents}

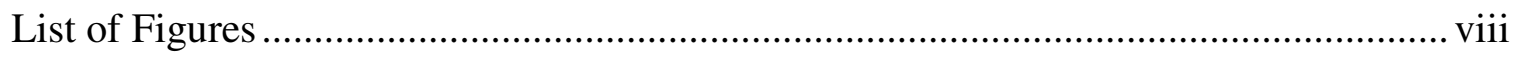

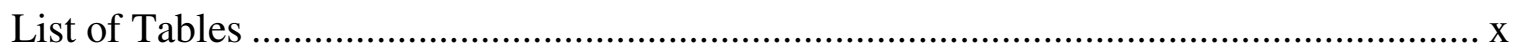

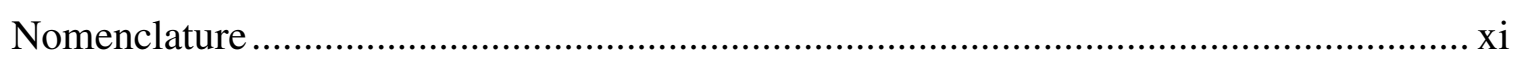

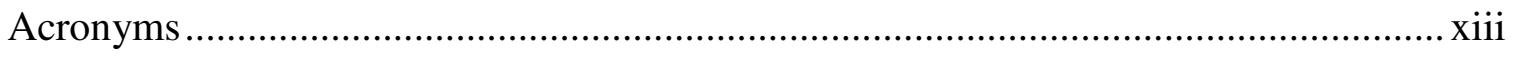

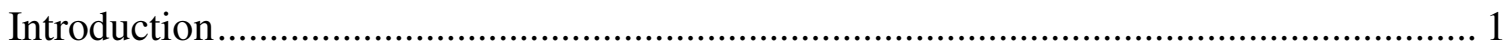

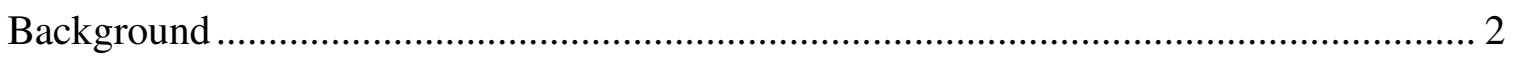

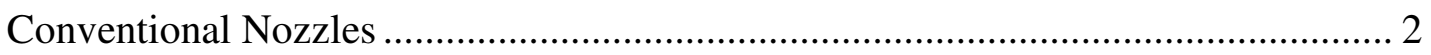

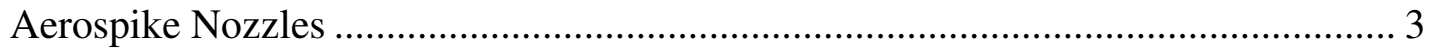

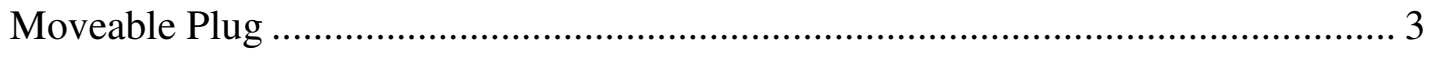

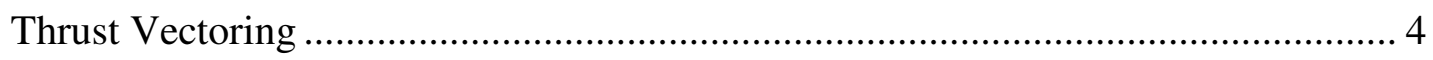

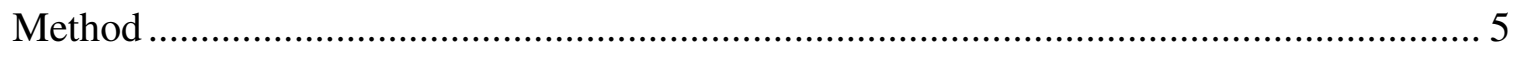

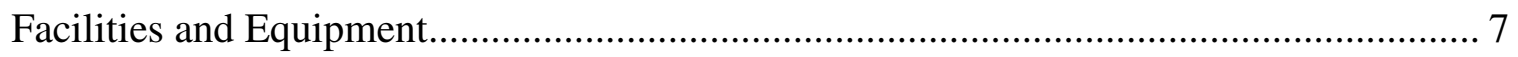

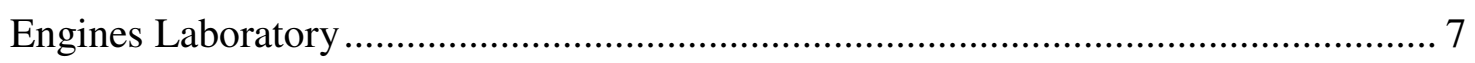

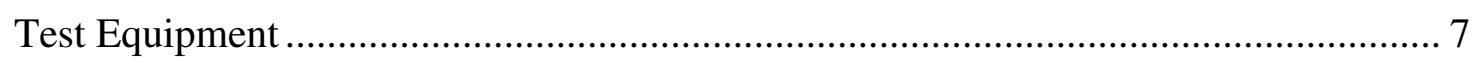

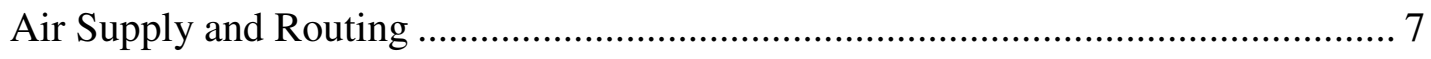

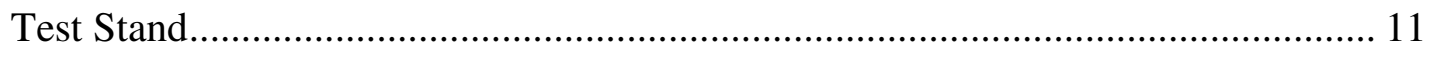

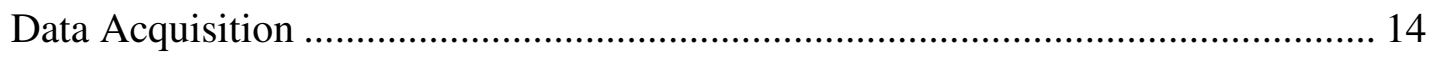

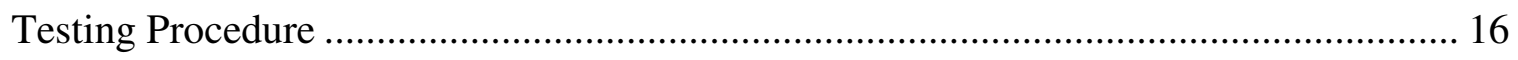

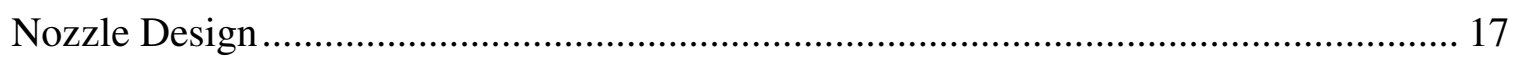

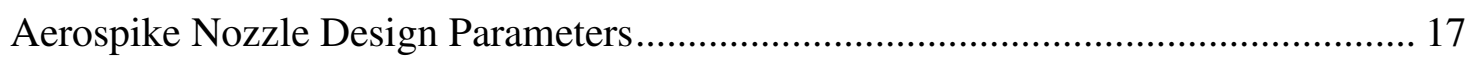

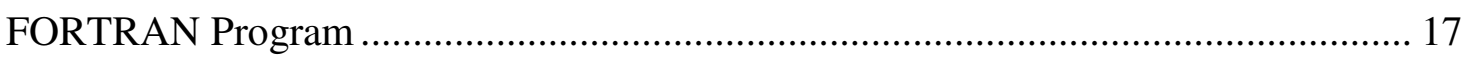

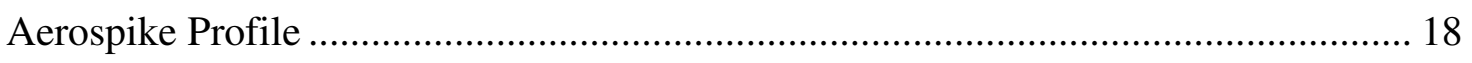

Thrust Vectoring Design ............................................................................... 18

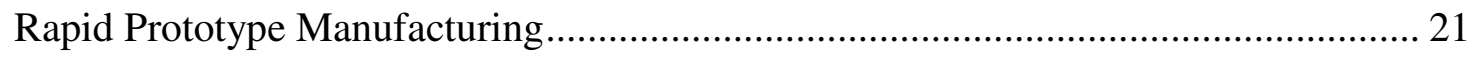

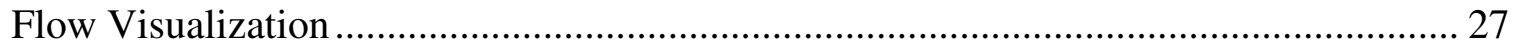

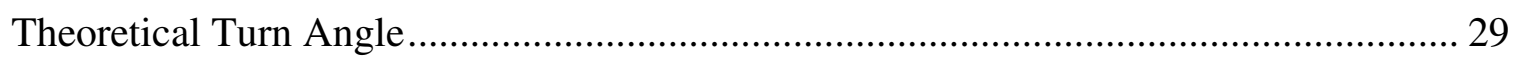




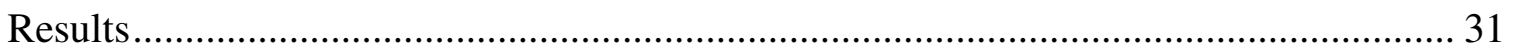

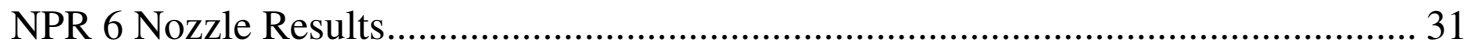

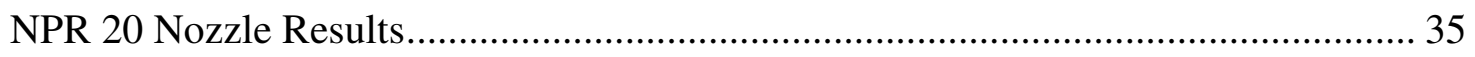

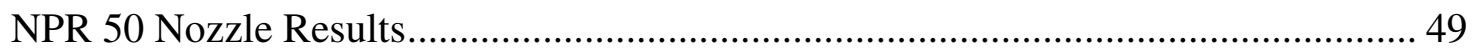

Resultant Turn Angle Based on Throat Area...................................................... 52

Axial Chamber Pressure Variation ........................................................................ 56

Turn Angle versus Chamber Pressure................................................................... 56

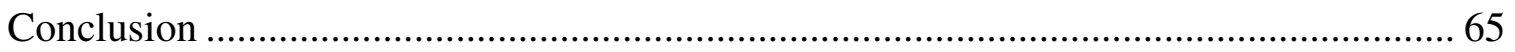

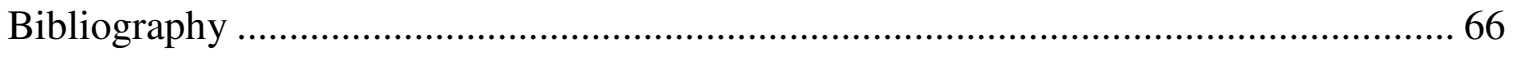




\section{List of Figures}

FIGURE 1. NPR 6 HOLE AND SLOT COMPOUND NOZZLES .............................................................................. 5

FIGURE 2: COMPRESSED AIR RECEIVER TANKS; LEFT $1400 \mathrm{FT}^{3}$ AND RIGHT $648 \mathrm{FT}^{3}$...................................... 9

FIGURE 3: 75 HP SSR INGERSOLL-RAND EP75 ELECTRIC COMPRESSOR; 330 ACFM AT 125 PSI.................... 9

FIGURE 4: AIR SUPPLY, CALIBRATED ORIFICE PLATES, VALVE CONTROLLERS AND THRUST VECTOR NOZZLE FLOW BENCH; U.S. PATENT NO. 6032545 T.W. CARPENTER AND J. GERHARDT CO-INVENTORS .10

FIGURE 5: ONE OF TWO BELLOWS ASSEMBLY ATTACHED TO THE TOROIDAL PLENUM .......................................10

FIGURE 6: SINGLE FLOW PLENUM ARRANGEMENT MOUNTED ON THRUST STAND ………............................11

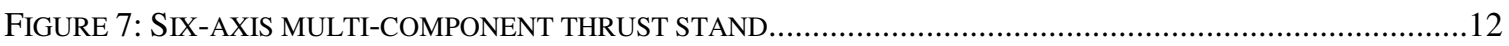

FIGURE 8: COORDINATE SYSTEM AND FORCE TRANSDUCER LOCATION FOR SIX-AXIS THRUST STAND .............13

FigURE 9: FLUKE HELIOS PLUS 2287A DATA ACQUISITION HARDWARE .......................................................15

FIGURE 10: PRESSURE TAP LOCATIONS FOR NPR 20 STRAIGHT NOZZLE...........................................................19

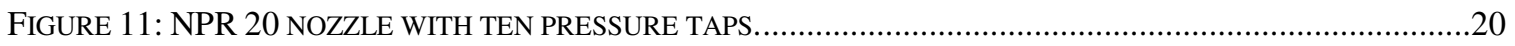

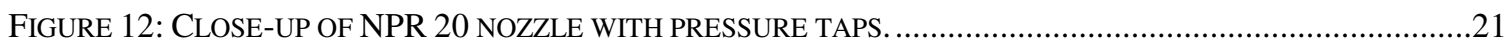

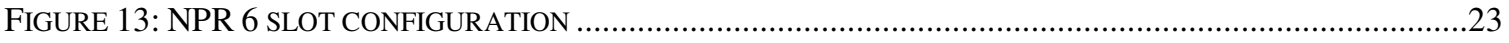

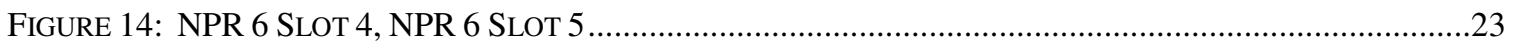

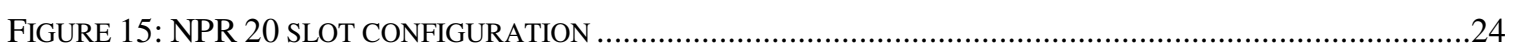

FIGURE 16: NPR 20 SLOT 3, NPR 20 SLOT 4, NPR 20 SLOT 5, NPR 20 SLOT 6 .........................................24

FIGURE 17: NPR 20 SLOT 8, NPR 20 SLOT 9, NPR 20 SLOT 10, NPR 20 SLOT 11 .......................................25

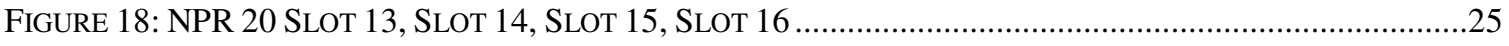

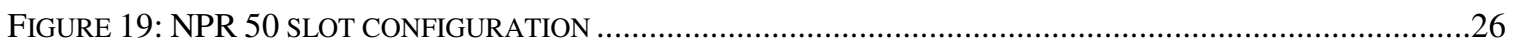

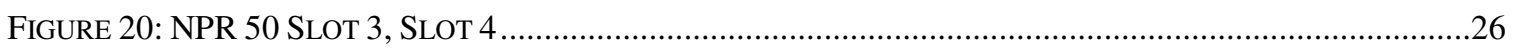

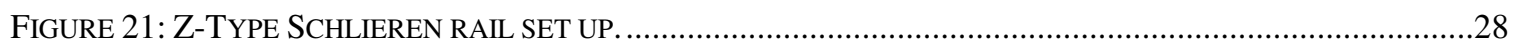

FIGURE 22: SCHLIEREN RAIL CONFIGURATION; (L-R) FIRST SURFACE PARABOLIC MIRROR, DENSITY FILTER, RED AND GREEN ACETATE FILTER, AND VIDEO CAMCORDER......................................................28

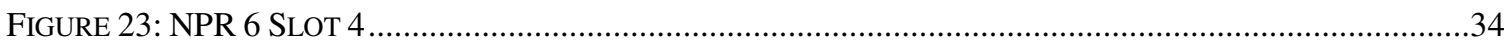

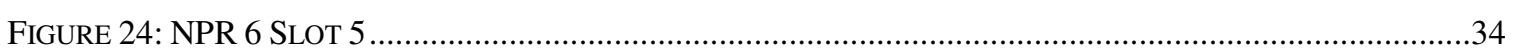

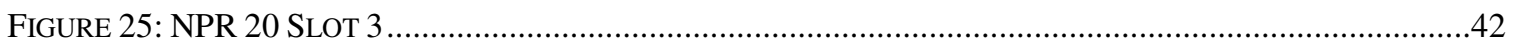

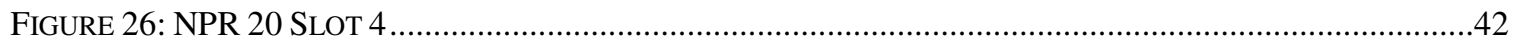

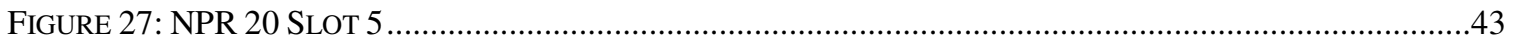

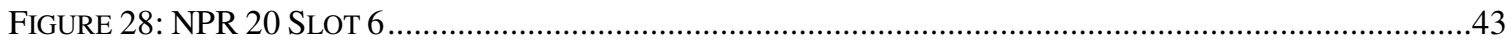

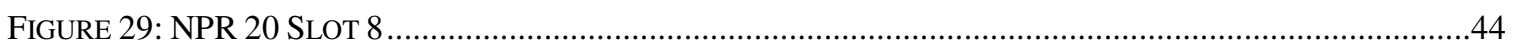

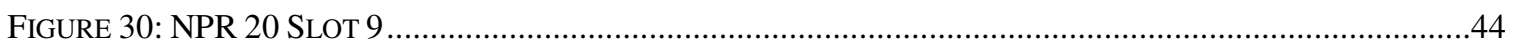

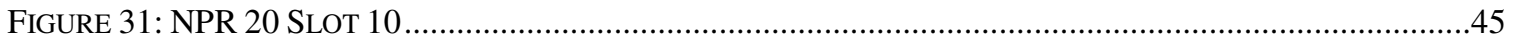

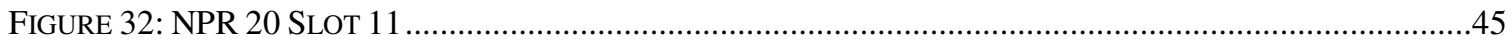

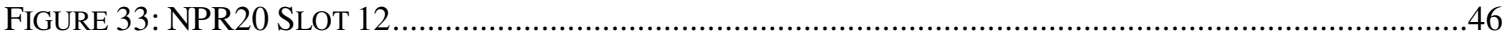

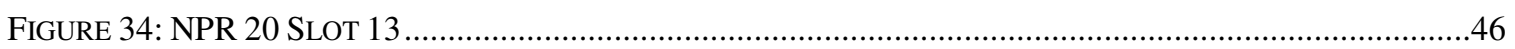




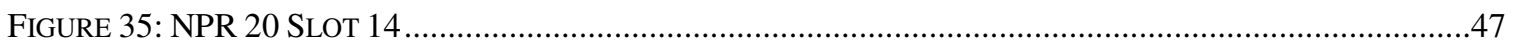

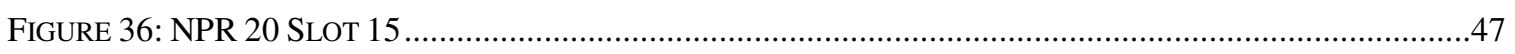

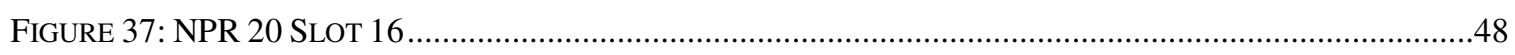

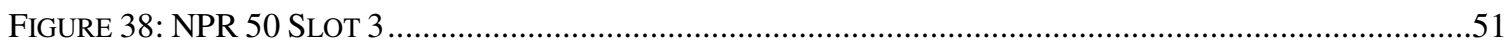

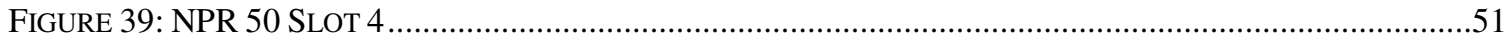

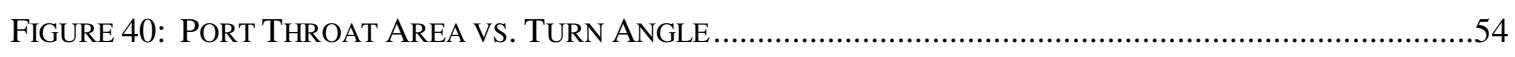

FIGURE 41: AXIAL PRESSURE DISTRIBUTION FOR NPR 20 AEROSPIKE NOZZLE.................................................56

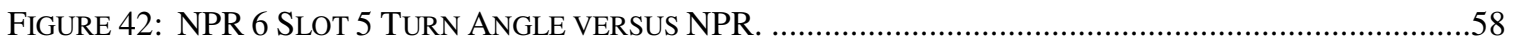

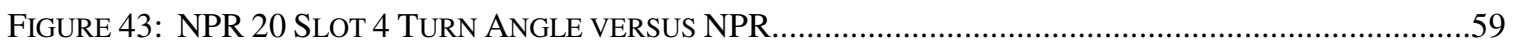

FIGURE 44: NPR 20 SLOT 12 TURN ANGLE VERSUS NPR...................................................................

FIGURE 45: NPR 50 SLOT 3 TURN ANGLE VERSUS NPR ...........................................................................60

FiguRE 46: NPR 6 SLOTTEd NOZZLES, MEASURED AND CALCULATEd VALUES. ...........................................61

FiguRE 47: NPR 20 SLOTTED NoZZLES, MEASUREd AND CALCULATEd VALUES. .......................................61

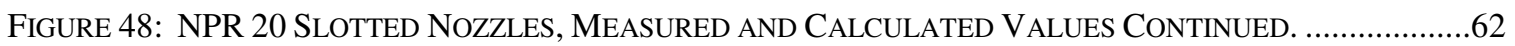

FiguRe 49: NPR 50 SLOTTED NoZZLES, MEASUREd AND CALCULATEd VALUES......................................62

FIGURE 50: PREDICTED VALUES BASED ON NPR FOR NPR 20 NOZZLES. ........................................................63

FIGURE 51: PREDICTED VALUES BASED ON NPR FOR NPR 50 NOZZLES. ......................................................64 


\section{List of Tables}

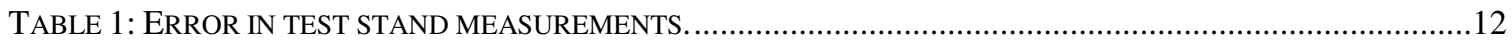

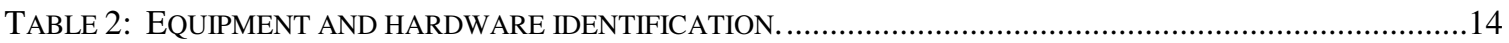

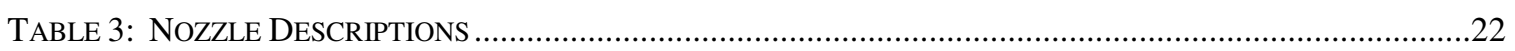

TABLE 4: SUMMARY OF BLOW-DOWN TEST RESULTS FOR NPR 6 PROTOTYPE AEROSPIKE NOZZLES. ...............33

TABLE 5: SUMMARY OF BLOW-DOWN TEST RESULTS FOR NPR 20 PROTOTYPE AEROSPIKE NOZZLES. ............39

TABLE 6: SUMMARY OF BLOW-DOWN TEST RESULTS FOR NPR 20 PROTOTYPE AEROSPIKE NOZZLES. ............40

TABLE 7: SUMMARY OF BLOW-DOWN TEST RESULTS FOR NPR 20 PROTOTYPE AEROSPIKE NOZZLES. ............41

TABLE 8: SUMMARY OF BLOW-DOWN TEST RESULTS FOR NPR 50 PROTOTYPE AEROSPIKE NOZZLES. ............50

TABLE 9: SLOT THROAT AREAS AND RESULTANT TURN ANGLE. ............................................................... 


\section{Nomenclature}

$F \quad$ Force

$1 b_{\mathrm{f}}$

$F_{i} \quad$ Ideal isentropic thrust

$w_{p} \sqrt{\frac{R}{g_{c}} \frac{2 \gamma}{(\gamma-1)}\left(T_{p}+460\right)\left(1-N P R^{\frac{\gamma}{(\gamma-1)}}\right)} \quad \mathrm{lb}_{\mathrm{f}}$

$F_{r} \quad$ Resultant thrust

$\sqrt{F_{x}^{2}+F_{y}^{2}+F_{z}^{2}}$

$\mathrm{lb}_{\mathrm{f}}$

M Moment

in- $1 b_{f}$

$P_{0} \quad$ Total nozzle chamber pressure

psig

$p_{a} \quad$ Atmospheric pressure

psia

$p_{e} \quad$ Static exit pressure

psig

$p_{o} \quad$ Orifice differential pressure

in $\mathrm{H}_{2} \mathrm{O}$

$p_{s} \quad$ Supply static pressure

psig

$T_{0} \quad$ Plenum total temperature

${ }^{\circ} \mathrm{F}$

$T_{s} \quad$ Supply total temperature

${ }^{\circ} \mathrm{F}$

$t \quad$ Air supply static temperature

$R \quad$ Gas constant

53.334

${ }^{\circ} \mathrm{F}$

$R$

$\left(f t \bullet l b_{f}\right) /\left(l b_{m} \bullet{ }^{\circ} R\right)$

$g_{c} \quad$ Proportionality factor

32.1740

$\left(l b_{m} \bullet f t\right) /\left(l b_{f} \bullet \sec ^{2}\right)$

$\approx 32.1740$

$f t / \sec ^{2}$

$g \quad$ Acceleration due to gravity

$\approx 1.4$ for air

$\gamma \quad$ Ratio of specific heats

$$
\text { (r) }
$$

$\Gamma \quad$ Specific heat relation

$$
\gamma\left(\frac{2}{(\gamma)}\right)^{\frac{(\gamma+1)}{2(\gamma-1)}}
$$

$w_{i} \quad$ Ideal mass flow rate

$$
\frac{\Gamma A_{t} g_{c} p_{a} N P R}{\sqrt{\gamma g_{c}\left(T_{p}+460\right)}}
$$

$l b_{m} / \mathrm{sec}$

$w_{p} \quad$ Measured mass flow rate

$$
0.09970190 \mathrm{CY}_{1} \mathrm{~d}^{2} \sqrt{\frac{p_{o} \rho_{f l}}{\left(1-\beta^{2}\right)}}
$$

$l b_{m} / \mathrm{sec}$

$\rho_{f l} \quad$ Fluid density

$$
\frac{144\left(p_{s}+p_{a}\right)}{R(t+460)}
$$

$l b_{m} / f t^{3}$

$d \quad$ Orifice plate diameter

1.80

in 
D Pipe inside diameter

$\beta \quad$ Ratio of orifice inside

diameter to pipe inside diameter

$\operatorname{Re}_{D} \quad$ Reynolds number

$$
\frac{D V \rho}{\mu}
$$

$Y_{1} \quad$ Expansion factor based on upstream pressure $\quad 1-\frac{\left(0.41+0.35 \beta^{4}\right) p_{o}}{27.73 \not p_{s}}$

C Discharge coefficient for calibrated orifice plate

$$
0.5959+0.312 \beta^{2.1}-0.1840 \beta^{8}+\frac{0.0900 \beta^{4}}{D\left(1-\beta^{4}\right)}-\frac{0.0337 \beta^{3}}{D}+\frac{91.71 \beta^{2.5}}{\operatorname{Re}_{D}^{0.75}}
$$

$\delta_{p} \quad$ Pitch vector angle

$$
\tan ^{-1}\left(\frac{F_{y}}{F_{z}}\right)
$$

$\delta_{y} \quad$ Yaw vector angle

$$
\tan ^{-1}\left(\frac{F_{x}}{F_{z}}\right)
$$

NPR Nozzle pressure ratio

$$
\frac{P_{c}}{p_{a}}
$$

$\mathrm{A}_{\mathrm{e}} \quad$ Exit area

A $\quad$ Throat area

$\varepsilon \quad$ Ratio of exit area to throat area $\quad \varepsilon=\frac{A_{e}}{A_{t}}$

Ma Mach number

a Speed of sound

$\mathrm{T}_{\mathrm{e}} \quad$ Temperature at slot exit

$\mathrm{V}_{\mathrm{e}} \quad$ Velocity at slot exit 


\section{Acronyms}

ABS Acrylonitrile Butadiene Styrene

ACFM Actual Cubic Feet per Minute

ASME American Society of Mechanical Engineers

CAD Computer Aided Design

CG Center of Gravity

IC Internal Combustion

NASA National Aeronautics and Space Administration

NPR Nozzle Pressure Ratio

RHRC Rolling Hills Research Corporation

RLV Reusable Launch Vehicles

SBIR Small Business Innovative Research

SSME Space Shuttle Main Engine

STTR Small Business Technology Transfer

TVC Thrust Vector Control 


\section{Introduction}

With the support of NASA(1), the Mechanical Engineering Department at the California Polytechnic State University located in San Luis Obispo has conducted research into the performance of aerospike nozzles. Different approaches have been studied for incorporating a thrust vectoring system as well as throttling capability into the annular aerospike nozzle. Due to the inherent altitude compensation capabilities of the aerospike nozzle, the overall goal of this research is to design advanced aerospike nozzles that may play an important role in helping to provide inexpensive access to low Earth orbit. Prior research at Cal Poly included the investigation of offset aerospikes, gimbled aerospikes, slotted nozzle body, a nozzle with a spike flap and one with a flap on the base. This initial research showed promise with the slotted compound nozzle and the use of flaps with the aerospike. The slotted compound nozzle concept is investigated further in this thesis. 


\section{Background}

\section{Conventional Nozzles}

The de Laval nozzle is perhaps the most commonly used nozzle in rockets today. The de Laval nozzle is characterized by its hourglass shape. In a properly designed nozzle, the exhaust gases leave the combustion chamber and enter the convergent section of the nozzle, where flow is subsonic, but increasing in velocity as it enters the throat. At the nozzle throat, the exhaust gases are now sonic (Mach number $=1.0$ ), which is known as choked flow. The divergent section accelerates the products of combustion that are supersonic at that point. At the exit of a properly designed conventional nozzle that is operating at its design condition, the exit flow is solely in the axial direction.

Conventional nozzles have reduced efficiency at altitudes lower or higher than the nozzle design altitude. The cause of the reduced efficiency is due to the difference between ambient pressure and the pressure of the exhaust gases. At lower than design altitudes, the pressure of the exhaust gases is not high enough to overcome the higher ambient pressure. The lower than ambient exit pressure causes the exhaust gases to be pushed inward by the higher atmospheric pressure. As a result, a condition referred to as overexpansion occurs, where the exhaust gases can separate from the interior wall of the nozzle, which in turn reduces thrust that is generated. At higher than design altitudes, the nozzle exhaust pressures are higher than atmospheric pressure. The exhaust gases are in an underexpanded state, where the exhaust will continue to expand past the nozzle exit. The exhaust gases have a region of expansion that is wasted due to the fact that it cannot exert thrust on the nozzle. Conventional bell-shaped nozzles work best when the pressure of the exhaust gases at the nozzles exit is equal to the atmospheric pressure. 
Unfortunately the bell-shape nozzle is designed for a single altitude at which to operate, thereby giving up efficiency above and below this altitude. In order to optimize the nozzle for differences in altitude while in flight, control of the nozzle contour, exit/throat area ratio, and length to maximize thrust at each altitude would be needed. Unfortunately, bell nozzles with variable geometry that can adapt to changes in altitude are mechanically complex, and are not cost effoctive.

\section{Aerospike Nozzles}

The altitude compensation ability of the aerospike nozzle is what makes this type of nozzle worth exploring. Initial research on the aerospike nozzle was first conducted in the 1950s, but there has been little testing done until the last twenty years(2). Theoretically the aerospike delivers excellent altitude compensation because the exhaust gases are at the same pressure as the ambient pressure. In comparison, the bell-shaped nozzle contains the exhaust gases and is fixed by the nozzle geometry until reaching the exit. In other words, since the exhaust gases of an aerospike are not contained by boundaries, the gas expansion is contained by the atmospheric pressure without regard to altitude.

\section{Moveable Plug}

To further optimize the altitude compensation capability of the aerospike, there has been research conducted to incorporate a moveable plug. By moving the aerospike plug it is possible to change the throat area to throttle the rocket body. Changing the throat area allows the rocket to adapt to differing atmospheric pressures and maintain an 
ideal nozzle pressure ratio(3). Adapting to changing atmospheric pressures makes the nozzle ideal for greater number of altitude ranges.

\section{Thrust Vectoring}

The purpose of thrust vectoring is to be able to turn a rocket body or aircraft by directing the thrust of the engine. The forces produced by the exiting exhaust gases are manipulated from the axial direction to produce a side or vertical force. The resulting force vector will have an axial component in line with the body that propels the aircraft forward and a radial or side force that will result in a turn angle of the body. Some aircraft that have incorporated thrust vectoring techniques are the McDonnel Douglas F15 and F/A-18, the Boeing X-32, the Lockheed Martin F-22 Raptor, and the Space Shuttle Solid Rocket Booster. Most thrust vectoring systems incorporate three main components: 1) an exhaust stream that produces the force or thrust; 2) a directing surface in which to control the exhaust stream; and 3) a way to activate or control the directing surface. The most common techniques used in thrust vectoring are gimbaling the nozzle

or the use of exterior vanes. In gimbaling, the nozzle is swiveled off axis causing the aircraft to rotate relative to its center of gravity or CG. The second most common technique is the use of vanes to push the exhaust stream a certain direction. These vanes are panels that are pushed directly into the exhaust stream to deflect the exhaust gases. The scope of this thesis is to introduce and examine an alternative approach to thrust vectoring for an aerospike nozzle using a slot-type compound nozzle configuration. 


\section{Method}

Methods that are now being researched could be considered a combination of the two previous methods. Such a combination method would be to install fins on a gimbaled aerospike. The gimbaled aerospike with fins has the advantage of combining the two methods and in theory should be able to outperform a single method by itself. This method could prove to be very effective but may be hard to implement. Due to the fins being in direct contact with the exhaust gases at all time, the materials will be susceptible to break-down and erosion with the prolonged exposure to these hot exhaust gases. Another proposed method is the introduction of compound nozzles. These nozzles are basically similar in function to the standard aerospike nozzle but have in essence a secondary throat directed radially outwards to induce thrust vectoring. When called upon the secondary nozzle is opened to allow gases to pass through. Two configurations of this type of nozzle have been studied to date, the first is a hole configuration, and the second is a slot configuration. Examples of these different nozzle configurations are illustrated in Figure 1. In the remainder of this study, the slotted compound nozzle configuration is explored in greater detail.

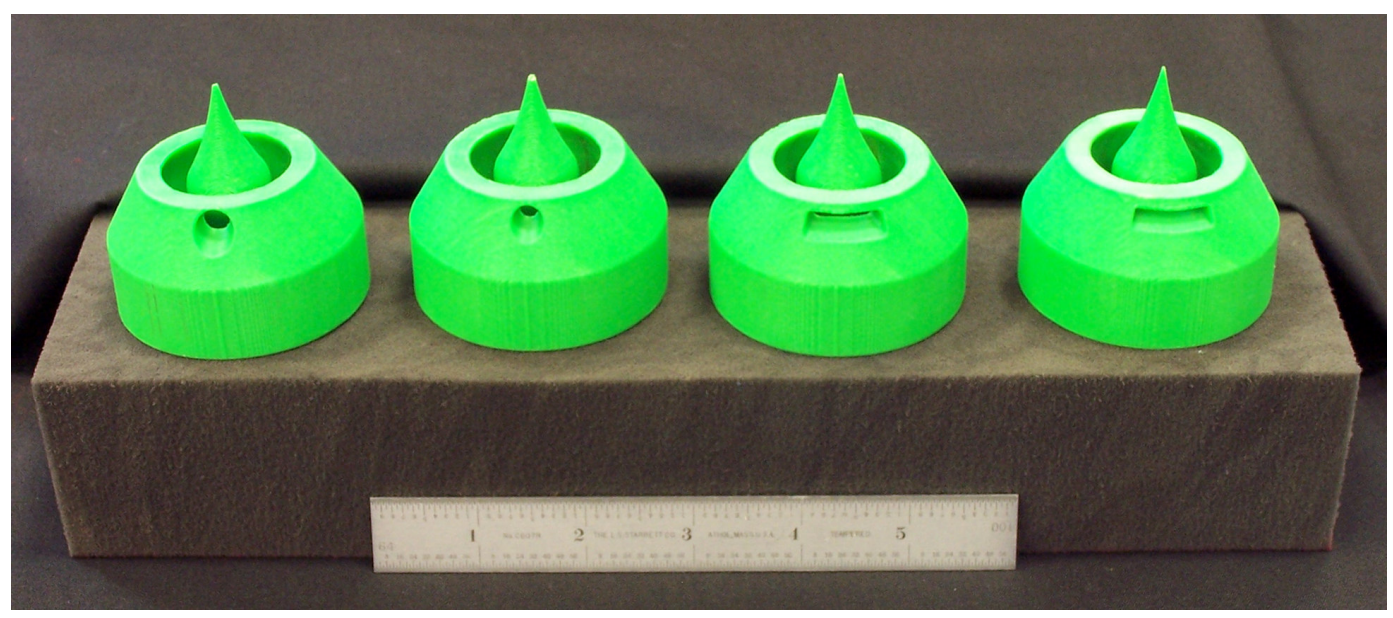

Figure 1: NPR 6 hole and slot compound nozzles. 
Compound nozzles were analyzed using a cold-flow method of testing. The nozzles were designed in a CAD program and were constructed using 3-D printing, which is also known as rapid prototyping. The rapid prototyped nozzles were inserted into a test stand and subjected to blow-down tests using compressed air at 110 to 120 psig. To analyze the thrust vectoring capability of each nozzle, the test conditions and loads produced, were collected with the data acquisition instrumentation along with Schlieren photography and utilized for interpreting flow stability, measured turn angles and forces. 


\section{Facilities and Equipment}

\section{Engines Laboratory}

Experimental testing was conducted using the cold-flow blow-down facility within the Engines Laboratory. The Engines Laboratory is located in the Department of Mechanical Engineering at California Polytechnic State University at San Luis Obispo. The test stand located inside the Engines Laboratory facility was adapted from prior research (4). The test stand was originally set up to run dual flow nozzles used in experiments for thrust vectoring analysis of the F/A-18 HARV. Half of the system was adapted to run the aerospike thrust vector control (TVC) tests. The test stand is isolated in a separate room and is controlled from outside to ensure safety. The supplied air is plumbed in from holding tanks on the exterior of the building.

\section{Test Equipment}

\section{Air Supply and Routing}

When conducting cold-flow blow-down experiments, it is necessary to have sufficient air supply for the duration of the test runs. In order to supply the amount of air needed for the blow-down tests, two air tanks are linked together just outside the Engines Laboratory. The total capacity of the air tanks combined is approximately 2050 cubic feet. This volume provided us enough air supply and sustained pressure to allow a 20 second duration of fully developed flow in a nozzle designed with a Nozzle Pressure Ratio (NPR) of 6. Nozzle Pressure Ratio is defined as the ratio of the absolute chamber pressure to the absolute atmospheric pressure. 
The air supply tanks are filled by a 75 horsepower Ingersoll-Rand compressor to a pressure of 120 psig. The air is routed into the Engine Laboratory by 3" diameter piping and is fed to the test stand through a 1.8" A.S.M.E. calibrated orifice plate, which determines the mass flow rate. A Worcester flow control valve controls the feed of supply air into the test stand and maintains plenum pressure to within 2.6 psig (5). In order to isolate the test stand, the airflow is split into two pipes and enters the test stand from opposite sides. The purpose of splitting the airflow is to cancel out the flow forces caused by the momentum in the air supply lines as they enter the stand. As supply pressure increases, the chamber and lines expand. Externally pressurized bellows are incorporated into the supply line on each side to accommodate these changes in dimensions. Externally pressurized bellows behave like a linear spring and the effects of these changing dimensions can be calibrated for. Following the bellows, the air enters the plenum located at the base of the stand. The air plenum is designed in a toroidal shape and theoretically cancels out the momentum forces of the air flow into the stand. With this equipment set up most of the effects of pressurizing the system and the dynamic flow effects are accommodated. However there are still minor coupling forces and momentum effects. These effects were calibrated out from the data acquired through the use of correction formulas developed in prior research, and static and dynamic calibration measurements. Photos of the air supply tanks, compressor and routings are shown in Figures 2-6. 


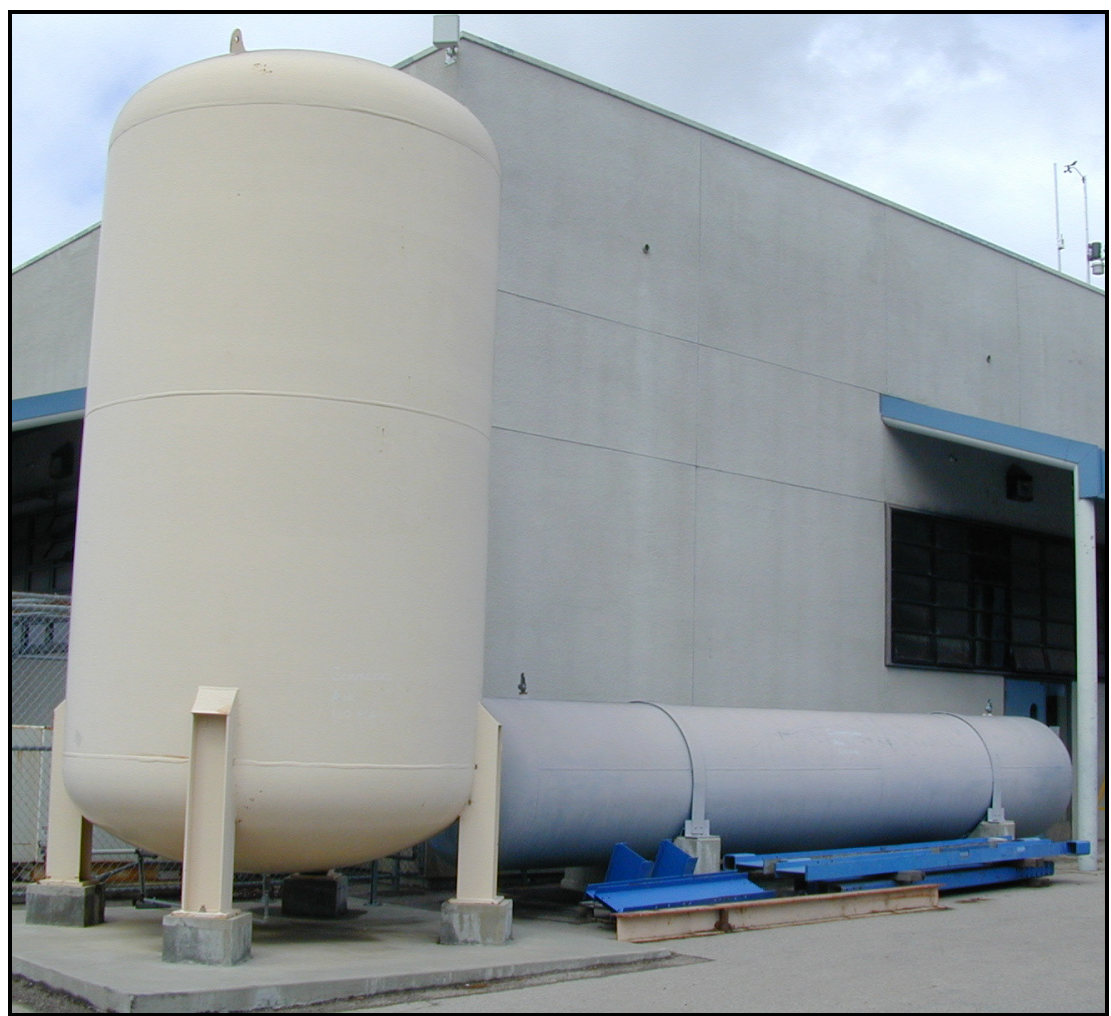

Figure 2: Compressed air receiver tanks; left $1400 \mathrm{ft}^{3}$ and right $648 \mathrm{ft}^{3}$.

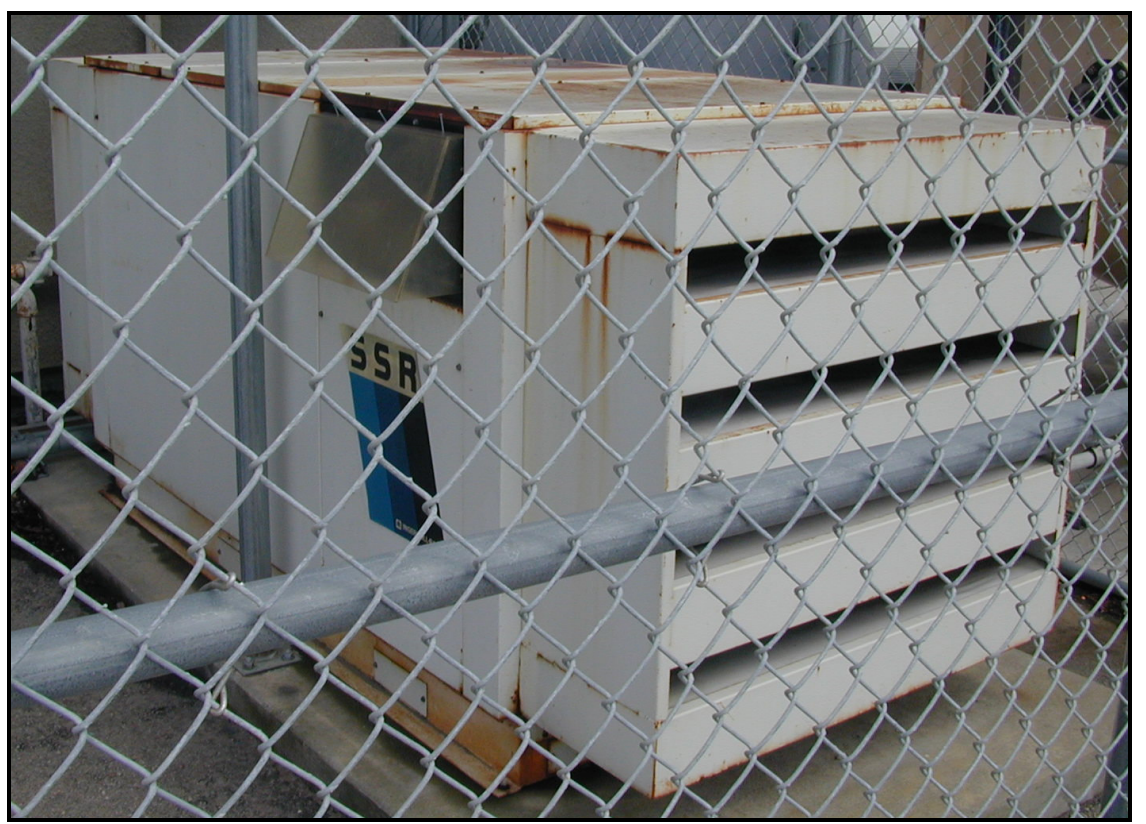

Figure 3: 75 hp SSR Ingersoll-Rand EP75 electric compressor; 330 ACFM at 125 psig. 

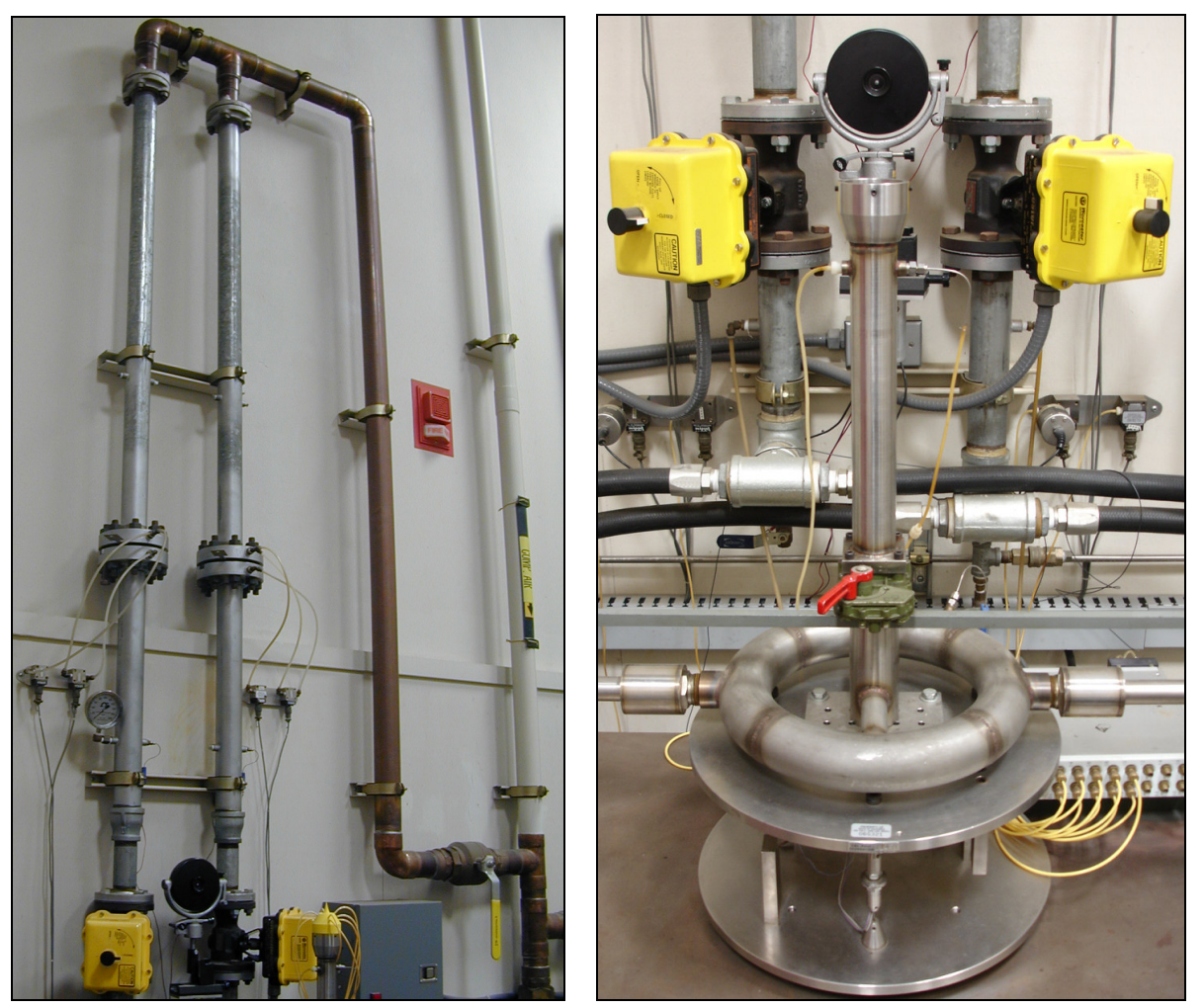

Figure 4: Air supply, calibrated orifice plates, valve controllers and thrust vector nozzle flow bench; U.S. Patent No. 6032545 T.W. Carpenter and J. Gerhardt co-inventors.

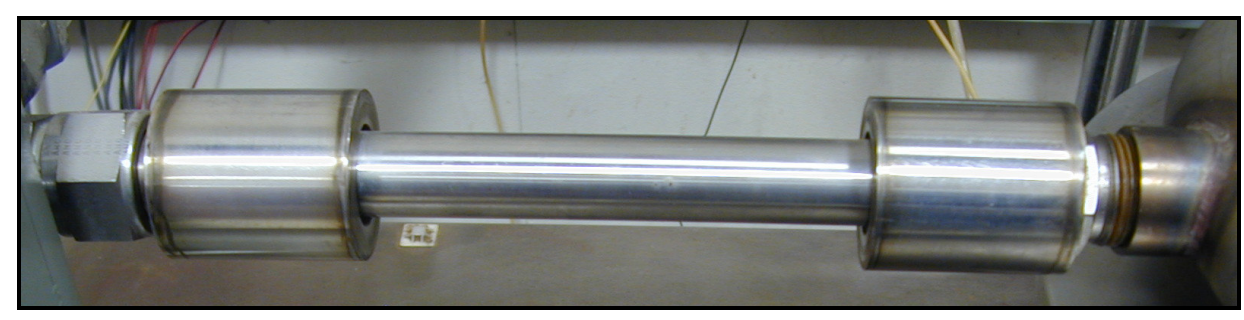

Figure 5: One of two bellows assembly attached to the toroidal plenum. 


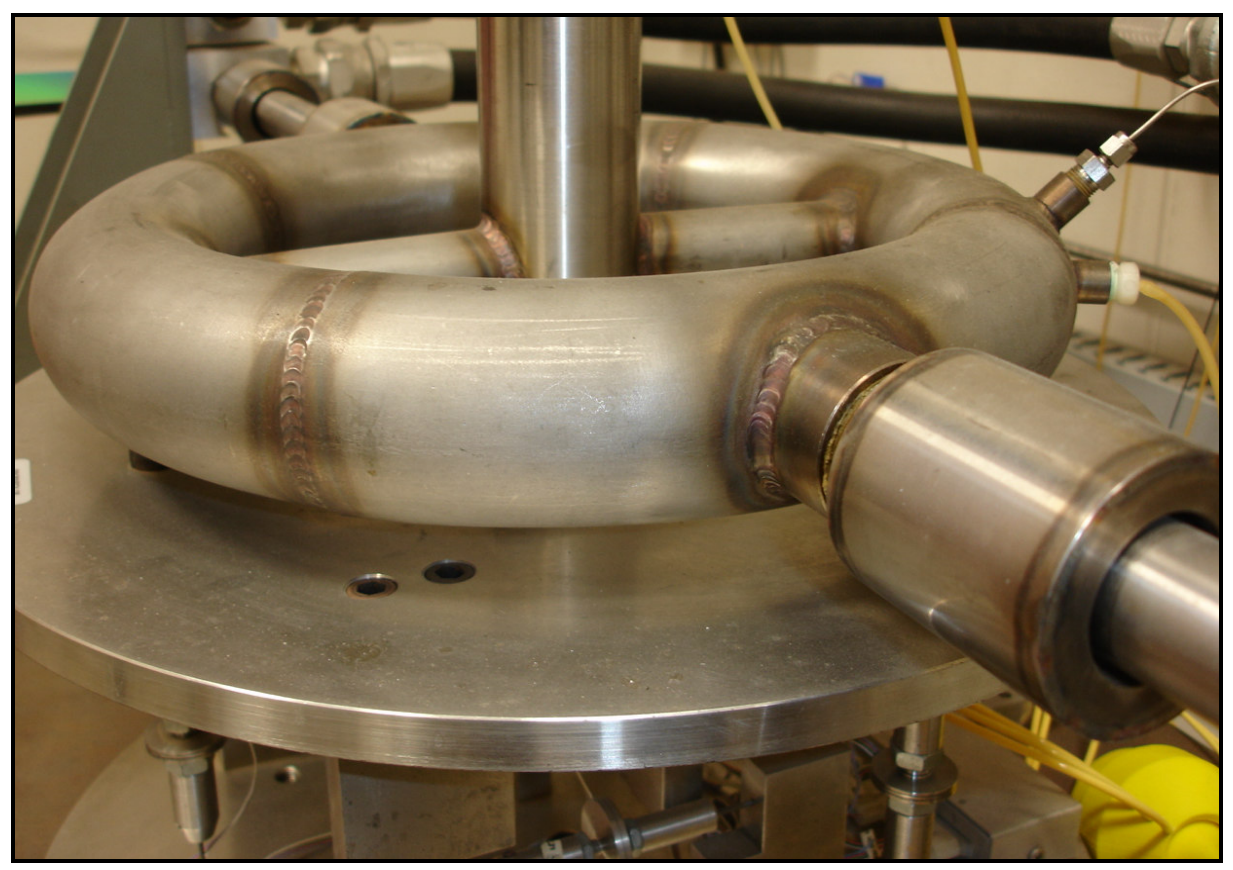

Figure 6: Single flow plenum arrangement mounted on thrust stand.

\section{Test Stand}

The test stand was built with six load cells. Three load cells were used to measure vertical force or thrust, and the remaining three were configured to measure horizontal forces. Each vertical load cell can accommodate up to $250 \mathrm{lb}_{\mathrm{f}}$ and each horizontal load cell can accommodate up to $25 \mathrm{lb}_{\mathrm{f}}$. The specialized configuration of these load cells provide axial rigidity without transverse rigidity, which makes it possible to take these measured readings and determine the resulting forces $\left(F_{x}, F_{y}, F_{z}\right)$ and moments $\left(M_{x}, M_{y}\right.$, $M_{z}$ ) at the base of the stand due to flow exiting the nozzle. Table 1 lists the measured forces and moments with their corresponding accuracies (4). A diagram and picture of the six-axis multi-component test stand can be seen in Figures 7 and 8 . Table 2 discusses the equipment used in the test apparatus. 
Table 1: Error in test stand measurements.

\begin{tabular}{|l|l|}
\hline Force & Error in force \\
\hline$F_{x}$ & $+/-0.2 \mathrm{lbf}$ \\
\hline$F_{y}$ & $+/-0.129 \mathrm{lbf}$ \\
\hline$F_{z}$ & $+/-0.34 \mathrm{lbf}$ \\
\hline Moment & Error in moment \\
\hline$M_{x}$ & $+/-1.81 \mathrm{in}-\mathrm{lbf}$ \\
\hline$M_{y}$ & $+/-2.2 \mathrm{in}-\mathrm{lbf}$ \\
\hline$M_{z}$ & $+/-0.52$ in-lbf \\
\hline Angle & Error in angle \\
\hline$\delta_{\text {pitch }}$ & $\pm 0.5^{\circ}$ \\
\hline$\delta_{\text {yaw }}$ & $\pm 0.5^{\circ}$ \\
\hline
\end{tabular}

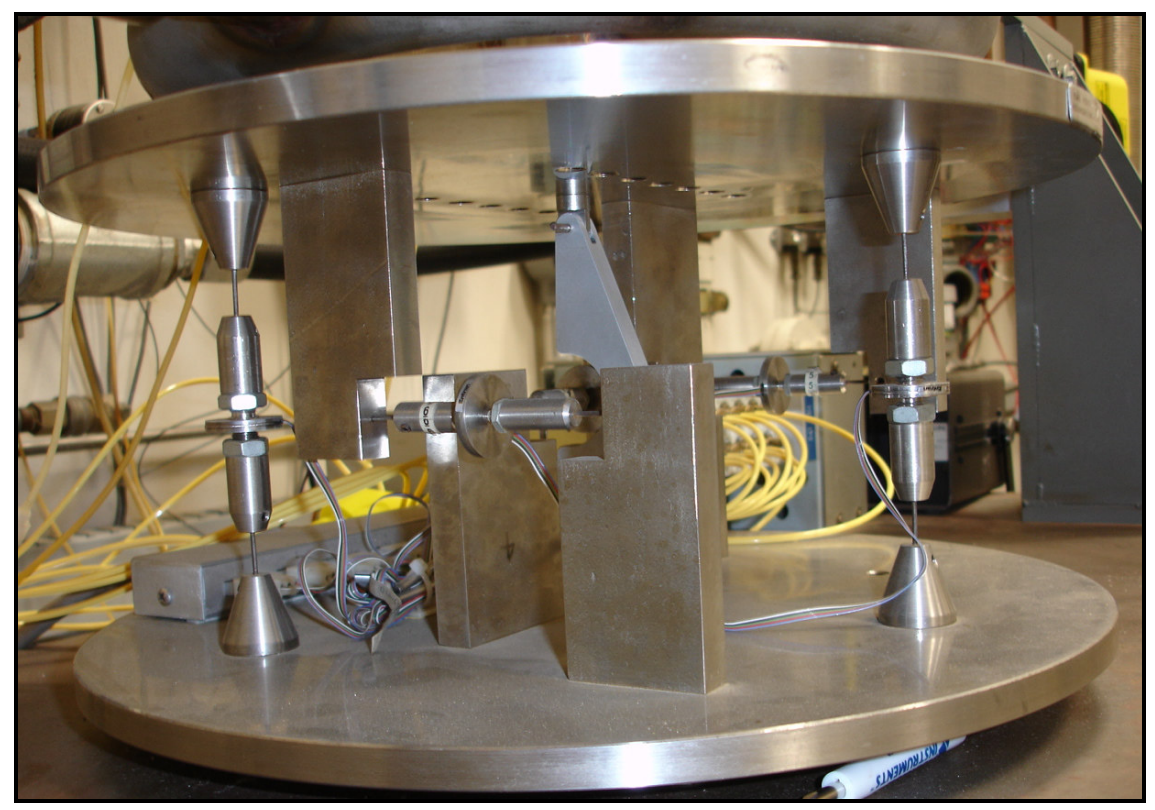

Figure 7: Six-axis multi-component thrust stand. 


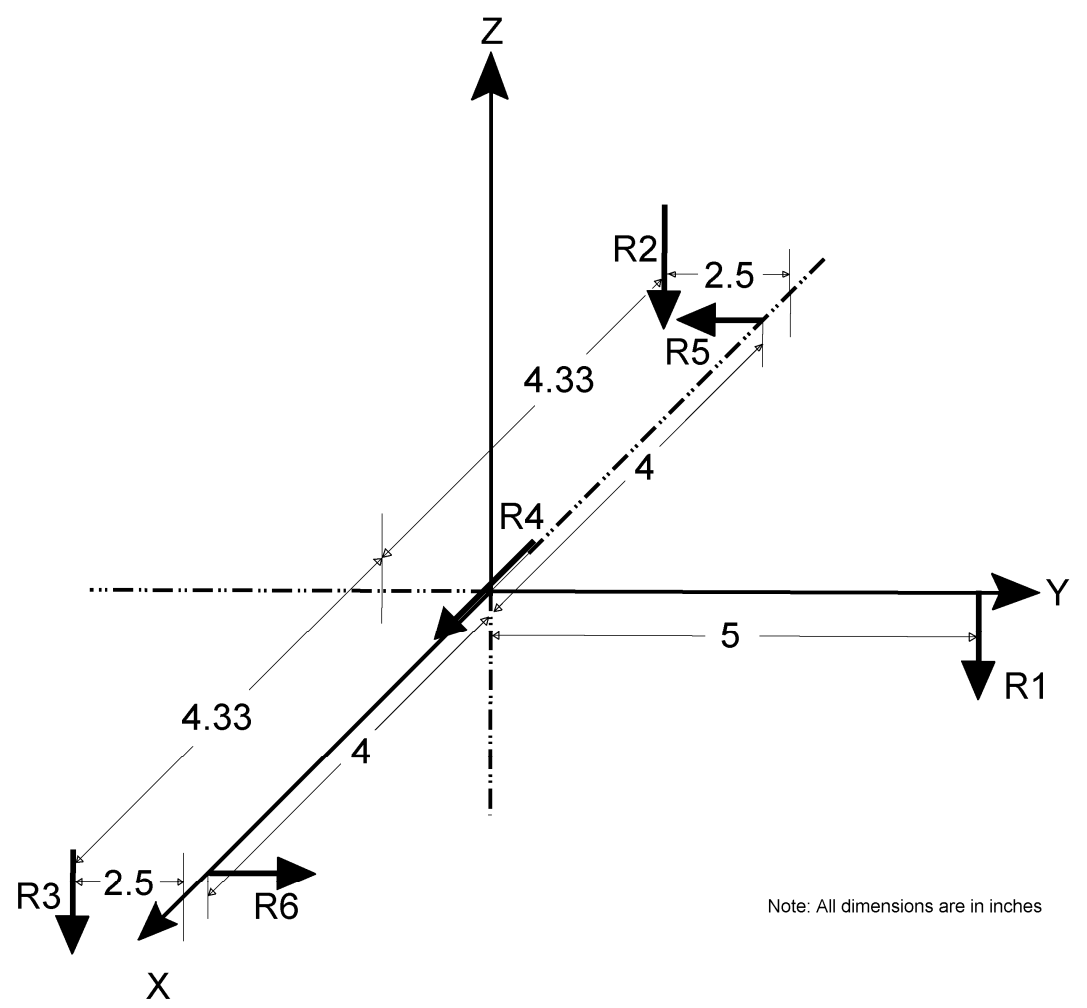

Figure 8: Coordinate system and force transducer location for six-axis multi-component thrust stand. 
Table 2: Equipment and hardware identification.

\begin{tabular}{|c|c|c|c|}
\hline Item & Manufacturer & Model & Serial Number \\
\hline Supply Regulating Valves & Worcester Controls & $\begin{array}{l}\text { L: 2CPT5146PT150A60P2 } \\
\text { R: 2CPT5146PT150A60P3 }\end{array}$ & $\begin{array}{l}\mathrm{n} / \mathrm{a} \\
\mathrm{n} / \mathrm{a}\end{array}$ \\
\hline Supply Regulating Valve Controllers & Worcester Controls & HQ99 & $n / a$ \\
\hline Data Collection Pressure Transducers & Validyne & DP-15 w/type 50 \&32 diaphragms & $\mathrm{n} / \mathrm{a}$ \\
\hline Pressure Feedback Pressure Transducers & Setra & $\mathrm{C} 206$ & $\begin{array}{l}\text { L: } 429440 \\
\text { L: } 429438 \\
\end{array}$ \\
\hline Load Cells & Entran & $\begin{array}{l}\text { ELF-TC1000-250 } \\
\text { ELF-TC1000-25 }\end{array}$ & $\begin{array}{l}\text { R1: } 89 H 89803-Y 10 \\
\text { R2: } 89 H 88 L 13-Y 09 \\
\text { R3: } 89 H 88 L 13-Y 11 \\
\text { R4: } 89 H 88 E 03-Y 12 \\
\text { R5: } 89 H 88 K 23-Y 07 \\
\text { R6: } 89 H 88 \text { K09-Y12 }\end{array}$ \\
\hline Data Collection Pressure Amplifier & Validyne & CD280-DUAL & 105915 \\
\hline Signal Conditioners & Entran & IMV-15715/40A-PW & $\begin{array}{l}\text { R1: 92F92F30-M01 } \\
\text { R2: } 92 \mathrm{~F} 92 \mathrm{~F} 30-\mathrm{M} 02 \\
\text { R3: } 92 \mathrm{~F} 92 \mathrm{~F} 30-\mathrm{M} 03 \\
\text { R4: } 92 \mathrm{~F} 92 \mathrm{~F} 30-\mathrm{M} 04 \\
\text { R5: } 92 \mathrm{~F} 92 \mathrm{~F} 30-\mathrm{M} 05 \\
\text { R6: } 92 \mathrm{~F} 92 \mathrm{~F} 30-\mathrm{M} 06\end{array}$ \\
\hline Data Collection Unit & John Fluke Mfg. Co. & Helios Plus $2287 \mathrm{~A}$ & 585500 \\
\hline Data Collection Software & John Fluke Mfg. Co. & Helios Logger Pkg. Ver 1.1 & n/a \\
\hline Personal Computer & Dell & Optiplex GX240 & D2B3011 \\
\hline Video Recorder & Sony & SLV-R1000 & AK8SLVR1000 \\
\hline Air Compressor & Ingersoll Rand & SSR EP-75 & $n / a$ \\
\hline
\end{tabular}

\section{Data Acquisition}

Data was collected using a Fluke Helios Plus 2287A data acquisition system taking measurements at one second intervals. Pressure taps, load cells and thermocouples were sampled at various locations and the resulting data written into a file. These data files were imported into Excel and processed with macros to arrange the data into a useable format and to output quantifiable data. Only data representing the initial condition and steady-state test condition were processed.

Mass flow rate was calculated using pressure tap data upstream and downstream of the orifice plate along with a downstream temperature reading. The total pressure in 
the nozzle was calculated using the average of the individual pressure readings over the measured data points. A photograph of the data acquisition system can be seen in Figure 9.

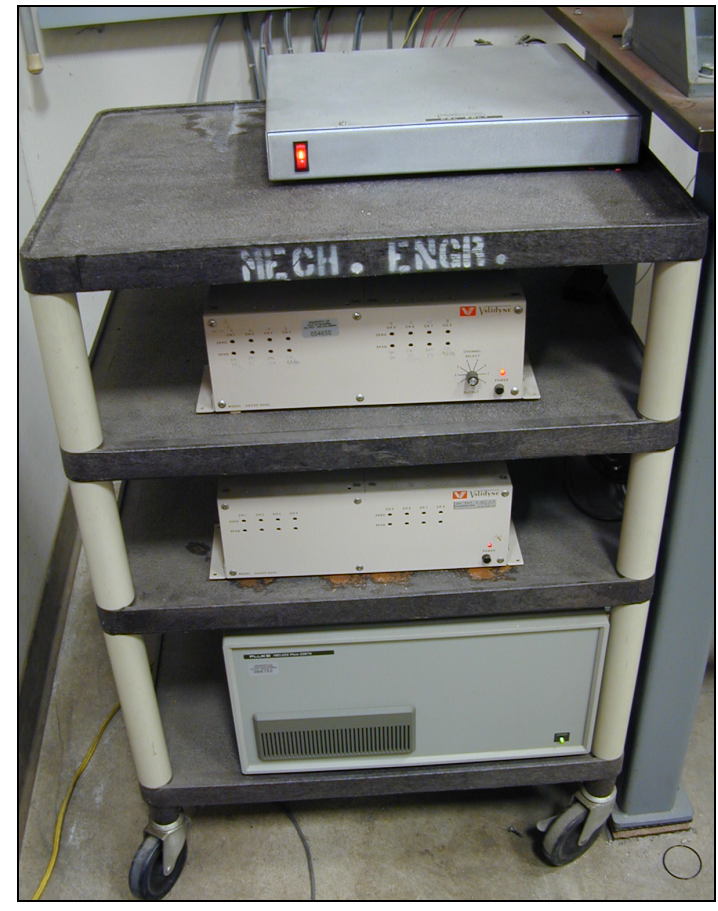

Figure 9: Fluke Helios Plus 2287A data acquisition hardware. 


\section{Testing Procedure}

The following procedures are used to setup the test stand and conduct blow-down tests. Due to ambient air being compressed to fill the tanks, the collected moisture from the air being used must be purged, so the moisture relief valve on each air tank is momentarily opened to allow the collected water to escape. With the moisture removed from the air supply, the Fluke Helios data acquisition system and the power supply to the actuator control valve are switched on. The system inside the test cell can be charged with air by opening a shut-off valve upstream from the test stand. With the air lines charged, the Helios data acquisition is initialized to record measurements. Once the data acquisition is initialized and the selected nozzle is in place, a blow-down test can be conducted. The data acquisition is started prior to opening the control valve. This allows the collection of data with no flow through the test stand, which is used to set the baseline condition. After the baseline has been established, the control valve is activated and the test stand comes up to pressure. The transient phase of the test run usually takes 15-30 seconds depending on nozzle geometry. Once steady-state conditions have been reached, the run continues for another 20 seconds before the data acquisition is stopped. Twenty seconds of data at steady-state conditions is sufficient for the averaging done in data processing. Once the data collection has been terminated, the control valve is closed to end the blow-down run.

The data is converted to a Microsoft Excel compatible format and imported to a spreadsheet using macros. The data is calculated to show the results of the blow-down test. This information can be evaluated for the results produced by each particular nozzle configuration. 


\section{Nozzle Design}

\section{Aerospike Nozzle Design Parameters}

The aerospike nozzles considered were designed to three NPRs: 6, 20 and 50. These NPR parameters were specifically chosen for the following reasons. The NPR 6 was chosen due to the constraint of the current test facility. The air supply pressure of 125 psig would allow up to an NPR of 9.5, but due to the volume of air used and the holding capacity of the two air tanks, steady-state flow would not be established with enough duration to gather sufficient data. In order to have tests of sufficient duration, an NPR 6 configuration was chosen. In the final phase of the STTR-II T2.02-9951, 2004 contract (1), the test facility will be upgraded to support 300 psig test runs. A 300 psig supply pressure will allow tests of a sufficient pressure for an NPR 20 nozzle. The NPR 50 design parameter was chosen to match the NASA Dryden aerospike flight tests in March 2004. The NPR 50 nozzle, although ran at lower than design pressure, would allow us to compare results obtained from the NASA Dryden experiments by scaling up or providing data useful for correlating analytical calculations.

\section{FORTRAN Program}

The nozzle designs tested where based on nozzle contours and design parameters constructed using a NASA FORTRAN program(6). The design method for the program was based on simple wave flow concepts. This program is based on calculating small intervals along the axis of symmetry, using the thrust coefficient, specific impulse, and dimensionless contour coordinates. These parameters are based on several basic concepts of 1-D isentropic supersonic flow and Prandtl-Meyer expansion wave theory. 


\section{Aerospike Profile}

The resulting aerospike contour line from the FORTRAN program is then imported into Solidworks by way of an $x-y$ plot curve. These points are used to define a 2-D spline curve, which is then circular extruded to give the shape contour of the aerospike body and corresponding throat contour. The rest of the nozzle body is constructed to interface with the test stand and to support the plug that is centrally located.

\section{Thrust Vectoring Design}

The approach used to induce thrust vectoring was to create a compound nozzle by adding a secondary port to the side of the nozzle body. This secondary port has been refined over the course of experimentation based on discoveries made throughout the process. The criteria used for evaluating the secondary port was, the direction of flow exit, measured forces and the resultant turn angle. By interpreting the results in each run and by visual inspection of the color Schlieren video, adjustments could be made to maximize the radial force generated by the secondary port. In the course of these refinements, many aspects of the geometry were considered. These adjustments varied the axial position of the secondary port with respect to the axis of symmetry, the exit angle relative to horizontal, and the entrance effects of the secondary port, as well as secondary port area.

In addition to the interpretation techniques previously mentioned, a pressure distribution along the inside wall of the nozzle body was measured using pressure taps located at fixed intervals along the axis of the nozzle. The pressure distribution was 
investigated to determine if there was a high pressure region along the inside of the nozzle body. A higher pressure region would help to determine the axial placement of the secondary port along the aerospike body to maximize the radial forced produced. A cross-sectional drawing of the NPR 20 nozzle with pressure taps is shown in Figure 10, and photographs of this nozzle mounted on the test stand are shown in Figures 11-12.

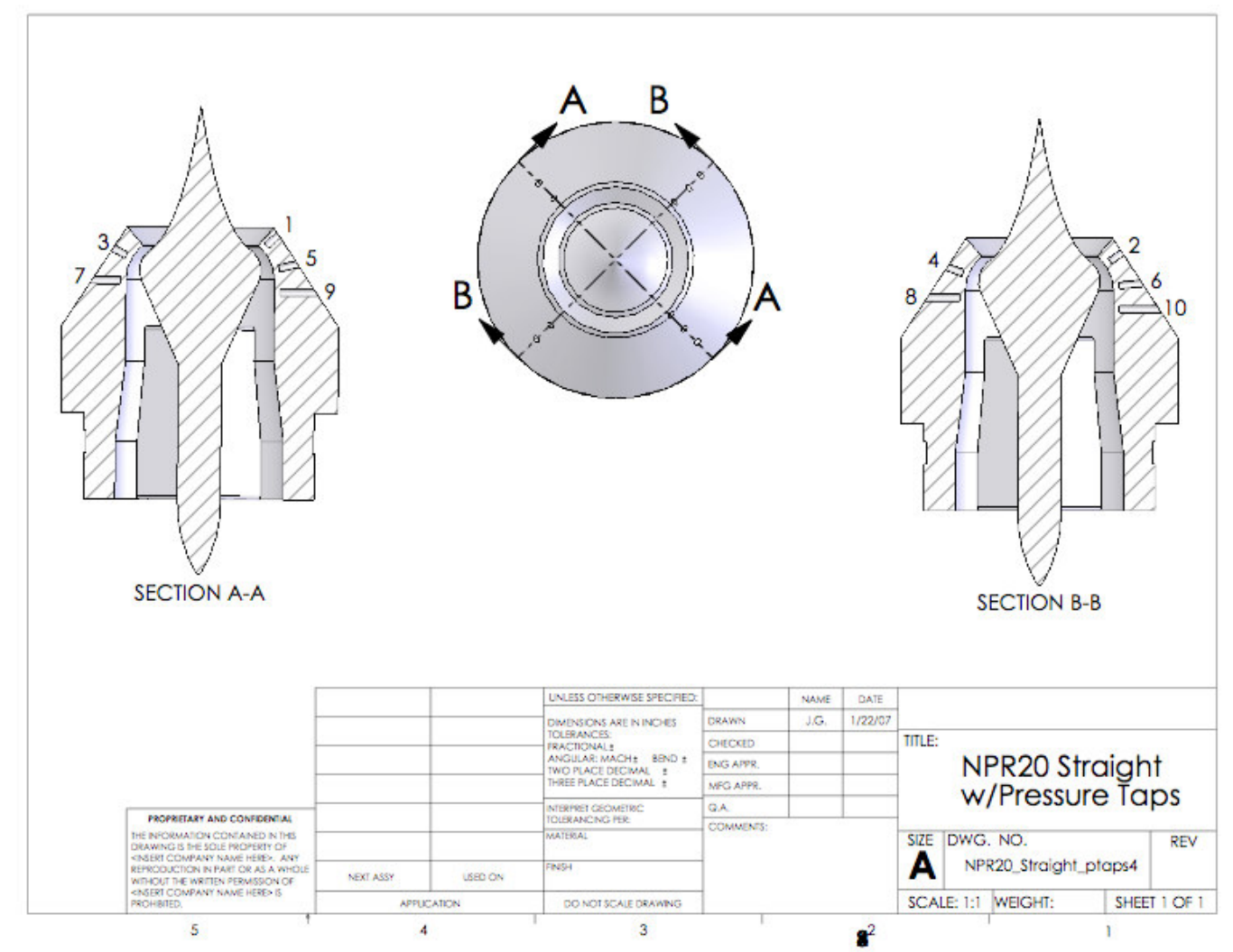

Figure 10: Pressure tap locations for NPR20 straight nozzle. 


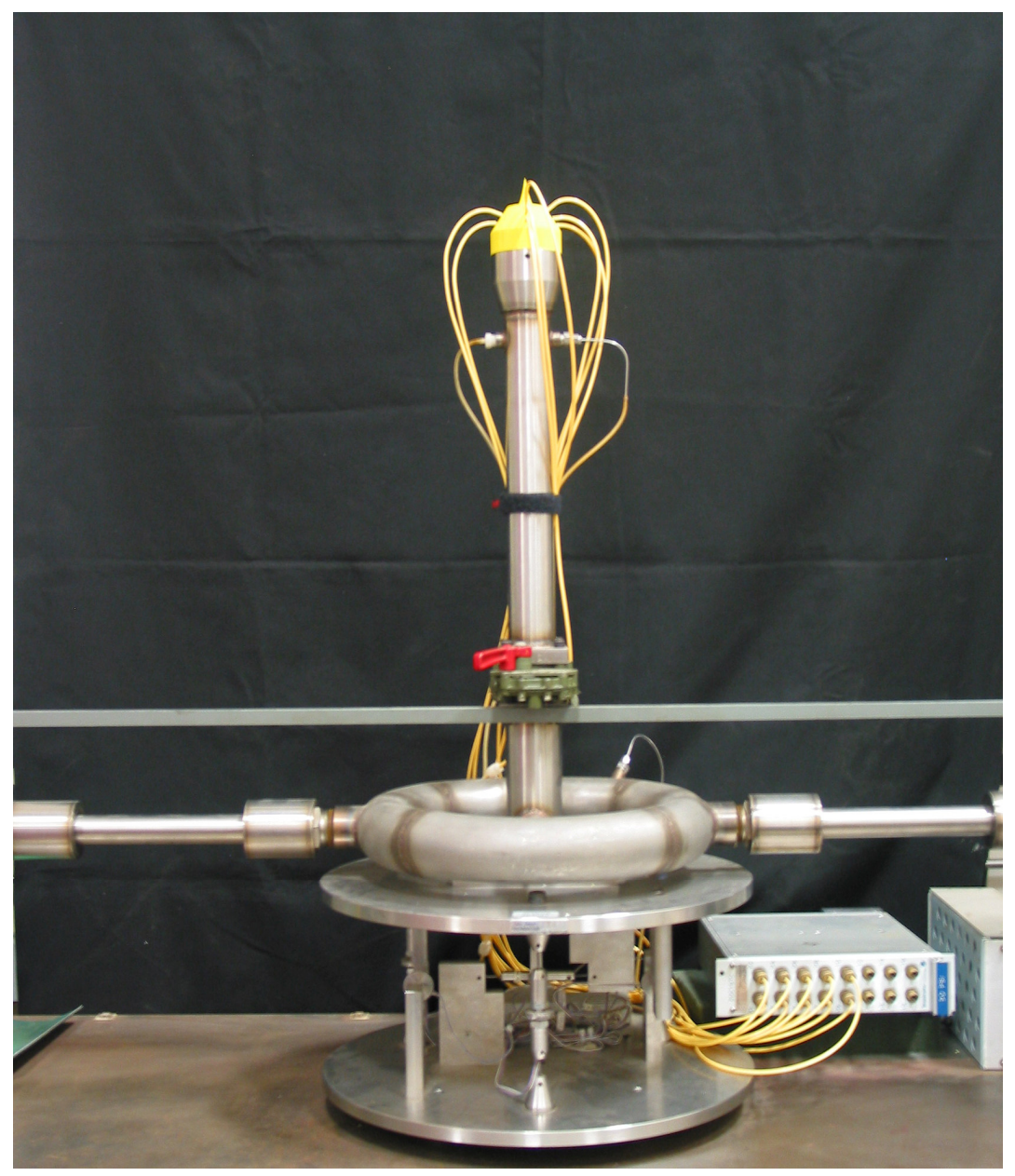

Figure 11: NPR 20 nozzle with ten pressure taps. 


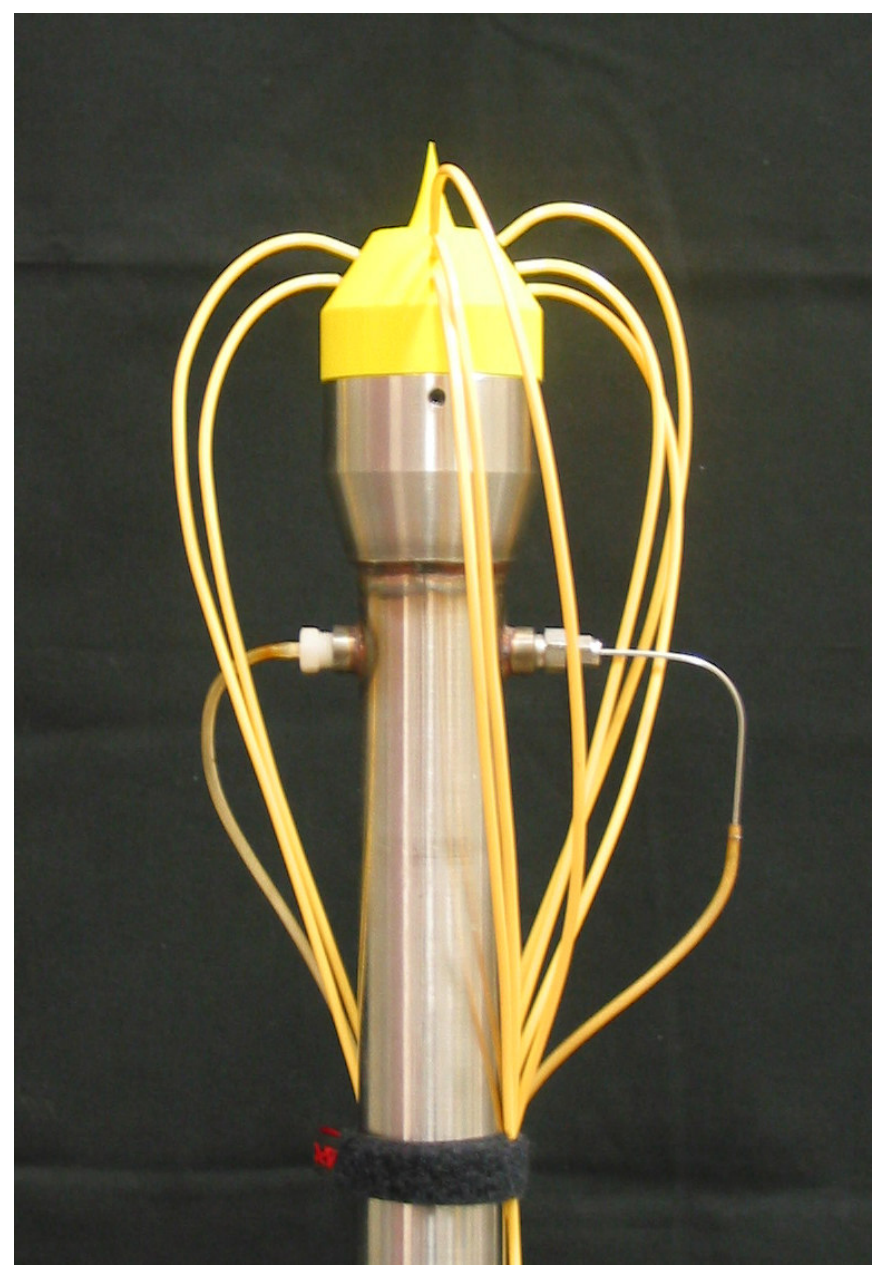

Figure 12: Close-up of NPR 20 nozzle with pressure taps.

\section{Rapid Prototype Manufacturing}

The use of computer aided design (CAD) and rapid prototype (RPT) manufacturing were incorporated into the experiment to enable easy construction of different nozzle configurations. The nozzle geometry was converted to a stereo lithography format and input into a program used in conjunction with a rapid prototype machine to generate an $\mathrm{ABS}$ part of the desired geometry. The cost and time to manufacture these rocket nozzles with conventional machining methods would have proved troublesome because of the number of nozzles and difficult geometries constructed. Table 3 discusses the nozzle number and its corresponding geometry. 
Sample nozzle photos and the cross-sectional drawings are shown in Figures 14-21. Although the RPT models are constructed out of plastic, the material had sufficient strength to hold up to the blow-down tests with a source pressure of $125 \mathrm{psig}$.

Table 3: Nozzle Descriptions

\begin{tabular}{|l|l|}
\hline Nozzle & Description \\
\hline NPR 6 & \\
\hline Slot 4 & Large Slot \\
\hline Slot 5 & Small Slot \\
\hline NPR 20 & \\
\hline Slot 3 & Large Slot \\
\hline Slot 4 & Small Slot \\
\hline Slot 5 & Small Slot $10^{\circ}$ aft \\
\hline Slot 6 & Small Slot $20^{\circ}$ aft \\
\hline Slot 8 & Small Slot $0.250^{\prime \prime}$ from throat \\
\hline Slot 9 & Small Slot $0.400^{\prime \prime}$ rom throat \\
\hline Slot 10 & Small Slot $0.025^{\prime \prime}$ radius \\
\hline Slot 11 & Small Slot $0.050^{\prime \prime}$ radius \\
\hline Slot 12 & Small Slot $0.075^{\prime \prime}$ radius \\
\hline Slot 13 & Small Slot $0.075^{\prime \prime}$ entrance edge radius only \\
\hline Slot 14 & Small Slot $0.075 "$ aft edge radius only \\
\hline NPR 50 & \\
\hline Slot 3 & Large Slot \\
\hline Slot 4 & Small Slot \\
\hline
\end{tabular}




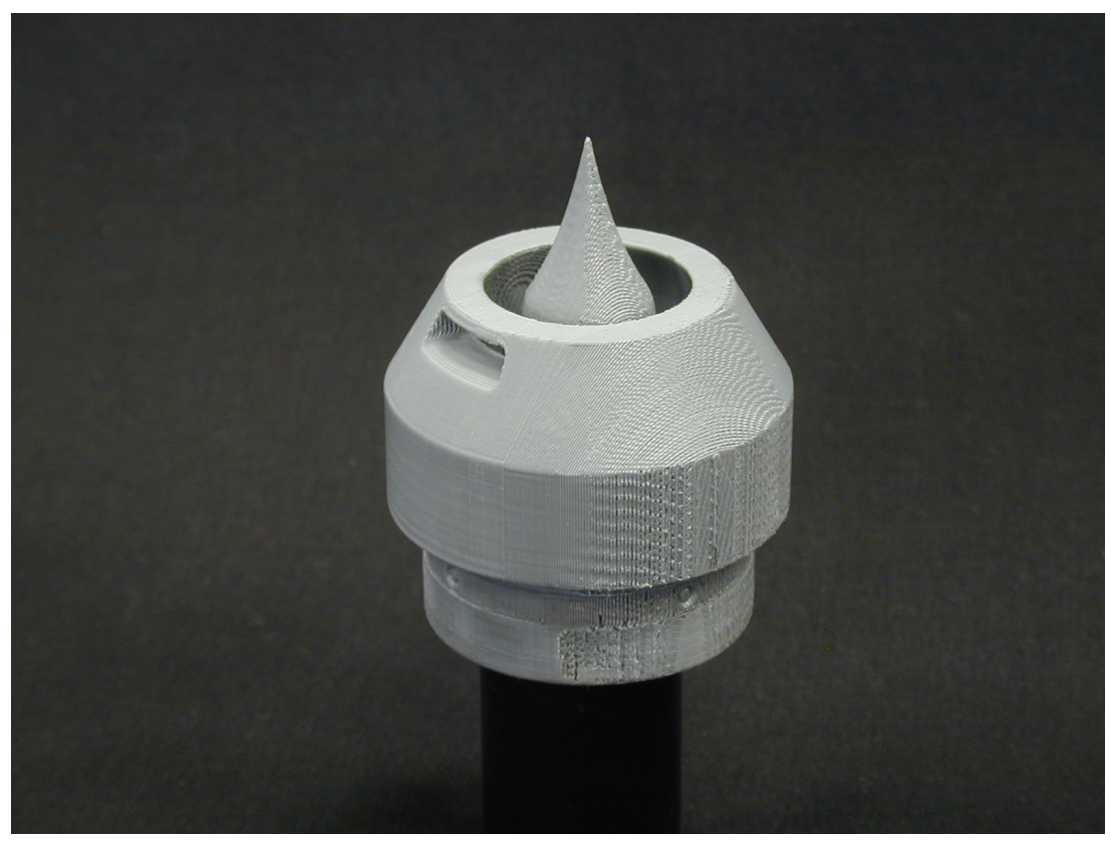

Figure 13: NPR 6 slot configuration.
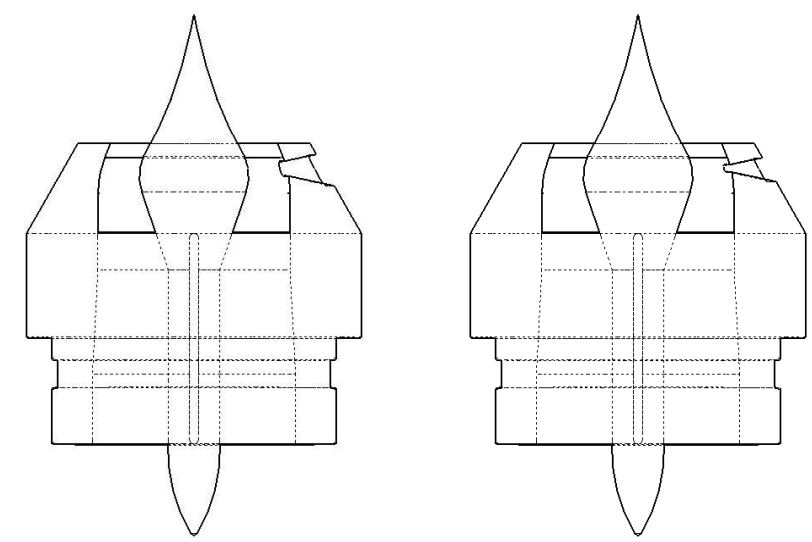

Figure 14: NPR 6 Slot 4, NPR 6 Slot 5. 


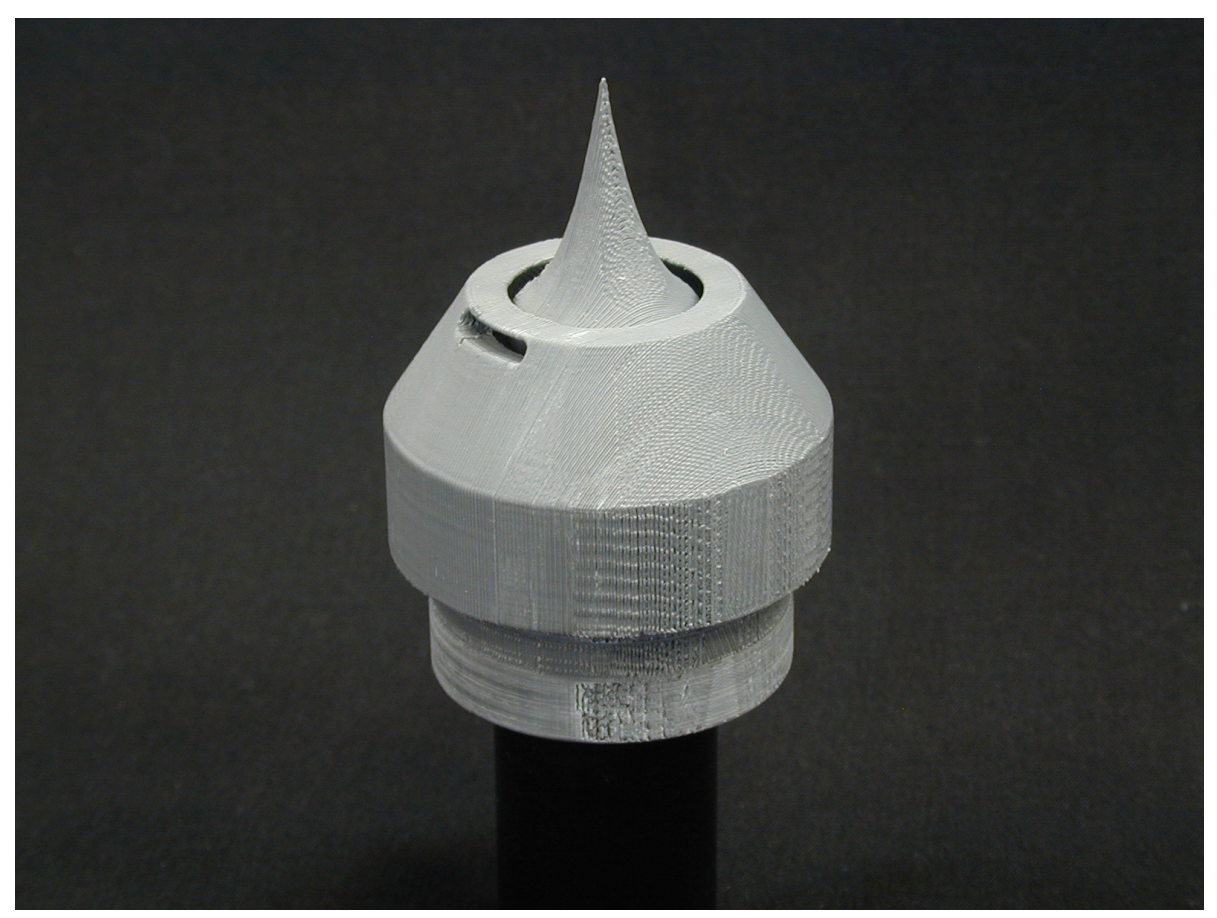

Figure 15: NPR 20 slot configuration.
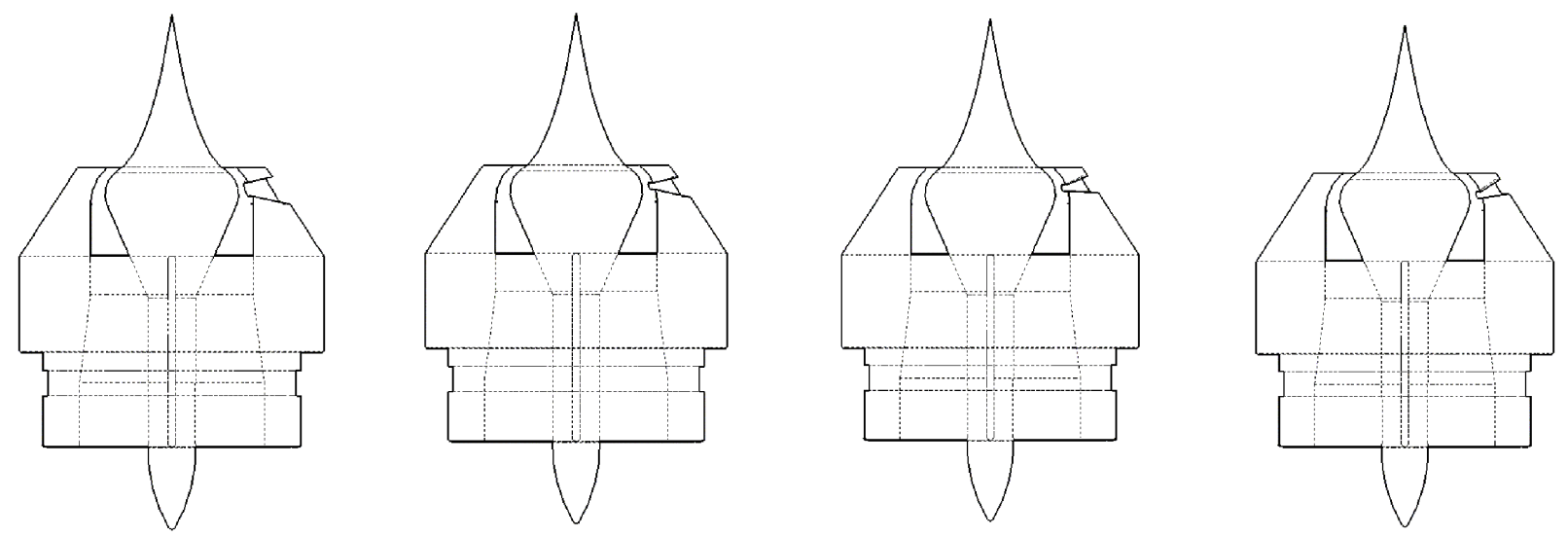

Figure 16: NPR 20 Slot 3, NPR 20 Slot 4, NPR 20 Slot 5, NPR 20 Slot 6. 

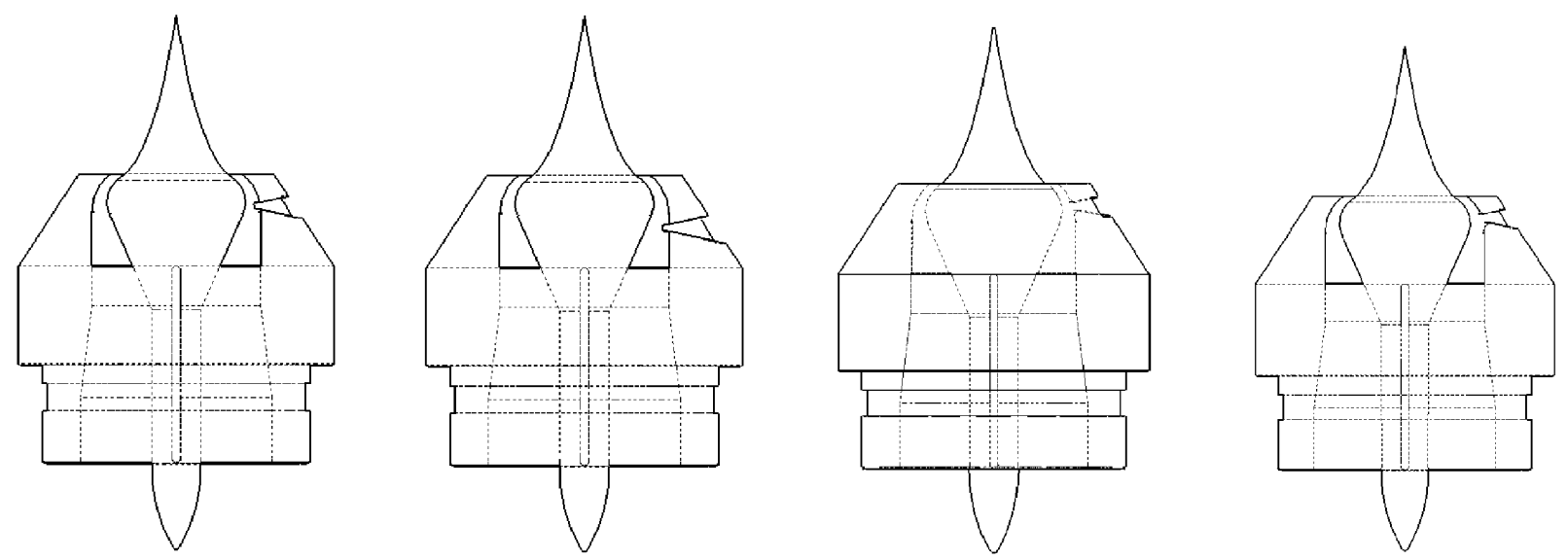

Figure 17: NPR 20 Slot 8, NPR 20 Slot 9, NPR 20 Slot 10, NPR 20 Slot 11.
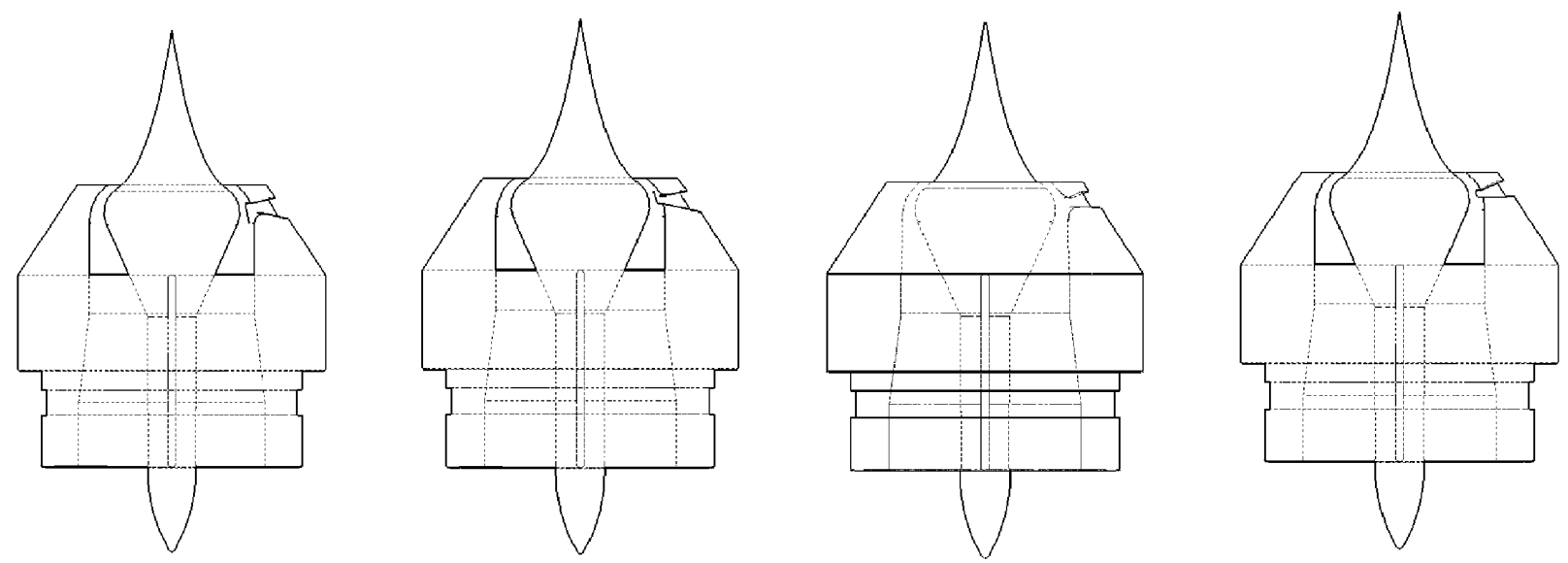

Figure 18: NPR 20 Slot 13, Slot 14, Slot 15, Slot 16. 


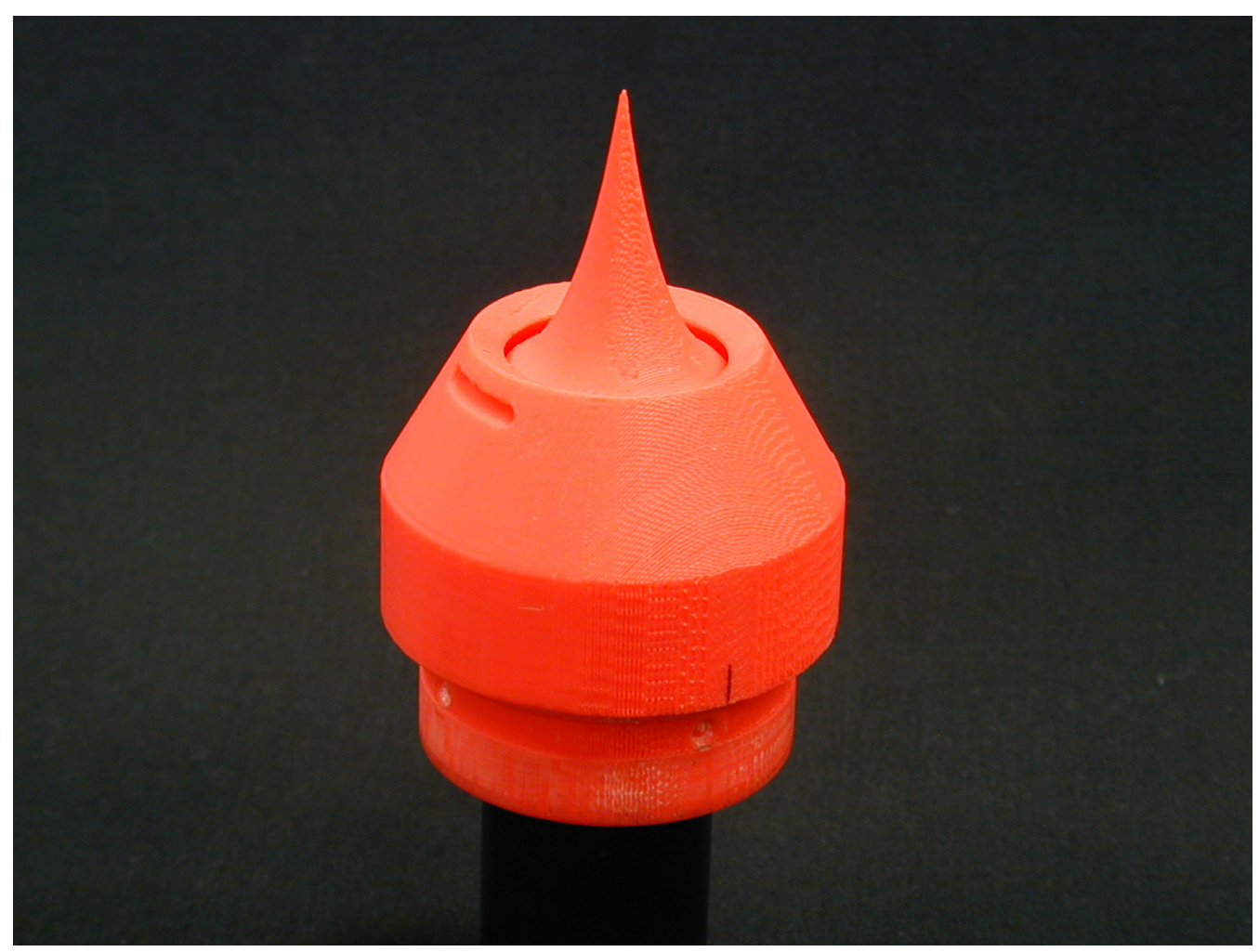

Figure 19: NPR 50 slot configuration.
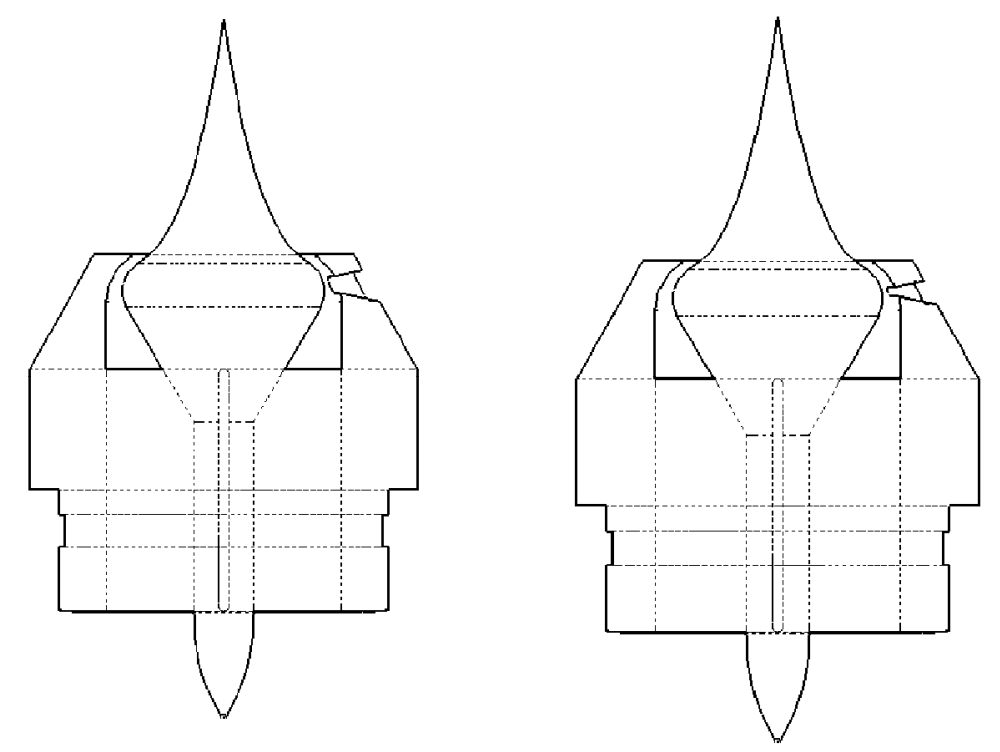

Figure 20: NPR 50 Slot 3, Slot 4. 


\section{Flow Visualization}

During testing, color Schlieren was recorded and subsequently utilized in order to visualize the flow exiting the nozzle from the main aerospike geometry as well as the compound nozzle geometry.

As shown in Figure 21, the Schlieren apparatus consisted of a xenon lamp, two 4" concave mirrors with 48 " focal lengths, a neutral density filter, a custom two colored acetate filters that acts as a knife edge and a high definition video camcorder. Each piece of equipment was brought into the same horizontal plane by using a tripod and laser level. The 75 watt Xenon lamp was placed in front of the test stand and slightly offset to one side at approximately $7.5^{\circ}$ angle. The light is fixed 48 inches away from the first concave mirror and positioned approximately 18 inches behind the test stand. After the light is reflected from the mirror it is directed at the aerospike nozzle. Once the light passes the nozzle, the beam of light continues on until reaching the second concave mirror. The light is collected by the second mirror and reflected back along the rail containing the neutral density filter and the acetate filter. The image enters the camera where it is recorded. The acetate filter is positioned along the rail exactly 48 inches from the second concave mirror. The neutral density filter is place approximately 8 inches in front of the acetate filter. The camera is positioned so that the focal point of the camera lens corresponds to the location of the acetate filter. Figure 21 shows a diagram of the Schlieren setup. A photograph of the Schlieren rail can be seen in Figure 22.

Through the use of Schlieren video the flow phenomenon of the shock patterns at the nozzle exits are able to be visualized. This image is produced by light being refracted by the density gradients of the shock waves. The different density gradients are picked 
up by the color filter and can be visually seen as black lines with shades of green or red in the image.

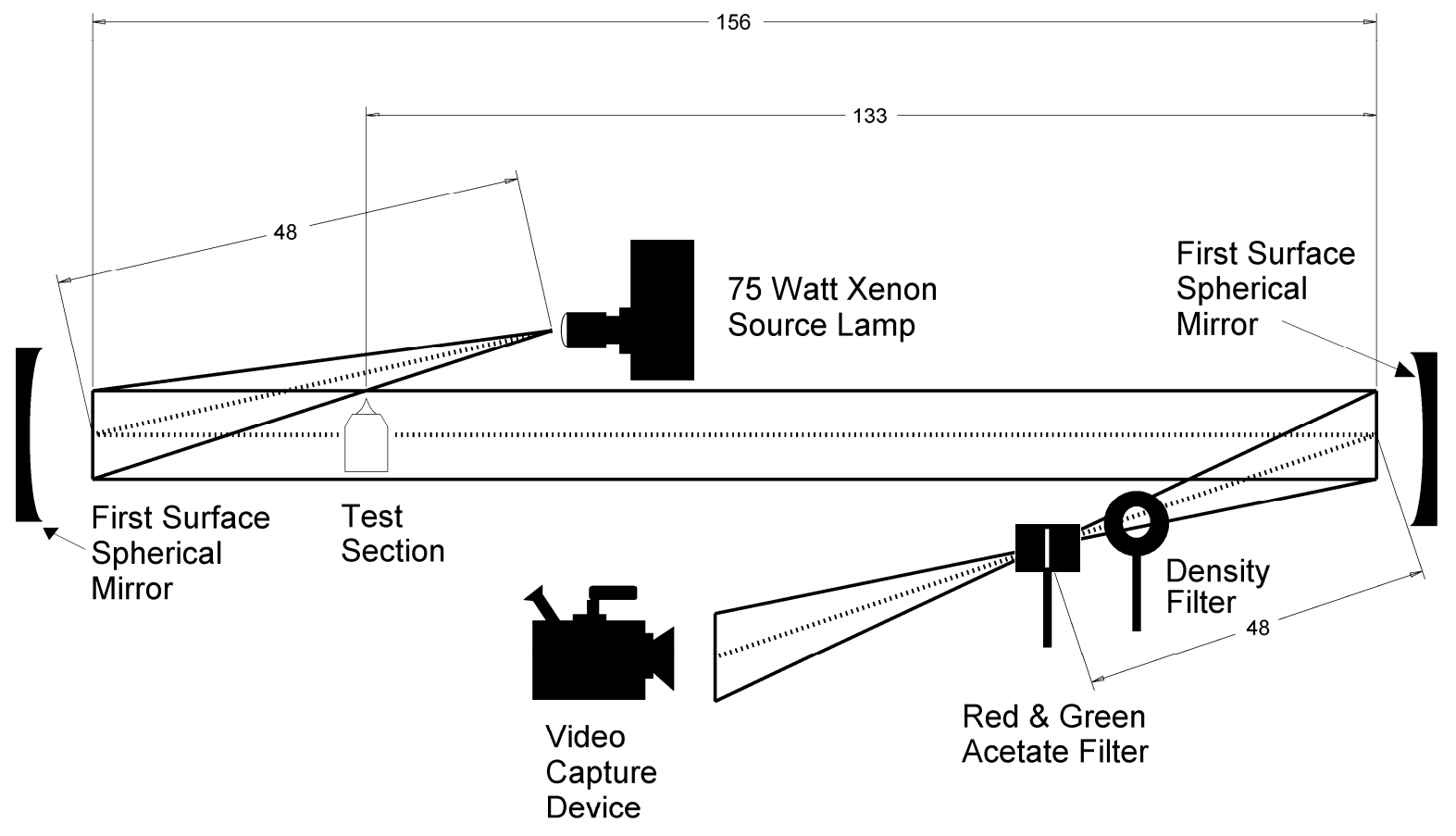

Note: All Dimensions in inches

Figure 21: Z-Type Schlieren rail set up.

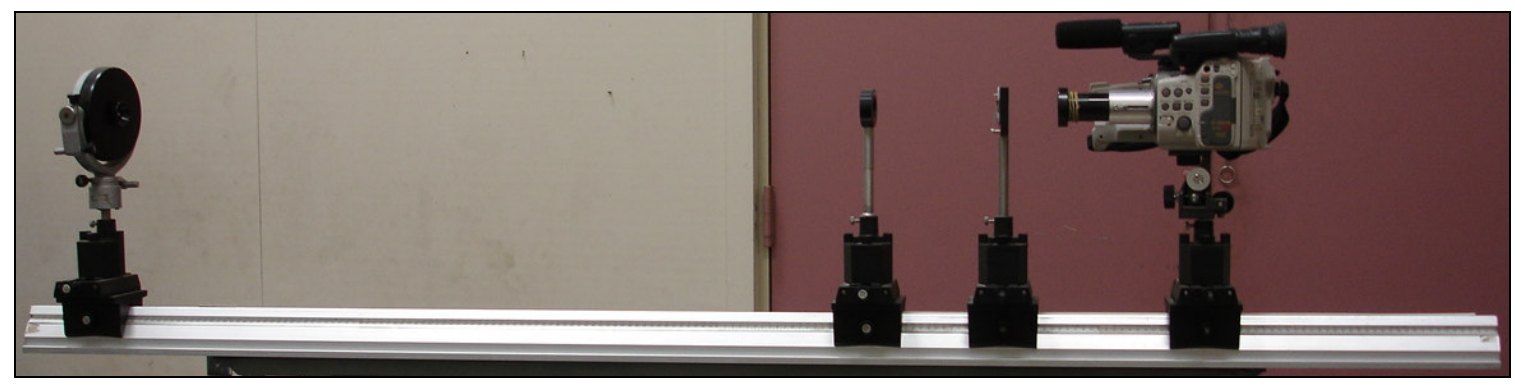

Figure 22: Schlieren rail configuration; (L-R) first surface parabolic mirror, density filter, red and green acetate filter, and video camcorder. 


\section{Theoretical Turn Angle}

Due to the current limitations of the facilities that prohibit testing NPR 20 and NPR 50 nozzles at design pressure, it is necessary to correlate the measured data to theoretical calculations in order to predict the behavior of the NPR 20 and NPR 50 nozzles at their intended chamber pressures. Assumptions made were, that the flow exiting the slot is radially outwards and perpendicular to aerospike main flow, and the secondary port does not effect the main flow. In order to calculate the predictions, the use of the basic equations for the one-dimensional mass flow rate and thrust along with the isentropic flow tables are utilized. In order to use the isentropic tables, the ratio of exit area to the throat area $(\varepsilon)$ of the secondary port had to be determined.

$\varepsilon=\frac{A_{e}}{A_{t}}$

To determine the exit area $\left(\mathrm{A}_{\mathrm{e}}\right)$ and throat area $\left(\mathrm{A}_{\mathrm{t}}\right)$ the CAD models were used.

The value for $\varepsilon$ returned values for $\frac{T}{T_{o}}, \frac{P}{P_{o}}, \mathrm{Ma}_{2}$. The NPR and temperature data from specific runs was used in order to correlate the theoretical values to the measured values. The mass flow rate was determined by the equation

$\dot{m}=\frac{A_{t} P_{0} \kappa \sqrt{\left(\frac{2}{\kappa+1}\right)^{\frac{\kappa+1}{\kappa-1}}}}{\sqrt{\kappa R T_{0}}}$

The exit velocity of the slot $\left(\mathrm{V}_{\mathrm{e}}\right)$ was determined by

$V_{e}=M a_{e} a_{e}$

Where the speed of sound at the exit $\left(a_{e}\right)$ is determined by 
$a_{e}=\sqrt{\kappa R T_{e}}$

Finally the force from the secondary port can be calculated using the thrust equation

$$
F=\dot{m} V_{e}+\left(P_{e}-P_{a}\right) A_{e}
$$

To determine the resultant turn angle $\left(\delta_{\text {calc }}\right)$, the calculated force vector from the secondary port and the measured thrust $\left(\mathrm{F}_{\mathrm{Z}}\right)$ at corresponding NPR values are taken from a nozzle with no secondary port or slot, and the resultant angle is calculated with the following equation

$$
\delta_{\text {calc }}=\left|T A N^{-1}\left(\frac{F}{F_{z}}\right)\right|
$$

The calculated results for the theoretical resultant turn angle are compared to the measured values in the conclusion section. 


\section{Results}

Over 100 cold-flow blow-down test were conducted. As stated previously test data were captured using the Helios Plus 2287A data acquisition unit. Tables 4-8 and Figures 23-39 summarize the results achieved from these experiments. The tabulated results show the measured forces, measured mass flow rate, and measured NPR. From the measured forces, the thrust vectored angles for yaw, pitch and the resultant turn are calculated. The Schlieren photographs were extracted from the Schlieren video to provide flow visualization. Calculations were conducted to compare measured and theoretical results.

\section{NPR 6 Nozzle Results}

Table 4 below shows the results obtained from all experiments on NPR 6 nozzles. As a baseline, an aerospike nozzle with no secondary port was tested as well as an aerospike nozzle with the spike gimbled $10^{\circ}$. Experiments were done at differing operating NPRs as well. The results show the typical thrust for an NPR 6 straight aerospike nozzle is approximately $75.2 \mathrm{lb}_{\mathrm{f}}$ of thrust with a slight turn of about $0.50^{\circ}$, when operating at the design NPR. The $10^{\circ}$ gimbled spiked produced an average thrust of $74.9 \mathrm{lb}_{\mathrm{f}}$ with a resultant turn of $1.95^{\circ}$. The two nozzles tested had secondary ports of two different sizes. The NPR Slot 4 Nozzle had a secondary port area of $0.0552 \mathrm{in}^{2}$, and NPR Slot 5 had a secondary port area of $0.0281 \mathrm{in}^{2}$. The NPR Slot 4 nozzle produced $73.0 \mathrm{lbs}$ of thrust with a resultant turn angle of $4.75^{\circ}$. NPR Slot 5 nozzle produced 73.1 lbs of thrust with a resultant average turn angle of $3.04^{\circ}$. Although the compound nozzle having slots for secondary ports did not produce the desired $10^{\circ}$ of turn, it is shown that 
these configurations exceeded the amount of turn established in the $10^{\circ}$ gimbled aerospike configuration and have matched and exceeded the slot and fin configuration previously tested in prior research $(1,7)$. The addition of the slot also increased the mass flow rate of the entire system. From the Schlieren photography, Figures 23 and 24, it can be shown that the flow through the secondary port detaches from the walls and the exit direction deviates from the expected radial direction. 
Table 4: Summary of blow-down test results for NPR 6 prototype aerospike nozzles.

\begin{tabular}{|c|c|c|c|c|c|c|c|c|c|c|c|c|c|c|}
\hline Nozzle Description & NPR & $\begin{array}{l}\mathrm{F}_{\mathrm{x}} \\
\mathrm{lbf}\end{array}$ & $\begin{array}{l}\mathrm{F}_{\mathrm{y}} \\
\mathrm{lbf}\end{array}$ & $\begin{array}{l}F_{z} \\
\mathrm{lbf}\end{array}$ & $\begin{array}{c}W_{p} \\
\mathrm{lbm} / \mathrm{s}\end{array}$ & $\begin{array}{c}\mathrm{W}_{\mathrm{i}} \\
\mathrm{lbm} / \mathrm{s}\end{array}$ & $\begin{array}{l}F_{i} \\
\mathrm{lbf}\end{array}$ & $\begin{array}{l}F_{r} \\
\mathrm{lbf}\end{array}$ & $F_{r} / F_{i}$ & $F_{z} / F_{i}$ & $W_{p} / W_{i}$ & $\begin{array}{c}\delta_{\text {pitch }} \\
(\stackrel{0}{)})\end{array}$ & $\begin{array}{c}\delta_{\text {yaw }} \\
(\stackrel{0}{)})\end{array}$ & $\begin{array}{l}\delta_{r} \\
(\stackrel{0}{)})\end{array}$ \\
\hline NPR6 Str & 5.995 & -0.419 & -0.561 & -75.152 & 1.368 & 1.408 & 75.051 & 75.155 & 1.001 & -1.001 & 0.971 & 0.428 & 0.319 & -0.534 \\
\hline NPR6 Str & 4.960 & -0.541 & -0.673 & -59.140 & 1.115 & 1.162 & 59.004 & 59.146 & 1.002 & -1.002 & 0.960 & 0.652 & 0.524 & -0.836 \\
\hline NPR6 Str & 3.648 & -0.618 & -0.159 & -40.008 & 0.635 & 0.665 & 40.040 & 40.014 & 0.999 & -0.999 & 0.955 & 0.228 & 0.885 & -0.914 \\
\hline NPR6 Str & 2.099 & -0.138 & -0.265 & -18.062 & 0.521 & 0.548 & 17.848 & 18.065 & 1.012 & -1.012 & 0.951 & 0.841 & 0.439 & -0.948 \\
\hline NPR6 Str & 1.229 & -0.187 & -0.007 & -5.232 & 0.255 & 0.321 & 4.790 & 5.236 & 1.093 & -1.092 & 0.796 & 0.080 & 2.050 & -2.052 \\
\hline NPR6 Slot4 & 5.983 & -6.047 & -0.515 & -72.970 & 1.569 & 1.547 & 77.958 & 73.221 & 0.939 & -0.936 & 1.014 & 0.404 & 4.737 & -4.754 \\
\hline NPR6 Slot4 & 5.545 & -5.548 & -0.343 & -66.864 & 1.452 & 1.432 & 71.011 & 67.094 & 0.945 & -0.942 & 1.014 & 0.294 & 4.743 & -4.752 \\
\hline NPR6 Slot5 & 5.958 & -4.223 & -0.298 & -73.119 & 1.530 & 1.540 & 76.008 & 73.242 & 0.964 & -0.962 & 0.994 & 0.234 & 3.305 & -3.314 \\
\hline NPR6 Slot5 & 5.520 & -3.230 & -0.246 & -66.679 & 1.425 & 1.426 & 69.674 & 66.757 & 0.958 & -0.957 & 1.000 & 0.211 & 2.773 & -2.781 \\
\hline NPR6 Slot5 & 5.957 & -3.695 & -0.257 & -72.758 & 1.238 & 1.252 & 75.894 & 72.852 & 0.960 & -0.959 & 0.989 & 0.202 & 2.907 & -2.914 \\
\hline NPR6 Slot5 & 4.949 & -2.715 & -0.062 & -58.452 & 1.050 & 1.068 & 60.160 & 58.515 & 0.973 & -0.972 & 0.983 & 0.061 & 2.659 & -2.660 \\
\hline NPR6 Slot5 & 3.566 & -2.479 & -0.209 & -38.753 & 0.772 & 0.775 & 40.166 & 38.832 & 0.967 & -0.965 & 0.996 & 0.309 & 3.660 & -3.672 \\
\hline NPR6 Slot5 & 2.087 & -0.908 & 0.027 & -17.404 & 0.514 & 0.534 & 17.960 & 17.427 & 0.970 & -0.969 & 0.964 & -0.088 & 2.985 & -2.987 \\
\hline NPR6 Slot5 & 1.292 & -0.445 & -0.037 & -6.148 & 0.286 & 0.336 & 5.965 & 6.164 & 1.033 & -1.031 & 0.850 & 0.345 & 4.140 & -4.154 \\
\hline NPR6 10 deg gimbal & 5.997 & -2.721 & -0.959 & -74.717 & 1.529 & 1.551 & 76.261 & 74.772 & 0.980 & -0.980 & 0.986 & 0.735 & 2.086 & -2.211 \\
\hline NPR6 10 deg gimbal & 6.021 & -2.165 & -0.277 & -75.063 & 1.537 & 1.558 & 76.637 & 75.095 & 0.980 & -0.979 & 0.986 & 0.212 & 1.652 & -1.665 \\
\hline NPR6 10 deg gimbal & 5.991 & -2.573 & -0.329 & -74.837 & 1.522 & 1.550 & 75.841 & 74.882 & 0.987 & -0.987 & 0.982 & 0.252 & 1.969 & -1.985 \\
\hline
\end{tabular}




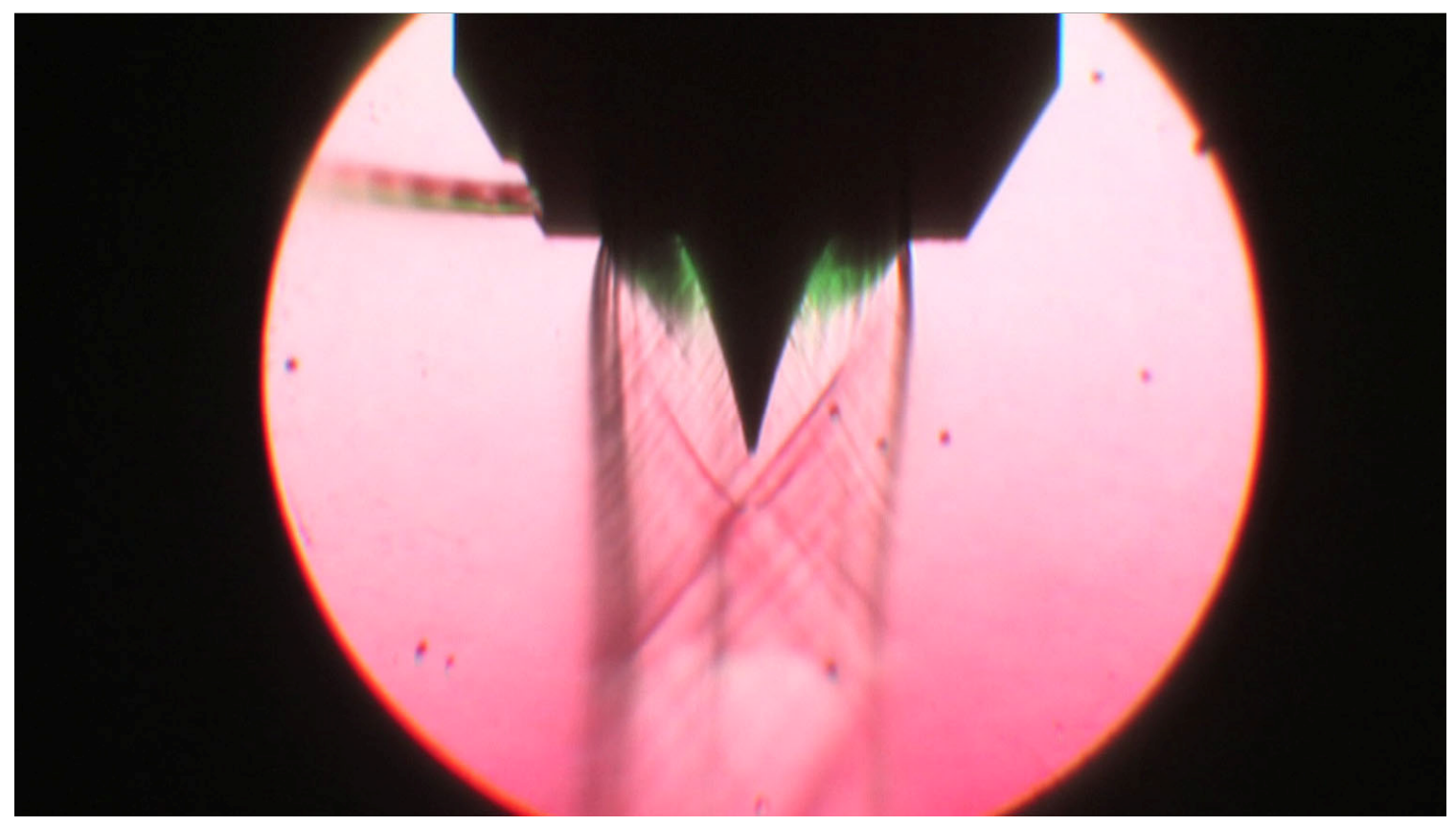

Figure 23: NPR 6 Slot 4.

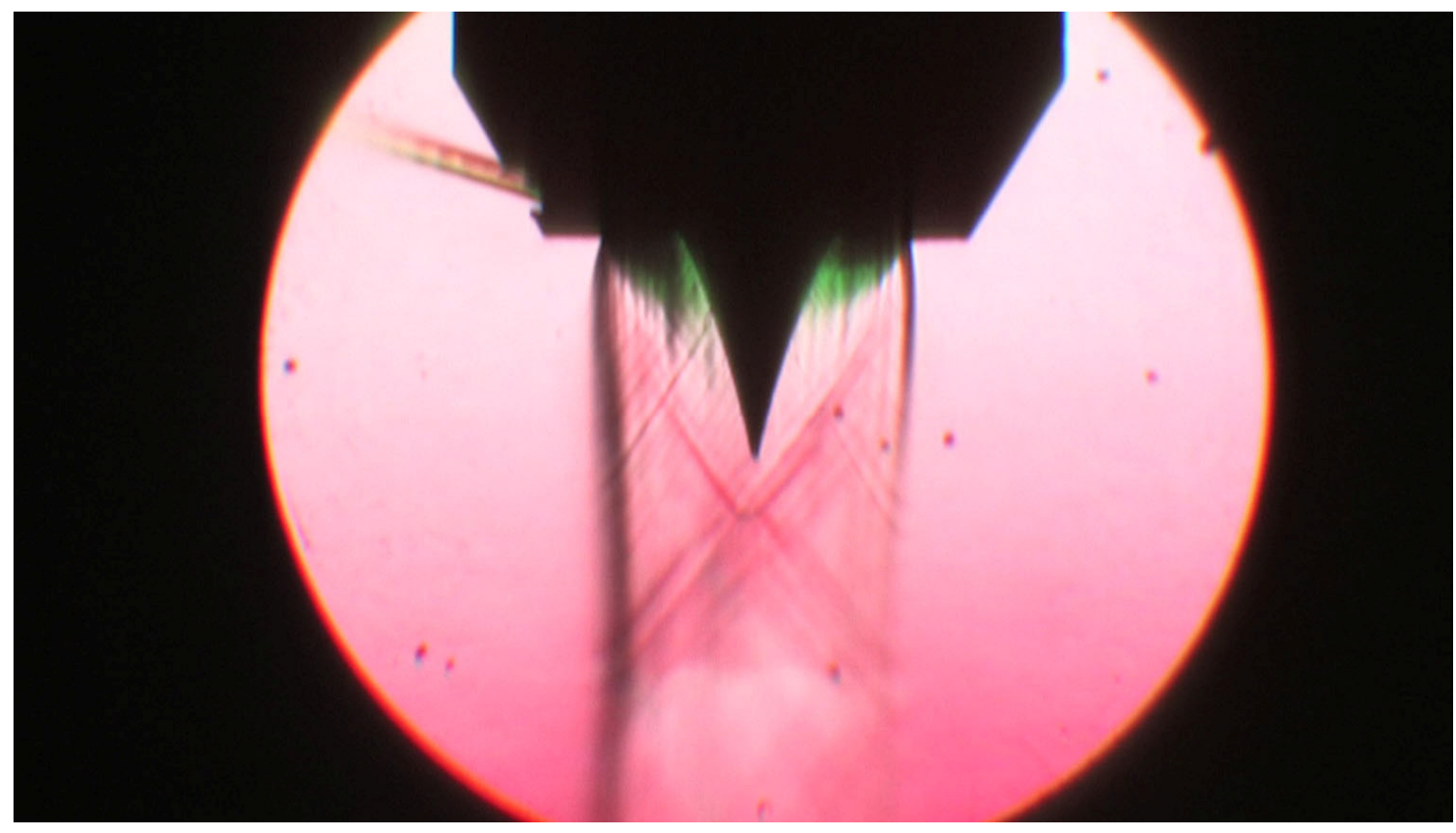

Figure 24: NPR 6 Slot 5. 


\section{NPR 20 Nozzle Results}

Tables 5-7 show the tabulated results for the cold-flow blow-down experiments of NPR 20 nozzles. The NPR 20 straight plastic configuration nozzles produced approximately $27.5 \mathrm{lb}_{\mathrm{f}}$ of thrust with a turn angle of $0.45^{\circ}$. In comparison, the metal nozzle of the same configuration produced $25.4 \mathrm{lb}_{\mathrm{f}}$ of thrust with a turn angle of $0.14^{\circ}$. The thrust difference between the machined aluminum nozzles to the RPT nozzles can be attributed to the inability for the RPT process to form knife edges. Since the edge is rounded off the resulting throat area is larger. To round out the baseline configurations, the $10^{\circ}$ gimbled spike produced an average thrust of $27.0 \mathrm{lb}_{\mathrm{f}}$ with a resultant turn angle of $3.54^{\circ}$.

The NPR 20 Slot 3 configuration (large slot) produced an average thrust of 26.5 $1 b_{f}$ with a resultant turn angle of $11.94^{\circ}$. The smaller slot configuration, NPR 20 Slot 4 produced average numbers of $27.31 \mathrm{~b}_{\mathrm{f}}$ of thrust with a resultant turn of $7.46^{\circ}$. As seen in the previous NPR 6 section, larger resultant turn angles are developed by increasing the throat area of the secondary port. The detached flow phenomena, as seen in the NPR 6 nozzles, is seen again in the NPR 20 nozzles. The NPR 20 Slot 3 configuration Schlieren, Figure 26, shows that the flow only fills the aft half of the secondary port and the flow does not exit perpendicular to the thrust axis. In the NPR 20 Slot 4 configuration, Figure 27, it is seen that the flow fills the slot, but exits at a much sharper angle than the NPR 20 Slot 3 configuration. The addition of the slot also increased the mass flow rate of the entire system, which can be seen throughout the NPR 20 nozzles. 
The next two slot configurations were constructed to force the flow to exit perpendicular to the thrust axis. To achieve a perpendicular flow exit the slots were constructed at an angle. The NPR 20 Slot 5 had a $10^{\circ}$ slope, angled towards the aft on the nozzle, in the slot. The NPR 20 Slot 6 configuration had a $20^{\circ}$ slope. The NPR 20 Slot 5 produced an average thrust of $27.3 \mathrm{lb}_{\mathrm{f}}$ and a resultant turn angle of $6.91^{\circ}$. The NPR 20 Slot 6 produced average thrusts of $29.2 \mathrm{lb}_{\mathrm{f}}$ with a turn angle of $6.57^{\circ}$. From the Schlieren photo, Figure 28 , it can be seen that the $10^{\circ}$ slot still exits in the same direction as the previous configurations. In the NPR 20 Slot 6 configuration, Figure 29, the flow exits to the aft side of the radial axis and results in slightly larger measured thrust.

NPR 20 Slot 8 and Slot 9 where constructed to investigate the effects of moving the slot axially along nozzle. The approach was to verify if there were any significant changes in the pressure along the inside wall of the aerospike body. In the NPR 20 slot 8 nozzle, the slot was moved by $0.075 "$ and slot 9 was moved by $0.225 "$ upstream of the throat. For the NPR slot 8 configuration, an average thrust of $27.2 \mathrm{lb}_{\mathrm{f}}$ with a resultant turn of $6.68^{\circ}$ are achieved. The NPR 20 Slot 9 configuration yielded an average thrust of $27.0 \mathrm{lb}_{\mathrm{f}}$ and a resultant turn of $6.30^{\circ}$. The same trend of the flow turning back in the opposite direction of the main aerospike flow, as well as some detachment from the lower wall is seen in the Schlieren photos, Figures 30-31.

The next set of slots was constructed as a second attempt to straighten the flow exiting the secondary port of the aerospike nozzle. The slot was modified to have a radius on the inside lip so that the flow does not have to round a sharp corner. Radii of 0.025 inches, 0.050 inches and 0.075 inches were added to the small slot configuration and designated NPR 20 Slots 10, 11 and 12, respectively. NPR 20 Slot 10 produced an 
average thrust of $27.1 \mathrm{lb}_{\mathrm{f}}$ with a resultant turn angle of $9.24^{\circ}$. By comparison, NPR 20 Slot 1 produced an average thrust of $27.8 \mathrm{lb}_{\mathrm{f}}$ with a resultant turn angle of $11.37^{\circ}$. NPR 20 Slot 12 produced an average thrust of $28.0 \mathrm{lb}_{\mathrm{f}}$ with a resultant turn angle of $11.37^{\circ}$. It can be shown that the thrust produced by these three nozzle configurations were generally equal within $1 \mathrm{lb}_{\mathrm{f}}$ of each other, but the turn angles increased with the increasing radii. Also of note, is the Schlieren photography, Figures 32-34, showed that flow exiting the secondary port was exiting nearly radially in the NPR 20 Slot 12 configuration.

NPR 20 Slot 13 and 14 compares the performance of slots with radii to the leading edge of the slot versus the trailing edge of the slot. The Slot 13 configuration has a leading edge radius and Slot 14 has a radius placed on the aft edge. For cross-sectional views of the radius, see the cross-sectional drawings in the rapid prototype design section. NPR 20 Slot 13 produced an average thrust of $26.9 \mathrm{lb}_{\mathrm{f}}$ with a resultant turn angle of $13.70^{\circ}$, while the NPR 20 Slot 14 produced an average thrust of $27.9 \mathrm{lb}_{\mathrm{f}}$ with a resultant turn angle of $7.86^{\circ}$. From these numbers it is apparent that the radius on the leading edge has more influence on the resultant turn angle. The Schlieren, Figure 35, shows the flow exiting the secondary port was closest to the radial axis of the nozzle with the leading edge radius.

The last two NPR 20 Slots 15 and 16 were constructed to combine the discoveries made in the previous tests and determine the optimum configuration. NPR 20 slot 15 incorporated a $10^{\circ}$ aft slot angle in the nozzle with the 0.075 inch radius and NPR 20 slot 16 used a $12.5^{\circ}$ aft slot angle in the nozzle with no radius. The NPR 20 Slot 15 design achieved $28.3 \mathrm{lb}_{\mathrm{f}}$ of thrust with a resultant turn angle of $12.82^{\circ}$. The NPR 20 Slot 16 
configuration resulted in an average thrust of $28.3 \mathrm{lb}_{\mathrm{f}}$ and $6.72^{\circ}$ of resultant turn. The Schlieren for Slot 15, Figure 37, showed that the flow exited to the aft side of the radial axis, but yielded the highest resultant turn angle. The NPR20 Slot 16 configuration did exit parallel to the radial axis, Figure 38, but had approximately half the resultant turn angle of Slot 15. 
Table 5: Summary of blow-down test results for NPR 20 prototype aerospike nozzles.

\begin{tabular}{|c|c|c|c|c|c|c|c|c|c|c|c|c|c|c|}
\hline Nozzle Description & NPR & $\begin{array}{l}\mathbf{F}_{\mathbf{x}} \\
\mathrm{lbf}\end{array}$ & $\begin{array}{l}\mathbf{F}_{\mathrm{y}} \\
\mathrm{lbf}\end{array}$ & $\begin{array}{l}\mathbf{F}_{\mathbf{z}} \\
\mathrm{lbf}\end{array}$ & $\begin{array}{c}\mathbf{W}_{\mathbf{p}} \\
\mathrm{lbm} / \mathrm{s}\end{array}$ & $\begin{array}{c}\mathbf{W}_{\mathbf{i}} \\
\mathrm{lbm} / \mathrm{s}\end{array}$ & $\begin{array}{l}\mathbf{F}_{\mathbf{i}} \\
\mathrm{lbf}\end{array}$ & $\begin{array}{l}\mathbf{F}_{\mathbf{r}} \\
\mathrm{lbf}\end{array}$ & $F_{r} / F_{i}$ & $F_{z} / F_{i}$ & $\mathbf{W}_{\mathbf{p}} / \mathbf{W}_{\mathbf{i}}$ & $\begin{array}{c}\mathbf{d}_{\text {pitch }} \\
(\stackrel{o}{ })\end{array}$ & $\begin{array}{c}d_{\text {yaw }} \\
(\boldsymbol{o})\end{array}$ & $\begin{array}{l}d_{r} \\
(\varrho)\end{array}$ \\
\hline NPR 20 Straight & 7.392 & 0.217 & 0.036 & $\overline{-27.770}$ & $\overline{0.540}$ & $\overline{0.541}$ & 27.956 & 27.771 & 0.993 & -0.993 & 0.997 & -0.074 & -0.448 & -0.454 \\
\hline NPR 20 Straight & & 0.178 & .010 & -27.734 & 538 & 0.550 & 27.949 & 27.734 & 992 & 992 & 978 & 0.020 & -0.367 & -0.368 \\
\hline NPR 20 Straight & & 0.039 & -0.209 & -25.553 & 544 & 516 & 27.957 & 5.554 & 914 & 914 & 053 & 470 & -0.087 & -0.478 \\
\hline NPR 20 Straight & 485 & 0.038 & -0.217 & -28.144 & 0.560 & .547 & 29.127 & 28.145 & .966 & .966 & 1.024 & 441 & -0.078 & -0.448 \\
\hline NPR 20 Straight & 413 & -0.220 & -0.068 & -28.170 & 0.507 & .542 & 26.304 & 28.171 & 1.071 & .071 & .936 & .138 & 0.448 & -0.468 \\
\hline NPR 20 Straight & .486 & -0.259 & -0.029 & -27.769 & 0.547 & 0.547 & 28.446 & 27.771 & 0.976 & .976 & 1.000 & 0.060 & 0.534 & -0.537 \\
\hline NPR 20 Straight & 7.541 & -0.032 & 0.190 & -27.581 & 0.574 & 0.551 & 29.914 & 27.582 & 0.922 & -0.922 & 1.043 & -0.394 & 0.065 & -0.399 \\
\hline NPR 20 Straight & 7.392 & -0.132 & 0.176 & -27.662 & 0.558 & 0.540 & 28.992 & 27.663 & 0.954 & -0.954 & 1.035 & -0.364 & 0.273 & -0.455 \\
\hline NPR 20 Str Metal & 7.501 & -0.057 & -0.042 & -25.909 & 0.488 & 0.549 & 25.266 & 25.909 & 1.025 & -1.025 & 0.887 & 0.093 & 0.126 & -0.157 \\
\hline NPR 20 Str Metal & .482 & -0.012 & 0.003 & -26.120 & 0.479 & 0.548 & 24.789 & 26.120 & 1.054 & -1.054 & 0.873 & -0.008 & 0.025 & -0.027 \\
\hline NPR $20 \varsigma$ & 505 & 0.018 & 0.004 & -25.326 & 0.506 & 0.550 & 26.208 & 25.326 & 0.966 & -0.966 & 0.920 & -0.009 & -0.041 & -0.042 \\
\hline NPR 20 Str & & -0.127 & -0.063 & -26.383 & 0.478 & 0.552 & 24.843 & 26.383 & 1.062 & -1.062 & 0.866 & 0.138 & 0.276 & -0.309 \\
\hline NPR 20 Str Metal & & -0.025 & -0.044 & -25.635 & 0.504 & 0.550 & 26.153 & 25.635 & 0.980 & 0.980 & 0.916 & 0.098 & 0.057 & -0.113 \\
\hline NPR $2 C$ & & 0.011 & -0.092 & -25.480 & 0.483 & 0.550 & 25.070 & 25.480 & 1.016 & 1.016 & 0.877 & 0.207 & -0.024 & -0.208 \\
\hline NPR 2 & 7.4 & -0.099 & -0.005 & -25.680 & 0.500 & 0.547 & 25.957 & 25.680 & 0.989 & .989 & 916 & 0.011 & 0.222 & -0.222 \\
\hline NPR 2 & 7.514 & -0.054 & -0.127 & -25.740 & 0.488 & 0.549 & 25.343 & 25.740 & 1.016 & .016 & 888 & 0.284 & 0.121 & -0.308 \\
\hline NPR 20 & 7.461 & -0.080 & -0.038 & -23.713 & 0.471 & 0.546 & 24.408 & 23.713 & 0.972 & -0.971 & 0.863 & 0.091 & 0.194 & -0.214 \\
\hline NPR 20 & 7.499 & 0.029 & 0.013 & -25.929 & 0.488 & 0.548 & 25.337 & 25.929 & 1.023 & -1.023 & 0.890 & -0.029 & -0.065 & -0.071 \\
\hline NPR 20 Str Metal & 7.490 & 0.025 & -0.023 & -25.447 & 0.512 & 0.547 & 26.567 & 25.447 & 0.958 & -0.958 & 0.935 & 0.052 & -0.057 & -0.077 \\
\hline NPR 20 Str Metal & 7.512 & -0.041 & 0.029 & -25.666 & 0.501 & 0.549 & 26.056 & 25.666 & 0.985 & -0.985 & 0.913 & -0.064 & 0.090 & -0.111 \\
\hline NPR 20 Str Metal & 7.485 & -0.026 & -0.043 & -24.327 & 0.504 & 0.547 & 26.164 & 24.327 & 0.930 & -0.930 & 0.921 & 0.101 & 0.060 & -0.117 \\
\hline NPR 20 Str Metal & 7.500 & 0.010 & -0.042 & -25.476 & 0.456 & 0.548 & 23.690 & 25.476 & 1.075 & -1.075 & 0.832 & 0.095 & -0.023 & -0.098 \\
\hline NPR 20 Str Metal & 7.490 & 0.029 & -0.028 & -24.966 & 0.486 & 0.547 & 25.256 & 24.966 & 0.989 & -0.989 & 0.889 & 0.064 & -0.067 & -0.093 \\
\hline NPR 20 Str Metal & 7.403 & 0.056 & -0.008 & -25.248 & 0.469 & 0.548 & 24.129 & 25.248 & 1.046 & -1.046 & 0.857 & 0.018 & -0.127 & -0.128 \\
\hline NPR 20 Str Metal & 5.825 & -0.027 & 0.013 & -18.834 & 0.371 & 0.431 & 18.188 & 18.834 & 1.036 & -1.036 & 0.862 & -0.039 & 0.082 & -0.091 \\
\hline NPR 20 Str Metal & 4.218 & 0.004 & -0.011 & -12.729 & 0.267 & 0.312 & 12.091 & 12.730 & 1.053 & -1.053 & 0.857 & 0.049 & -0.020 & -0.053 \\
\hline NPR 20 Str Metal & 2.416 & -0.035 & -0.044 & -5.565 & 0.149 & 0.179 & 5.483 & 5.565 & 1.015 & -1.015 & 0.836 & 0.454 & 0.365 & -0.583 \\
\hline NPR $20 \mathrm{~S}$ & 1.551 & -0.047 & -0.022 & -2.421 & 0.082 & 0.115 & 2.202 & 2.421 & 1.099 & -1.099 & 0.717 & 0.519 & 1.120 & -1.234 \\
\hline NPR $2010^{\circ}$ & 7.613 & -1.659 & -0.473 & -27.387 & 0.553 & 0.555 & 29.013 & 27.441 & 0.946 & -0.944 & 0.997 & 0.989 & 3.467 & -3.605 \\
\hline NPR $2010^{\circ}$ & 7.545 & -1.601 & -0.385 & -26.901 & 0.528 & 0.550 & 27.675 & 26.951 & 0.974 & -0.972 & 0.961 & 0.820 & 3.405 & -3.502 \\
\hline NPR $2010^{\circ} \mathrm{gimbal}$ & 7.523 & -1.596 & -0.384 & -26.785 & 0.567 & 0.548 & 29.685 & 26.835 & 0.904 & -0.902 & 1.035 & 0.821 & 3.410 & -3.507 \\
\hline
\end{tabular}


Table 6: Summary of blow-down test results for NPR 20 prototype aerospike nozzles.

\begin{tabular}{|c|c|c|c|c|c|c|c|c|c|c|c|c|c|c|}
\hline $\begin{array}{l}\text { Nozzle } \\
\text { Description }\end{array}$ & NPR & $\begin{array}{l}F_{x} \\
\mathrm{lbf}\end{array}$ & $\begin{array}{l}F_{y} \\
\mathrm{lbf}\end{array}$ & $\begin{array}{l}F_{z} \\
\text { lbf }\end{array}$ & $\begin{array}{c}\mathrm{W}_{\mathrm{p}} \\
\mathrm{lbm} / \mathrm{s}\end{array}$ & $\begin{array}{c}\mathbf{W}_{\mathbf{i}} \\
\mathrm{lbm} / \mathrm{s}\end{array}$ & $\begin{array}{l}F_{i} \\
\mathrm{lbf}\end{array}$ & $\begin{array}{l}F_{r} \\
\text { lbf }\end{array}$ & $F_{r} / F_{i}$ & $F_{z} / F_{i}$ & $W_{p} / W_{i}$ & $\begin{array}{c}\delta_{\text {pitch }} \\
(\stackrel{\circ}{)}\end{array}$ & $\begin{array}{c}\delta_{\text {yaw }} \\
(\stackrel{0}{)})\end{array}$ & $\begin{array}{l}\delta_{r} \\
(\stackrel{9}{)})\end{array}$ \\
\hline NPR 20 Slot 3 & 7.477 & -5.643 & -0.273 & -26.470 & 0.623 & 0.546 & 32.338 & 27.066 & 0.837 & -0.819 & 1.140 & 0.590 & 12.035 & -12.049 \\
\hline NPR 20 Slot 3 & 7.467 & -5.593 & -0.257 & -26.643 & 0.654 & 0.546 & 33.964 & 27.225 & 0.802 & -0.784 & 1.199 & 0.552 & 11.854 & -11.867 \\
\hline NPR 20 Slot 3 & 7.478 & -5.588 & -0.248 & -26.504 & 0.618 & 0.546 & 32.113 & 27.087 & 0.843 & -0.825 & 1.131 & 0.536 & 11.905 & -11.916 \\
\hline NPR 20 Slot 4 & 7.427 & -3.713 & 0.102 & -28.163 & 0.632 & 0.540 & 32.804 & 28.407 & 0.866 & -0.859 & 1.170 & -0.207 & 7.510 & -7.513 \\
\hline NPR 20 Slot 4 & 7.482 & -3.717 & 0.045 & -28.419 & 0.661 & 0.544 & 34.333 & 28.661 & 0.835 & -0.828 & 1.214 & -0.092 & 7.452 & -7.452 \\
\hline NPR 20 Slot 4 & 7.438 & -3.614 & 0.252 & -28.123 & 0.638 & 0.541 & 33.138 & 28.355 & 0.856 & -0.849 & 1.180 & -0.514 & 7.323 & -7.341 \\
\hline NPR 20 Slot 4 & 7.480 & -3.751 & 0.124 & -28.446 & 0.655 & 0.544 & 34.115 & 28.692 & 0.841 & -0.834 & 1.203 & -0.250 & 7.512 & -7.516 \\
\hline NPR 20 Slot 4 & 6.386 & -3.079 & 0.142 & -23.460 & 0.546 & 0.471 & 27.463 & 23.662 & 0.862 & -0.854 & 1.159 & -0.347 & 7.478 & -7.486 \\
\hline NPR 20 Slot 4 & 5.798 & -2.638 & 0.155 & -20.682 & 0.520 & 0.428 & 25.517 & 20.850 & 0.817 & -0.811 & 1.216 & -0.429 & 7.268 & -7.281 \\
\hline NPR 20 Slot 4 & 4.010 & -1.695 & 0.052 & -13.202 & 0.339 & 0.296 & 15.155 & 13.310 & 0.878 & -0.871 & 1.145 & -0.227 & 7.318 & -7.322 \\
\hline NPR 20 Slot 4 & 2.445 & -0.849 & 0.058 & -6.549 & 0.195 & 0.180 & 7.229 & 6.604 & 0.914 & -0.906 & 1.081 & -0.507 & 7.391 & -7.408 \\
\hline NPR 20 Slot 4 & 1.489 & -0.314 & -0.031 & -2.468 & 0.105 & 0.110 & 2.693 & 2.488 & 0.924 & -0.916 & 0.958 & 0.724 & 7.245 & -7.280 \\
\hline NPR 20 Slot 5 & 7.454 & -3.254 & 0.139 & -27.303 & 0.607 & 0.544 & 31.532 & 27.497 & 0.872 & -0.866 & 1.115 & -0.292 & 6.795 & -6.802 \\
\hline NPR 20 Slot 5 & 7.468 & -3.327 & 0.059 & -27.221 & 0.598 & 0.545 & 31.092 & 27.424 & 0.882 & -0.876 & 1.097 & -0.124 & 6.968 & -6.969 \\
\hline NPR 20 Slot 5 & 7.473 & -3.351 & 0.057 & -27.490 & 0.626 & 0.545 & 32.553 & 27.694 & 0.851 & -0.844 & 1.148 & -0.120 & 6.950 & -6.951 \\
\hline NPR 20 Slot 6 & 7.460 & -3.305 & 0.178 & -29.059 & 0.623 & 0.543 & 32.344 & 29.247 & 0.904 & -0.898 & 1.147 & -0.350 & 6.489 & -6.499 \\
\hline NPR 20 Slot6 & 7.458 & -3.323 & 0.180 & -29.025 & 0.657 & 0.542 & 34.139 & 29.216 & 0.856 & -0.850 & 1.212 & -0.355 & 6.532 & -6.541 \\
\hline NPR 20 Slot 6 & 7.512 & -3.431 & 0.162 & -29.357 & 0.632 & 0.546 & 32.882 & 29.558 & 0.899 & -0.893 & 1.157 & -0.315 & 6.665 & -6.673 \\
\hline
\end{tabular}


Table 7: Summary of blow-down test results for NPR 20 prototype aerospike nozzles.

\begin{tabular}{|c|c|c|c|c|c|c|c|c|c|c|c|c|c|c|}
\hline \begin{tabular}{|l|} 
Nozzle \\
Description
\end{tabular} & $\begin{array}{l}\text { Right } \\
\text { NPR }\end{array}$ & $\begin{array}{l}\mathbf{F}_{\mathbf{x}} \\
\mathrm{lbf}\end{array}$ & $\begin{array}{l}\mathbf{F}_{\mathrm{y}} \\
\mathrm{lbf}\end{array}$ & $\begin{array}{l}\mathbf{F}_{\mathbf{z}} \\
\mathrm{lbf}\end{array}$ & $\begin{array}{c}\mathbf{W}_{\mathbf{p}} \\
\mathrm{lbm} / \mathrm{s}\end{array}$ & $\begin{array}{c}\mathbf{W}_{\mathbf{i}} \\
\mathrm{lbm} / \mathrm{s}\end{array}$ & $\begin{array}{l}\mathbf{F}_{\mathbf{i}} \\
\mathrm{lbf}\end{array}$ & $\begin{array}{l}F_{r} \\
\mathrm{lbf}\end{array}$ & $F_{r} / F_{i}$ & $F_{z} / F_{i}$ & $W_{p} / W_{i}$ & $\begin{array}{c}\delta_{\text {pitch }} \\
(\stackrel{o}{)}) \\
\end{array}$ & $\begin{array}{c}\delta_{\text {yaw }} \\
(\stackrel{\circ}{)} \\
\end{array}$ & $\begin{array}{l}\delta_{r} \\
(\stackrel{\circ}{)})\end{array}$ \\
\hline NPR 20 Slot 8 & 7.466 & -3.176 & -0.070 & -27.137 & 0.605 & 0.545 & 31.448 & 27.323 & 0.869 & -0.863 & 1.110 & 0.147 & 6.675 & -6.677 \\
\hline NPR 20 Slot 8 & 7.462 & -3.202 & -0.063 & -27.101 & 0.619 & 0.544 & 32.185 & 27.289 & 0.848 & -0.842 & 1.137 & 0.134 & 6.738 & -6.739 \\
\hline NPR 20 Slot 8 & 7.490 & -3.167 & -0.115 & -27.307 & 0.593 & 0.546 & 30.848 & 27.490 & 0.891 & -0.885 & 1.085 & 0.241 & 6.615 & -6.619 \\
\hline NPR 20 Slot 9 & 7.469 & -2.938 & -0.067 & -27.073 & 0.610 & 0.545 & 31.719 & 27.232 & 0.859 & -0.854 & 1.119 & 0.141 & 6.195 & -6.196 \\
\hline NPR 20 Slot 9 & 7.467 & -3.048 & -0.052 & -27.055 & 0.592 & 0.545 & 30.802 & 27.226 & 0.884 & -0.878 & 1.087 & 0.111 & 6.427 & -6.428 \\
\hline NPR 20 Slot 9 & 7.431 & -2.949 & -0.050 & -26.850 & 0.600 & 0.542 & 31.177 & 27.012 & 0.866 & -0.861 & 1.107 & 0.108 & 6.268 & -6.269 \\
\hline NPR 20 Slot 10 & 7.453 & -4.408 & -0.069 & -27.249 & 0.593 & 0.539 & 31.021 & 27.604 & 0.890 & -0.878 & 1.101 & 0.145 & 9.189 & -9.190 \\
\hline NPR 20 Slot 10 & 7.440 & -4.408 & 0.032 & -26.948 & 0.620 & 0.537 & 32.435 & 27.306 & 0.842 & -0.831 & 1.154 & -0.069 & 9.289 & -9.289 \\
\hline NPR 20 Slot 11 & 7.408 & -5.582 & 0.107 & -27.611 & 0.644 & 0.539 & 33.491 & 28.170 & 0.841 & -0.824 & 1.194 & -0.221 & 11.429 & -11.431 \\
\hline NPR 20 Slot 11 & 7.506 & -5.581 & 0.153 & -27.937 & 0.682 & 0.547 & 35.553 & 28.489 & 0.801 & -0.786 & 1.248 & -0.315 & 11.297 & -11.302 \\
\hline NPR 20 Slot 12 & 7.458 & -6.682 & 0.222 & -27.772 & 0.686 & 0.543 & 35.719 & 28.565 & 0.800 & -0.778 & 1.264 & -0.457 & 13.527 & -13.534 \\
\hline NPR 20 Slot 12 & 7.263 & -6.495 & 0.287 & -29.199 & 0.718 & 0.529 & 37.090 & 29.914 & 0.807 & -0.787 & 1.358 & -0.564 & 12.541 & -12.553 \\
\hline NPR 20 Slot 12 & 7.273 & -5.495 & 0.041 & -26.913 & 0.606 & 0.536 & 31.127 & 27.468 & 0.882 & -0.865 & 1.130 & -0.088 & 11.539 & -11.540 \\
\hline NPR 20 Slot 12 & 5.818 & -4.091 & 0.092 & -20.222 & 0.522 & 0.429 & 25.668 & 20.632 & 0.804 & -0.788 & 1.218 & -0.262 & 11.436 & -11.439 \\
\hline NPR 20 Slot 12 & 4.086 & -2.601 & 0.134 & -12.982 & 0.368 & 0.301 & 16.570 & 13.240 & 0.799 & -0.783 & 1.223 & -0.590 & 11.331 & -11.346 \\
\hline NPR 20 Slot 12 & 2.247 & -1.144 & 0.050 & -5.561 & 0.191 & 0.166 & 6.863 & 5.678 & 0.827 & -0.810 & 1.151 & -0.510 & 11.627 & -11.638 \\
\hline NPR 20 Slot 12 & 1.520 & -0.494 & 0.043 & -2.567 & 0.109 & 0.112 & 2.849 & 2.614 & 0.918 & -0.901 & 0.969 & -0.968 & 10.889 & -10.930 \\
\hline NPR 20 Slot 13 & 7.549 & -6.489 & 0.170 & -26.906 & 0.639 & 0.545 & 33.544 & 27.678 & 0.825 & -0.802 & 1.173 & -0.363 & 13.560 & -13.564 \\
\hline NPR 20 Slot 13 & 7.559 & -6.627 & 0.117 & -26.903 & 0.682 & 0.545 & 35.867 & 27.708 & 0.773 & -0.750 & 1.252 & -0.248 & 13.839 & -13.841 \\
\hline NPR 20 Slot 14 & 7.505 & -3.888 & 0.026 & -28.002 & 0.610 & 0.541 & 32.053 & 28.271 & 0.882 & -0.874 & 1.129 & -0.054 & 7.904 & -7.905 \\
\hline NPR 20 Slot 14 & 7.512 & -3.810 & 0.087 & -27.764 & 0.639 & 0.541 & 33.592 & 28.025 & 0.834 & -0.827 & 1.182 & -0.179 & 7.814 & -7.816 \\
\hline NPR 20 Slot 15 & 7.455 & -6.383 & 0.118 & -28.126 & 0.624 & 0.536 & 32.778 & 28.841 & 0.880 & -0.858 & 1.163 & -0.240 & 12.787 & -12.789 \\
\hline NPR 20 Slot 15 & 7.416 & -6.466 & 0.137 & -28.368 & 0.657 & 0.533 & 34.468 & 29.096 & 0.844 & -0.823 & 1.231 & -0.277 & 12.841 & -12.844 \\
\hline NPR 20 Slot 16 & 7.505 & -3.311 & 0.230 & -28.236 & 0.555 & 0.540 & 29.209 & 28.431 & 0.973 & -0.967 & 1.029 & -0.468 & 6.687 & -6.704 \\
\hline NPR 20 Slot 16 & 7.561 & -3.338 & 0.238 & -28.323 & 0.617 & 0.544 & 32.526 & 28.520 & 0.877 & -0.871 & 1.135 & -0.481 & 6.722 & -6.738 \\
\hline
\end{tabular}




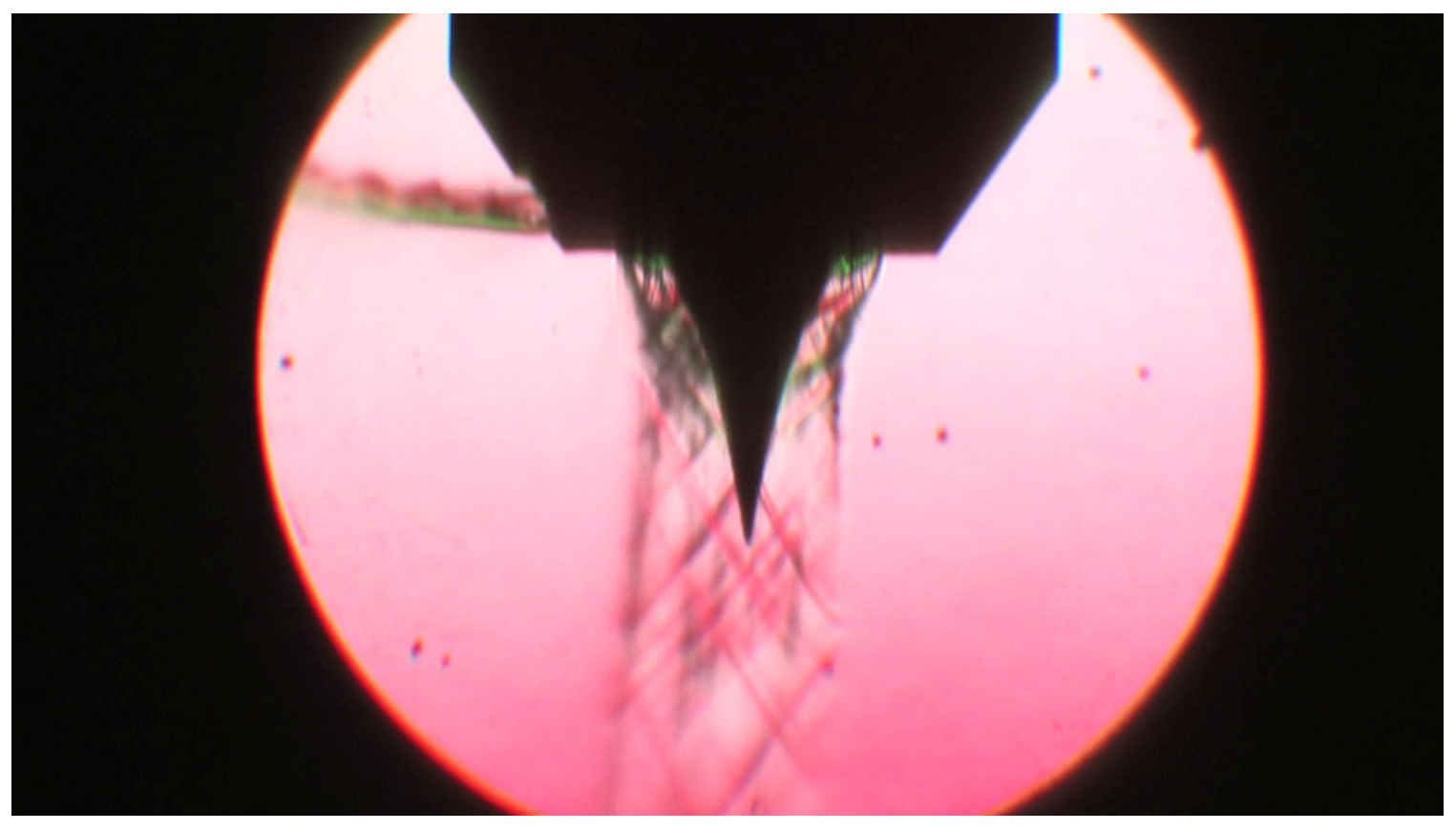

Figure 25: NPR 20 Slot 3.

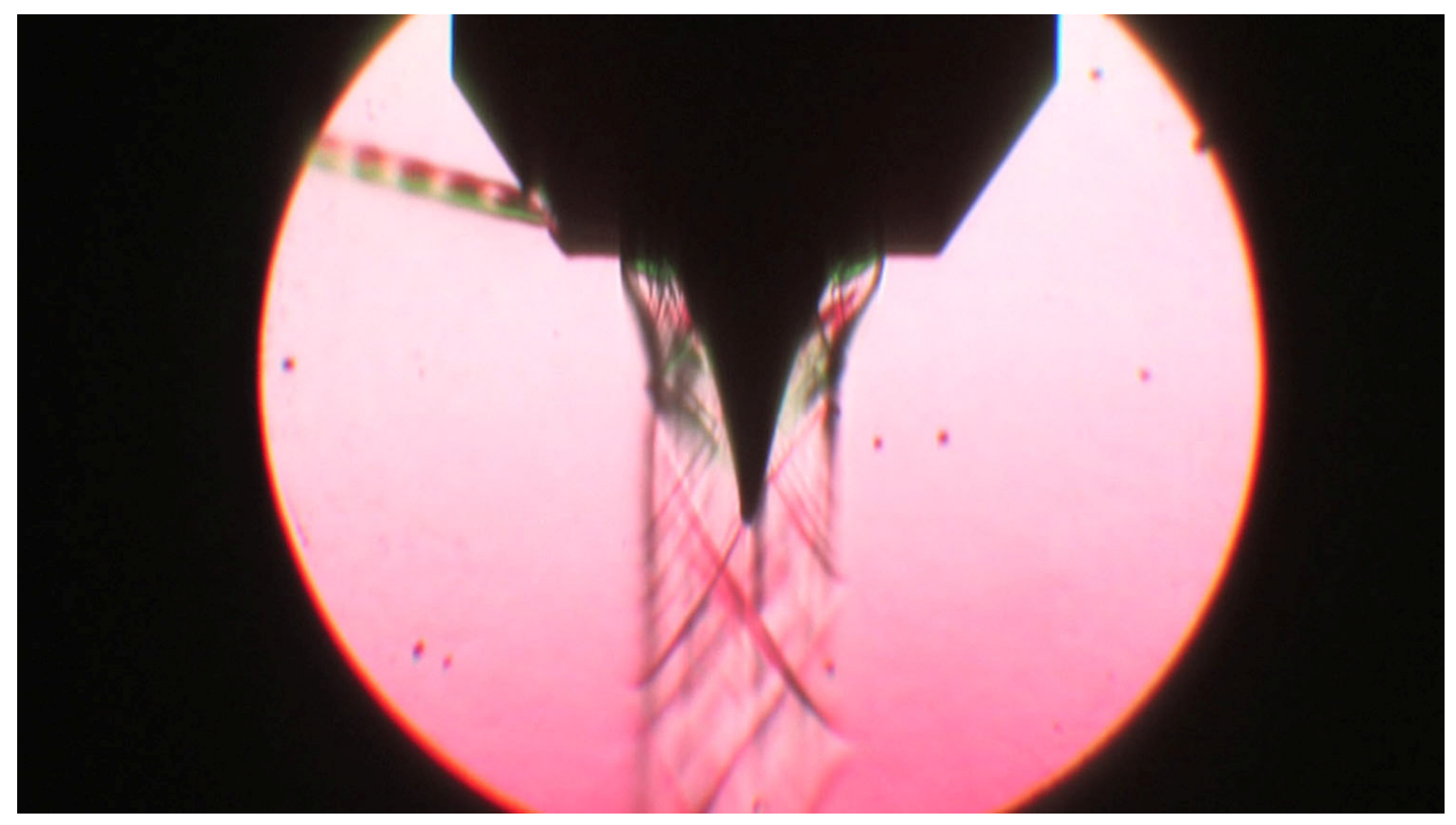

Figure 26: NPR 20 Slot 4. 


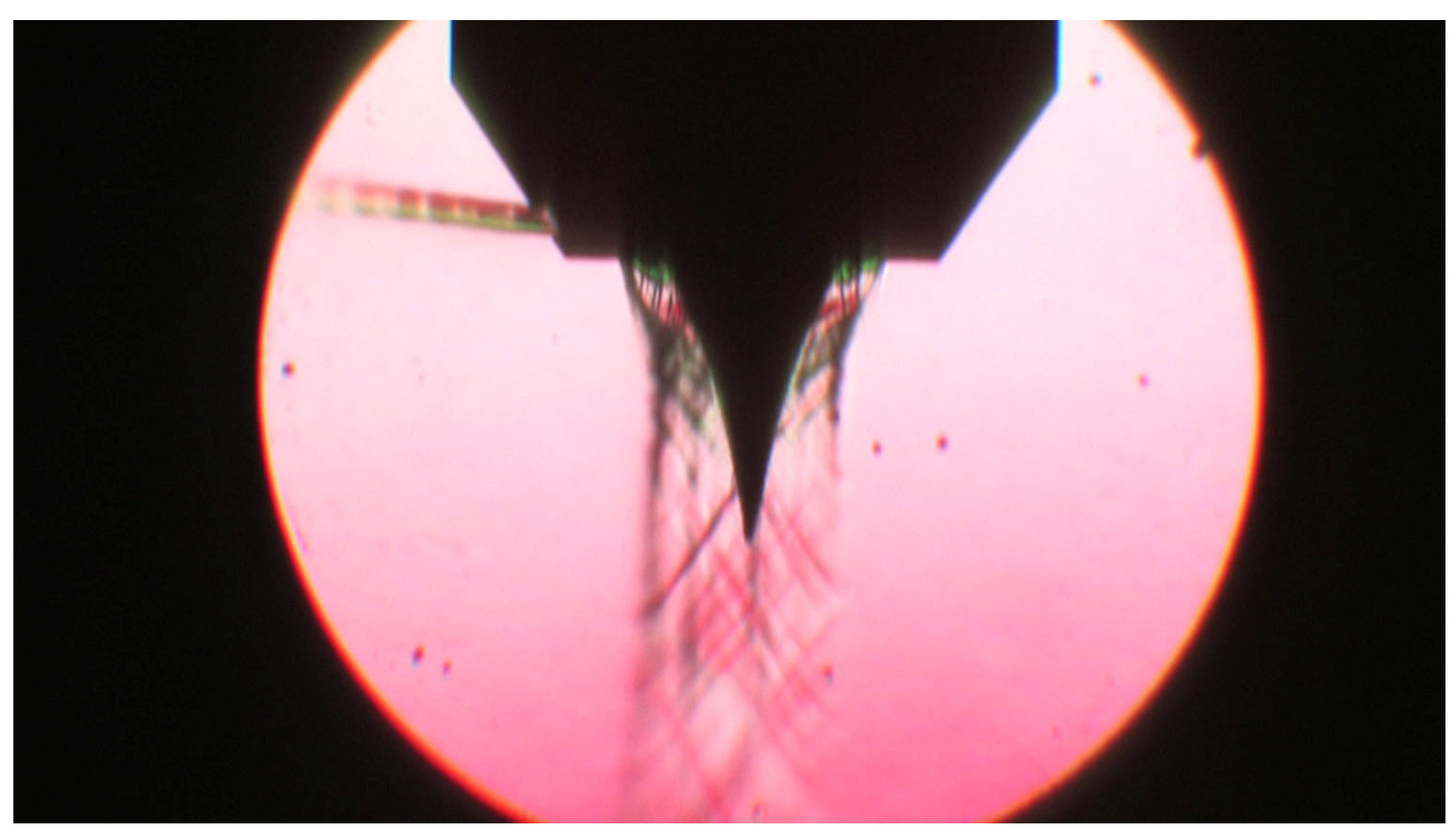

Figure 27: NPR 20 Slot 5.

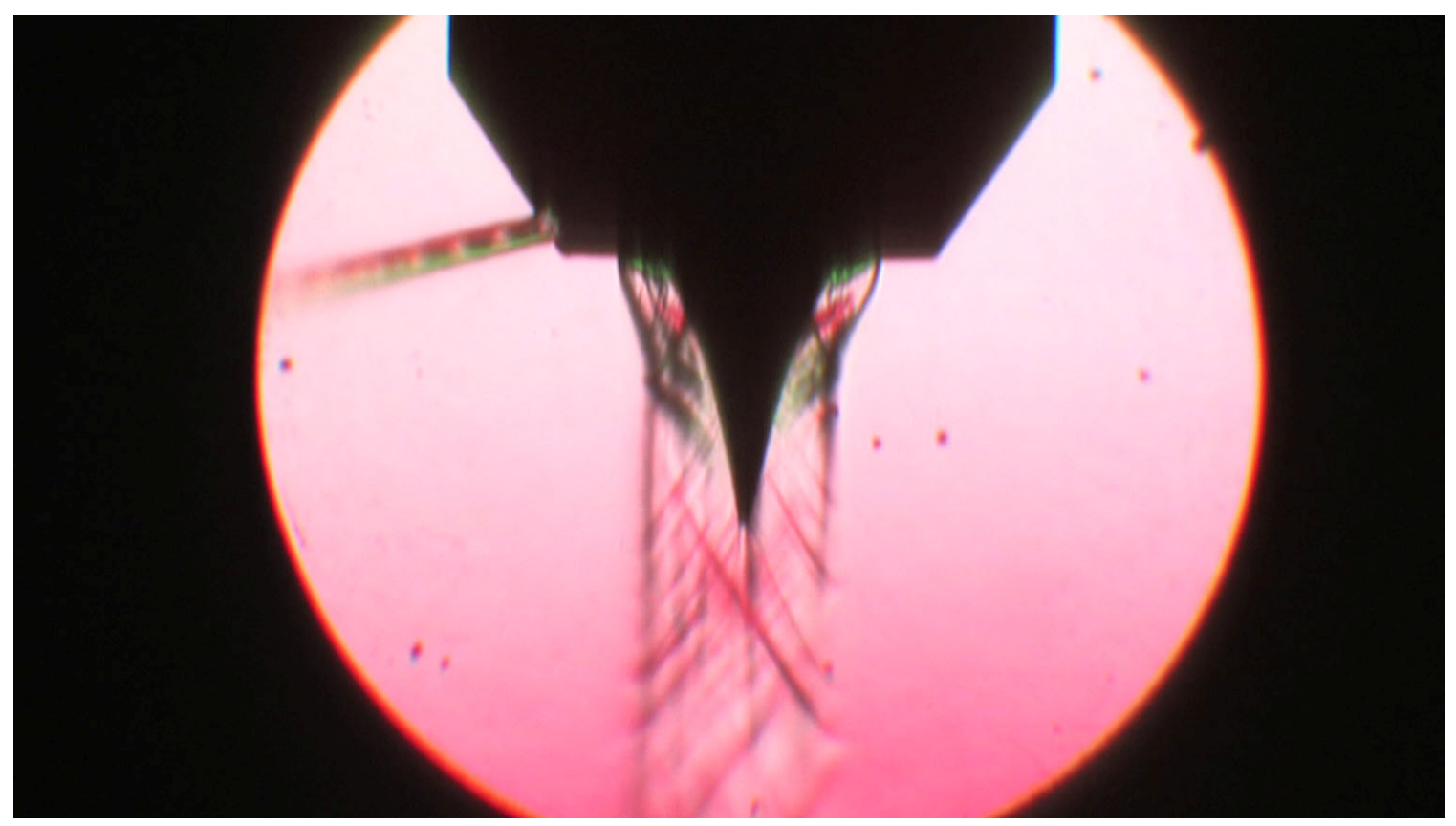

Figure 28: NPR 20 Slot 6. 


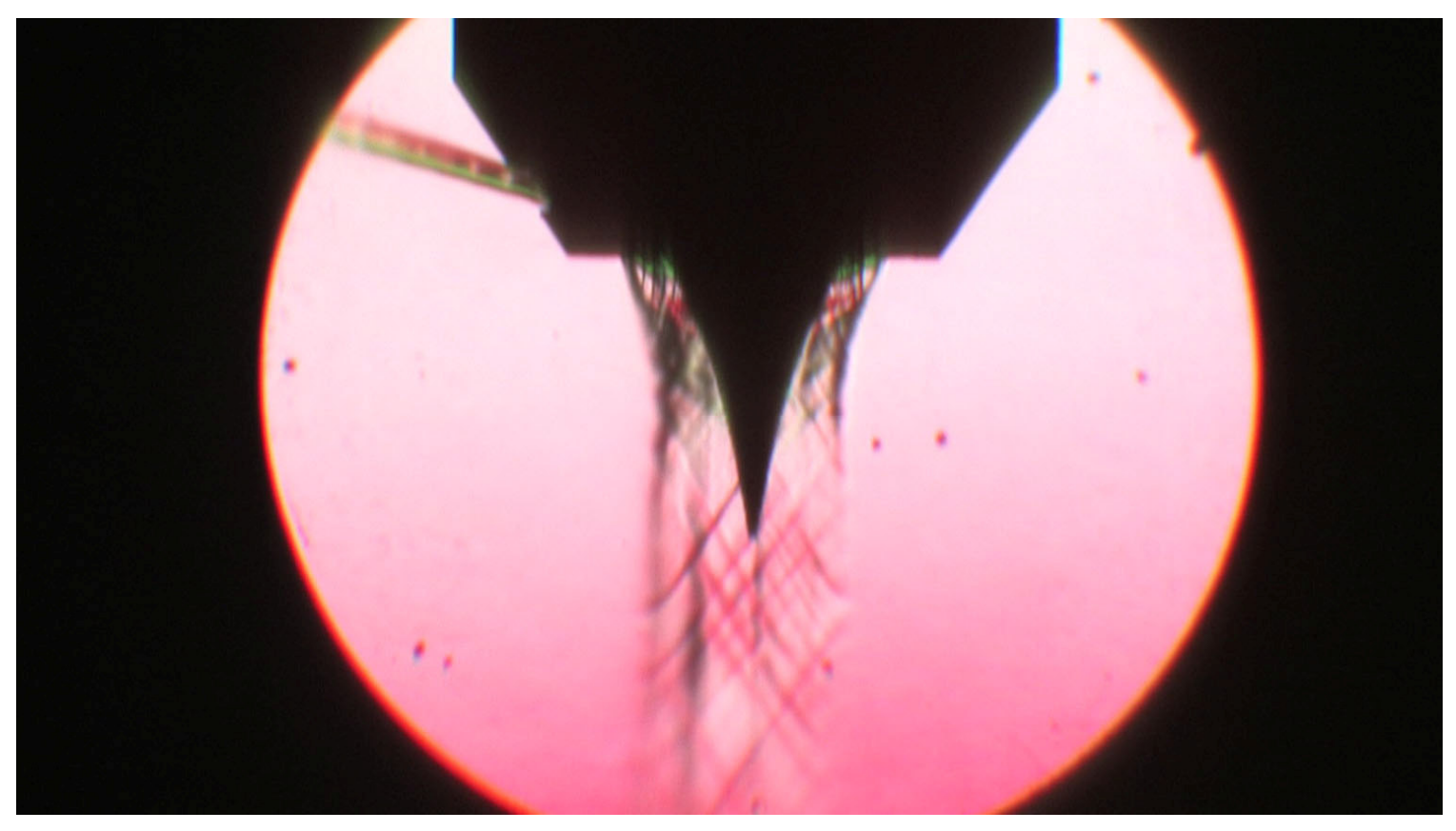

Figure 29: NPR 20 Slot 8.

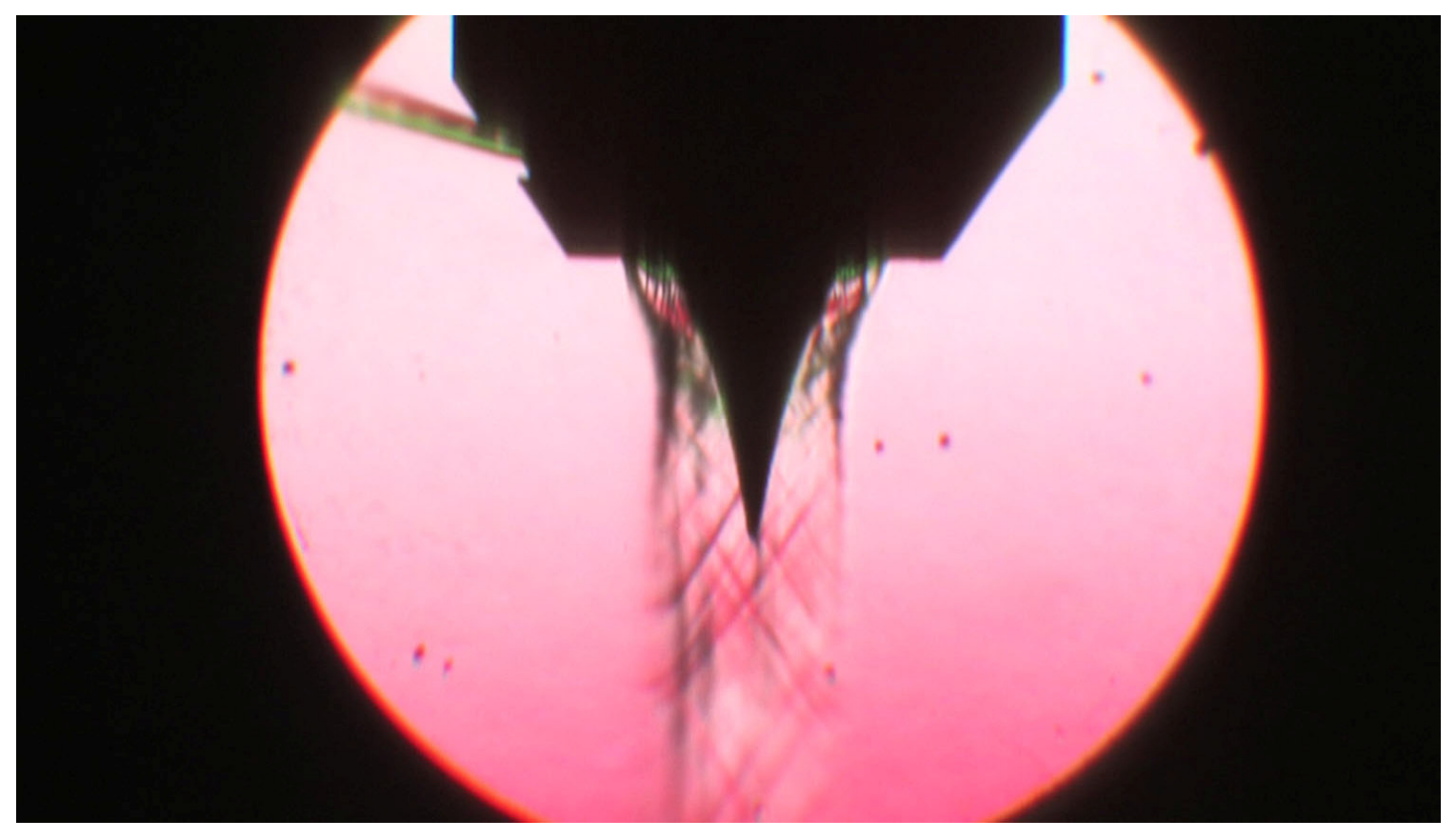

Figure 30: NPR 20 Slot 9. 


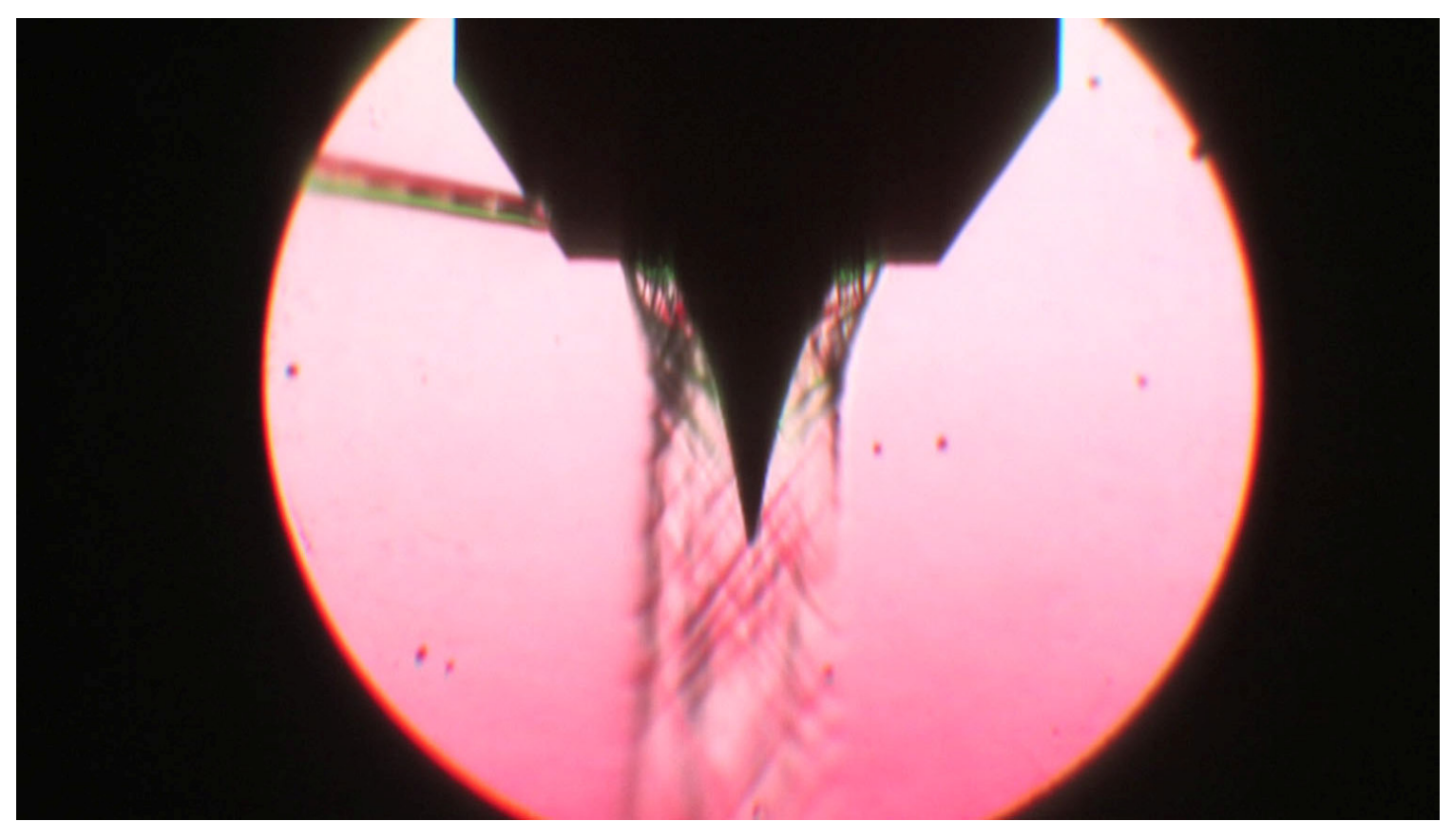

Figure 31: NPR 20 Slot 10.

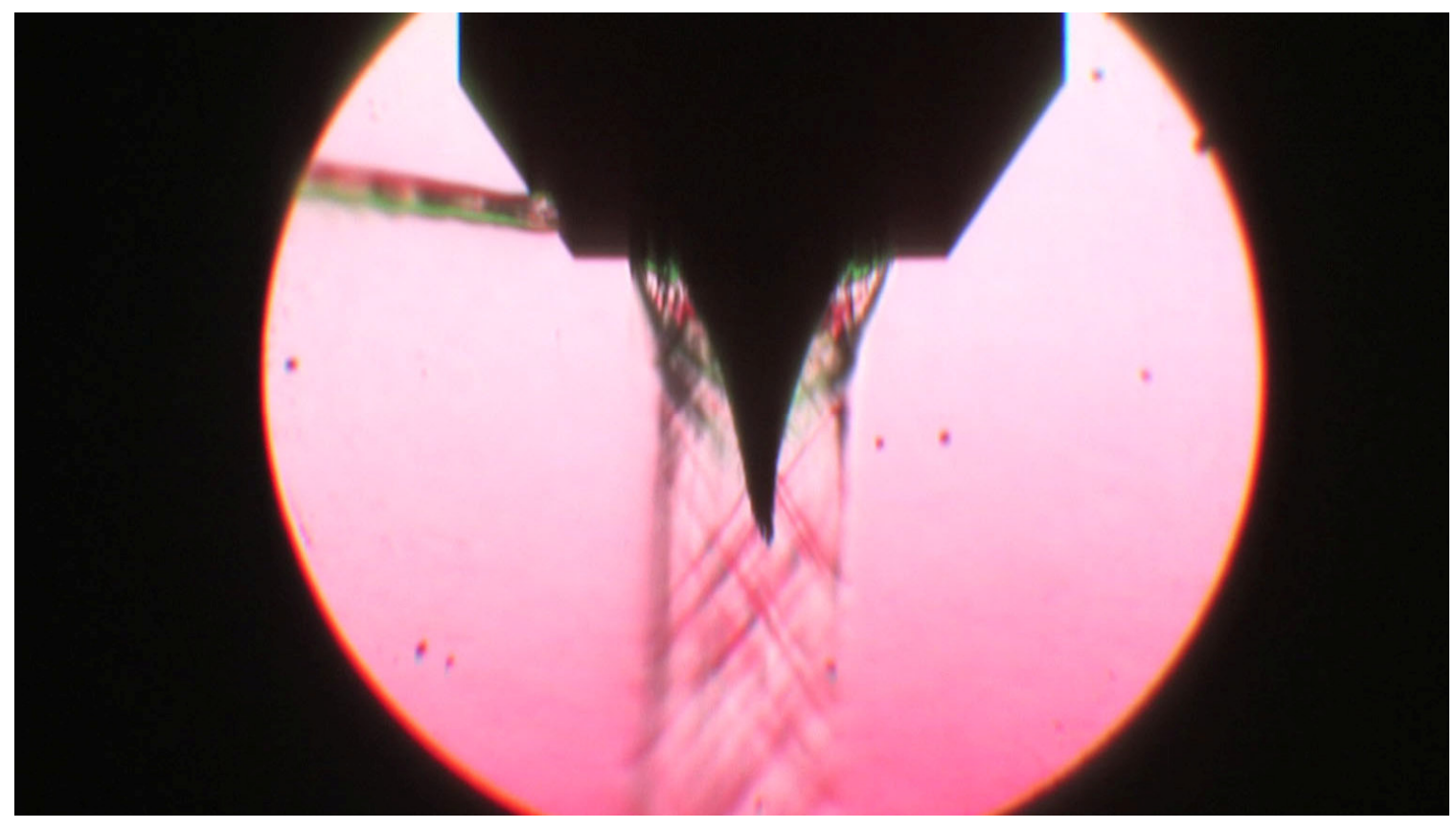

Figure 32: NPR 20 Slot 11. 


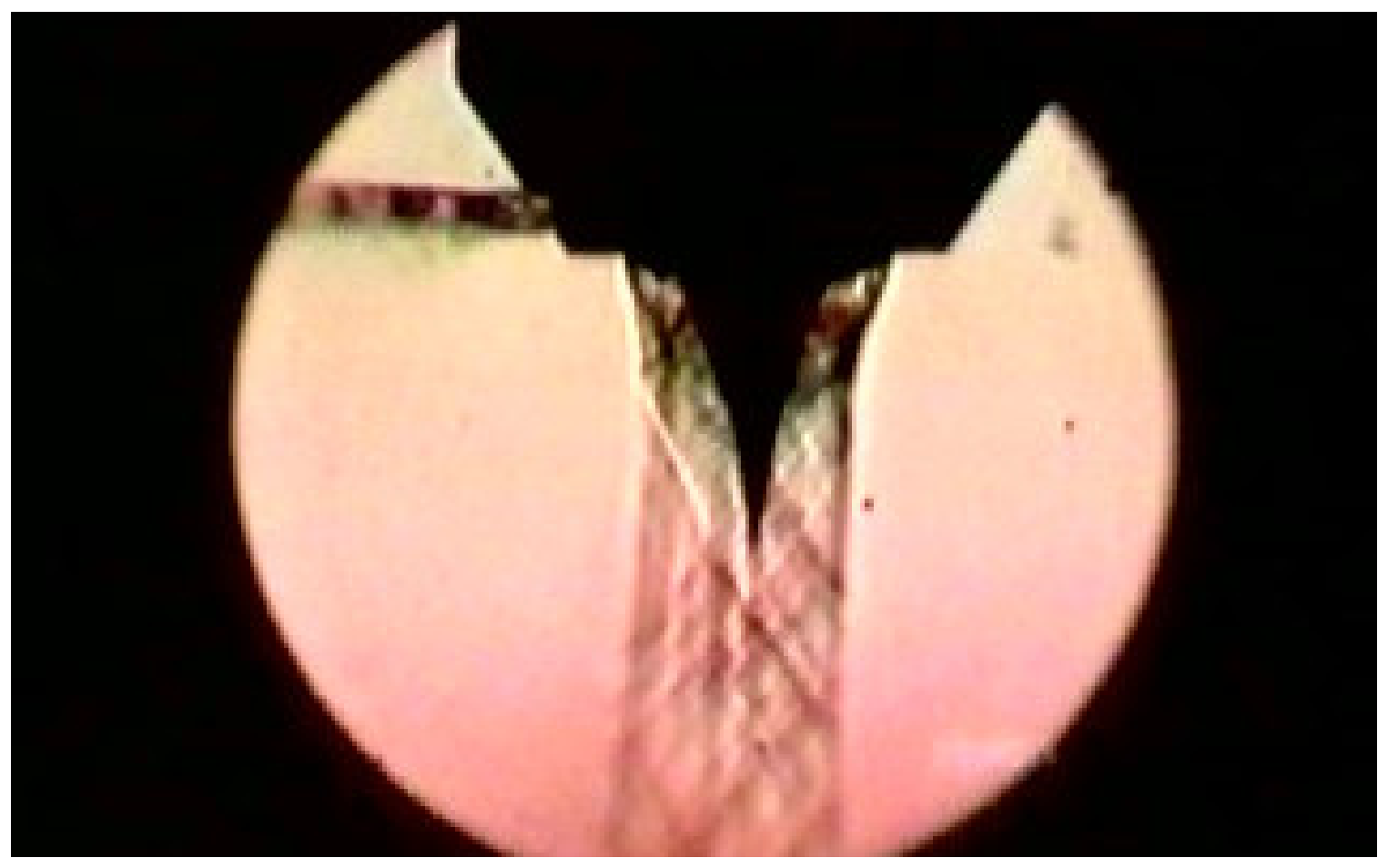

Figure 33: NPR 20 Slot 12.

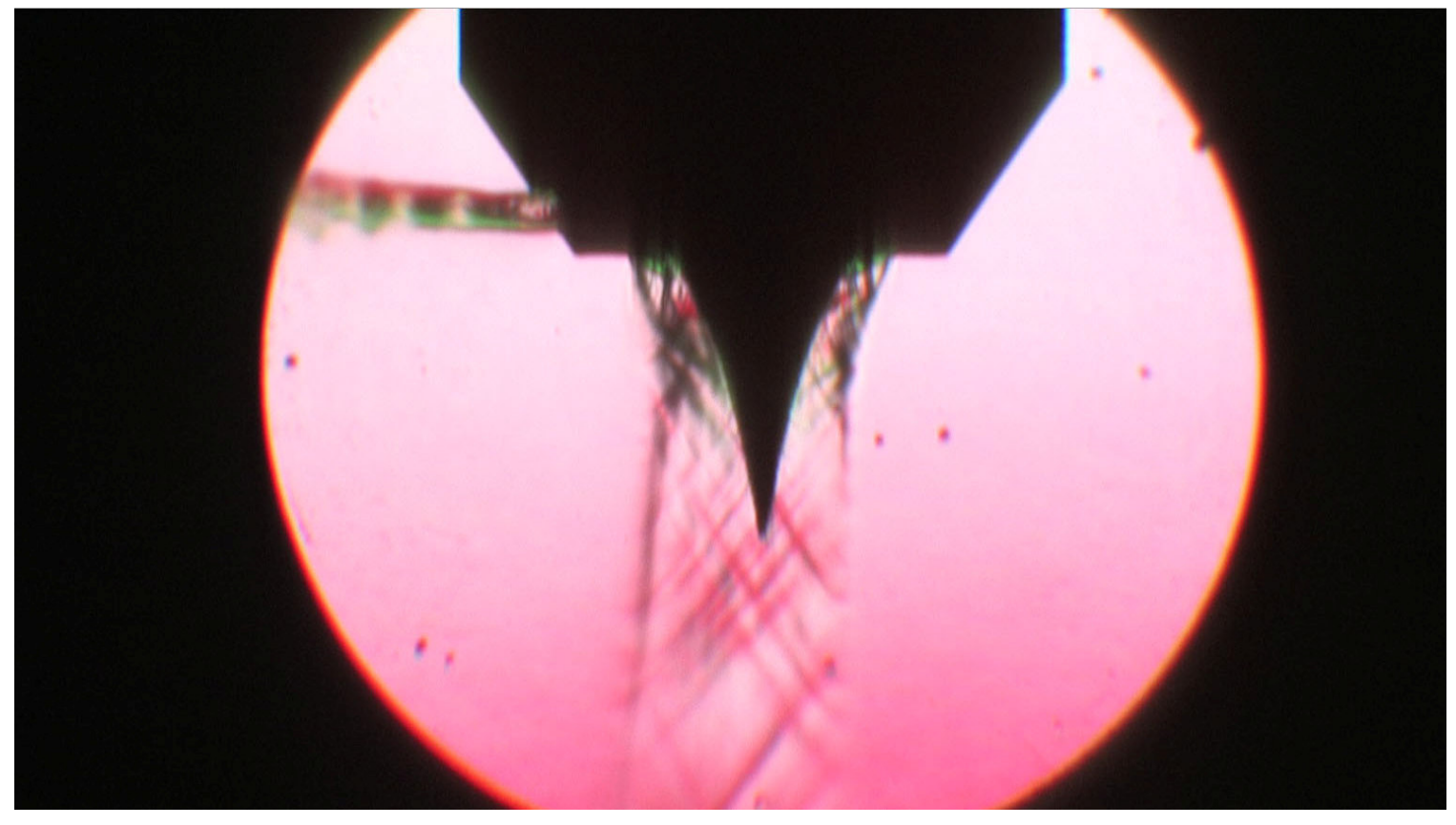

Figure 34: NPR 20 Slot 13. 


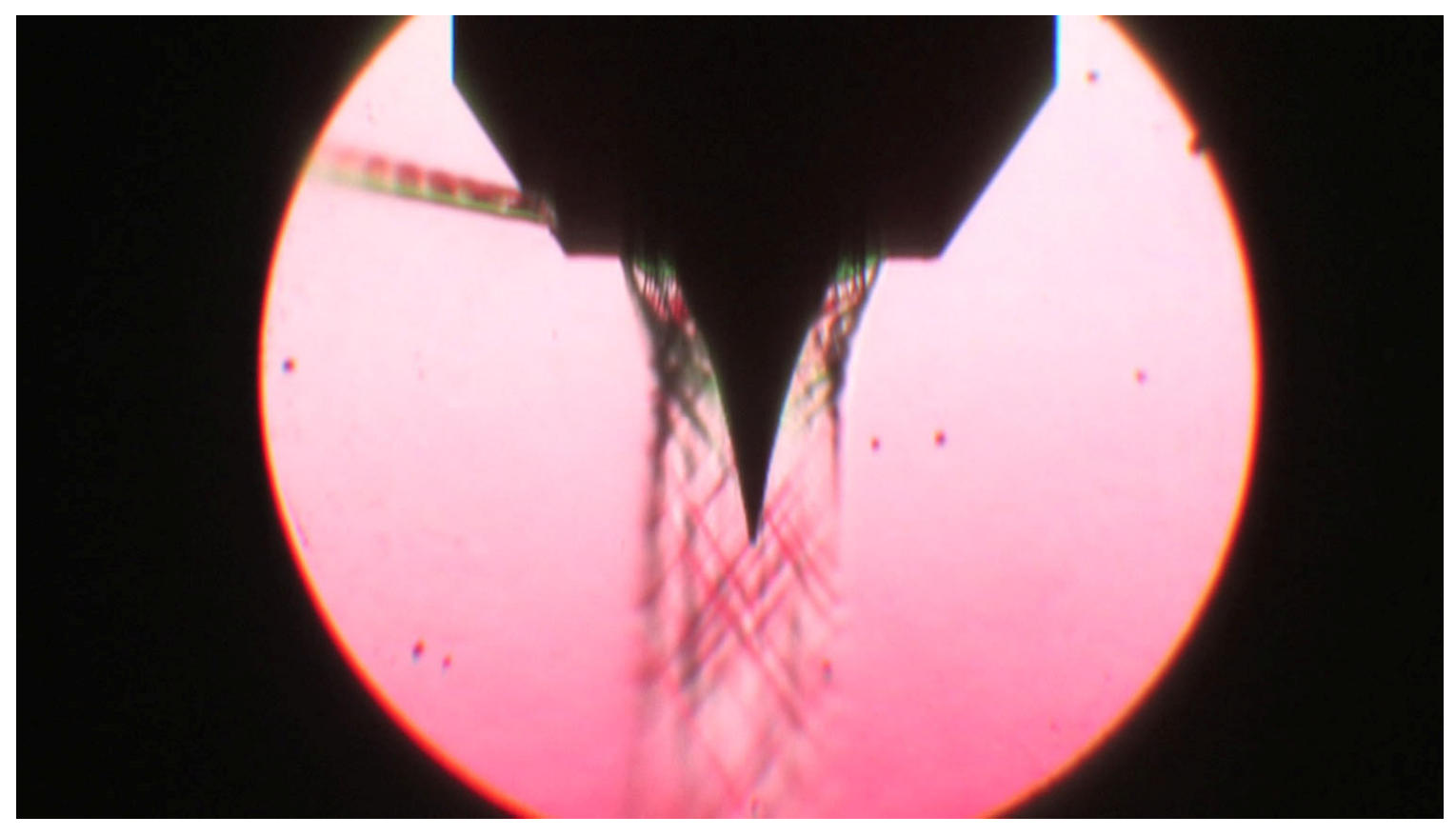

Figure 35: NPR 20 Slot 14.

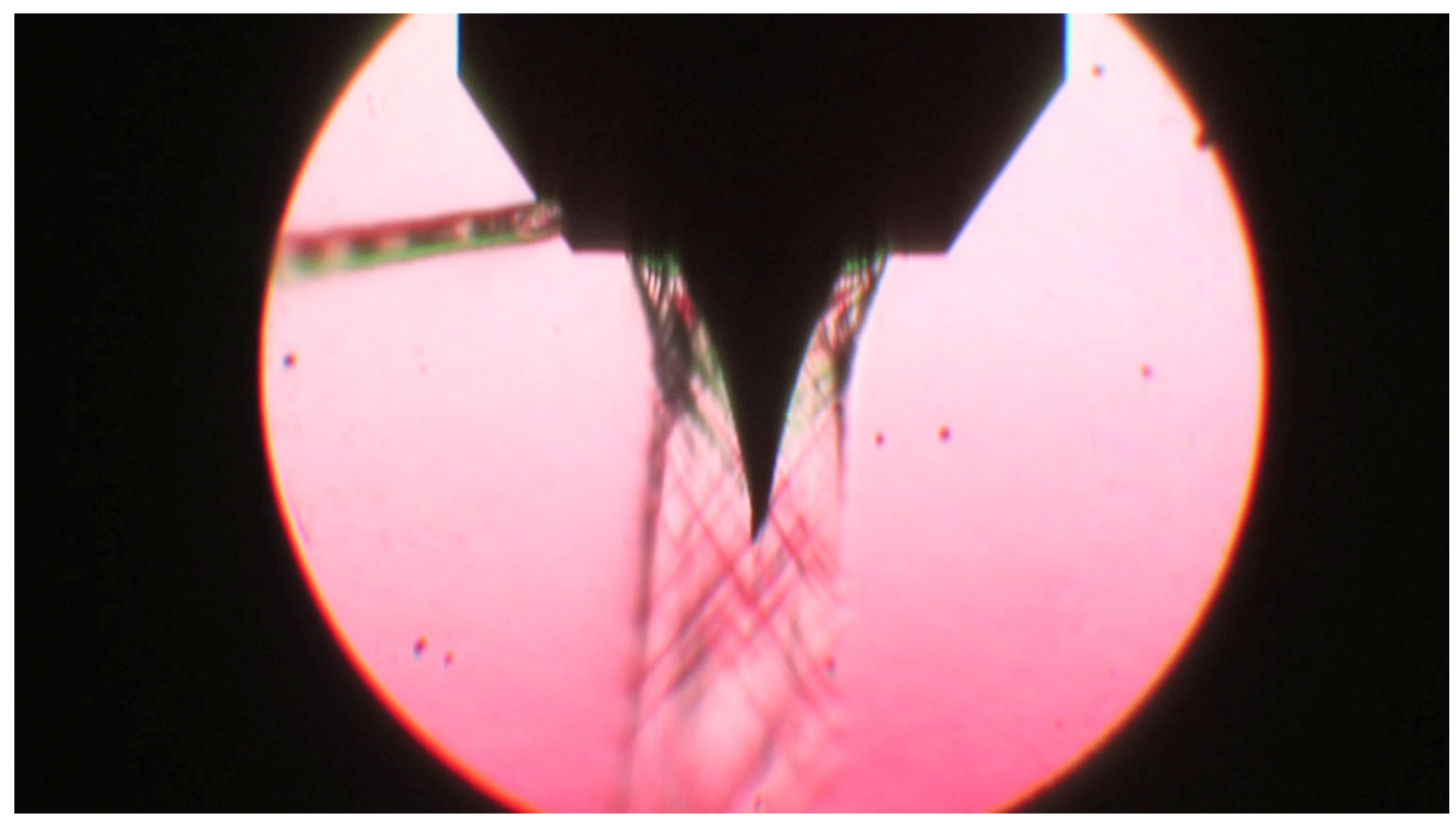

Figure 36: NPR 20 Slot 15. 


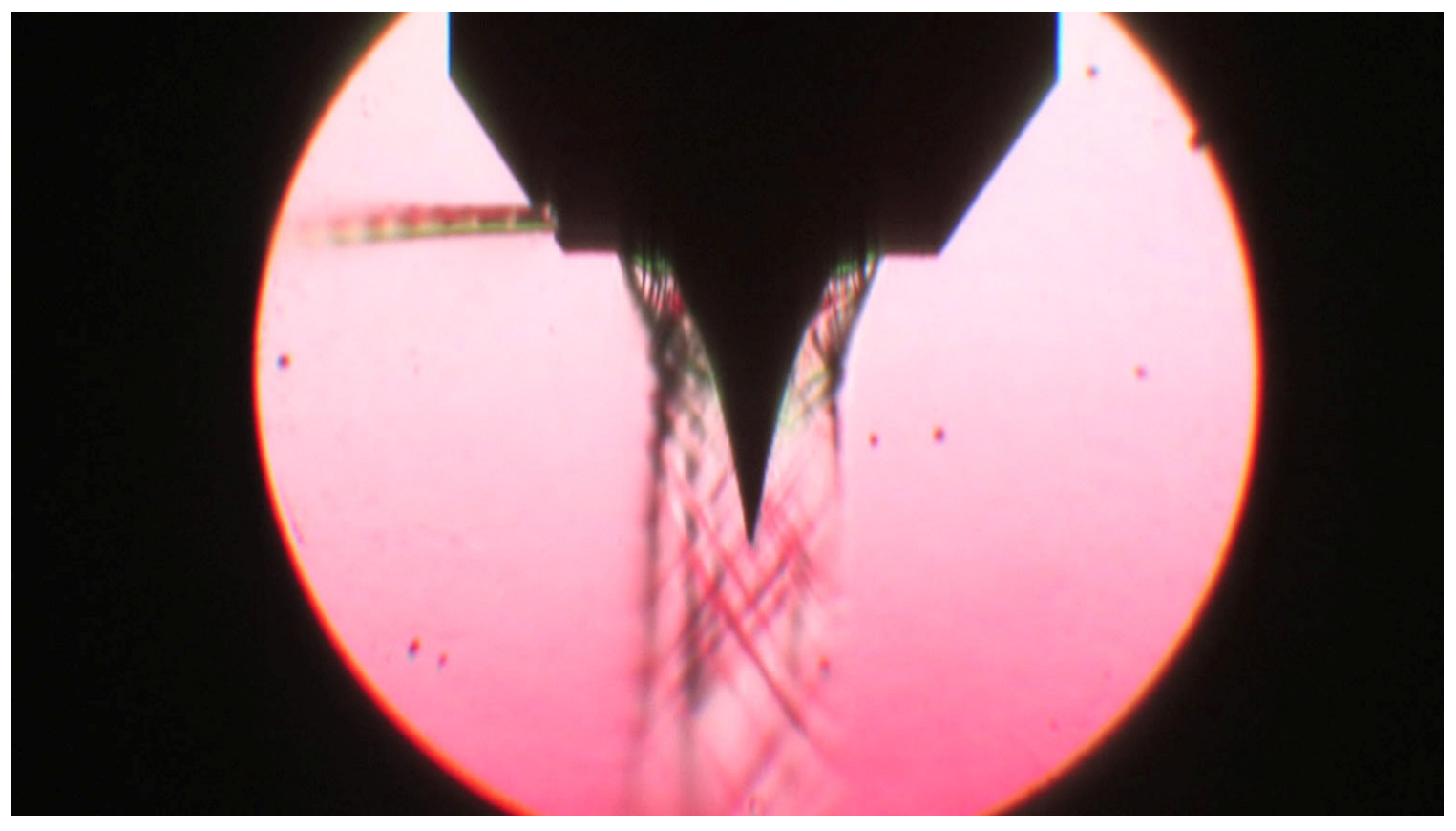

Figure 37: NPR 20 Slot 16. 


\section{NPR 50 Nozzle Results}

Shown in Table 8 are the cold-flow blow-down results for the NPR 50 nozzles, with the straight and gimbled aerospike nozzle configurations for comparison. The NPR 50 straight plastic configuration nozzles produced approximately $23.27 \mathrm{lb}_{\mathrm{f}}$ of thrust with a turn angle of $0.61^{\circ}$. The $10^{\circ}$ gimbled spiked produced an average thrust of $28.650 \mathrm{lb}_{\mathrm{f}}$ with a resultant turn of $3.48^{\circ}$.

The NPR 50 Slot 3 configuration (large slot) produced an average thrust of 22.96 $\mathrm{lb}_{\mathrm{f}}$ of thrust with a resultant turn angle of $15.70^{\circ}$. The smaller slot configuration, NPR 50 Slot 4 produced $23.64 \mathrm{lb}_{\mathrm{f}}$ of thrust with a resultant turn of $9.35^{\circ}$. The addition of the slot also increased the mass flow rate of the entire system. From the Schlieren photographs, Figures $39-40$, it can be seen that there is separation of flow from the secondary port wall in the case of the NPR 50 Slot 3 nozzle. In both cases the flow is exiting to the fore side of the radial axis. 
Table 8: Summary of blow-down test results for NPR 50 prototype aerospike nozzles.

\begin{tabular}{|c|c|c|c|c|c|c|c|c|c|c|c|c|c|c|}
\hline Nozzle Description & NPR & $\begin{array}{l}\mathbf{F}_{\mathbf{x}} \\
\text { lbf }\end{array}$ & $\begin{array}{l}\mathbf{F}_{\mathbf{y}} \\
\mathrm{lbf}\end{array}$ & $\begin{array}{l}\mathbf{F}_{\mathbf{z}} \\
\mathrm{lbf}\end{array}$ & $\begin{array}{c}\mathbf{W}_{\mathbf{p}} \\
\mathrm{lbm} / \mathrm{s}\end{array}$ & $\begin{array}{c}\mathbf{W}_{\mathbf{i}} \\
\mathrm{lbm} / \mathrm{s}\end{array}$ & $\begin{array}{l}\mathbf{F}_{\mathbf{i}} \\
\mathrm{lbf}\end{array}$ & $\begin{array}{l}F_{r} \\
\mathrm{lbf}\end{array}$ & $F_{r} / F_{i}$ & $F_{z} / F_{i}$ & $\mathbf{W}_{\mathrm{p}} / \mathbf{W}_{\mathrm{i}}$ & $\begin{array}{c}\delta_{\text {pitch }} \\
(\stackrel{o}{)})\end{array}$ & $\begin{array}{c}\delta_{\text {yaw }} \\
(\stackrel{o}{)} \\
\end{array}$ & $\begin{array}{l}\delta_{r} \\
(\%)\end{array}$ \\
\hline NPR 50 Straight STR4 & 7.571 & -0.055 & -0.078 & -23.520 & 0.461 & 0.478 & 24.041 & 23.520 & 0.978 & -0.978 & 0.964 & 0.189 & 0.135 & -0.232 \\
\hline NPR 50 Straight STR4 & 7.552 & -0.144 & -0.119 & -23.614 & 0.487 & 0.477 & 25.388 & 23.615 & 0.930 & -0.930 & 1.021 & 0.289 & 0.348 & -0.453 \\
\hline NPR 50 Straight STR4 & 7.594 & -0.205 & 0.168 & -22.812 & 0.489 & 0.479 & 25.569 & 22.814 & 0.892 & -0.892 & 1.022 & -0.421 & 0.514 & -0.665 \\
\hline NPR 50 Straight STR4 & 7.640 & -0.274 & 0.160 & -22.692 & 0.456 & 0.489 & 23.792 & 22.694 & 0.954 & -0.954 & 0.933 & -0.403 & 0.691 & -0.800 \\
\hline NPR 50 Straight STR4 & 7.617 & 0.184 & 0.259 & -23.604 & 0.475 & 0.487 & 24.784 & 23.606 & 0.952 & -0.952 & 0.976 & -0.630 & -0.445 & -0.771 \\
\hline NPR 50 Straight STR4 & 7.599 & 0.020 & 0.248 & -23.761 & 0.463 & 0.486 & 24.119 & 23.763 & 0.985 & -0.985 & 0.952 & -0.597 & -0.048 & -0.599 \\
\hline NPR 50 Straight STR4 & 7.582 & 0.311 & -0.115 & -22.481 & 0.478 & 0.484 & 24.934 & 22.483 & 0.902 & -0.902 & 0.987 & 0.293 & -0.792 & -0.844 \\
\hline NPR 50 Straight STR4 & 7.587 & 0.225 & -0.117 & -22.523 & 0.466 & 0.484 & 24.307 & 22.525 & 0.927 & -0.927 & 0.961 & 0.297 & -0.572 & -0.644 \\
\hline NPR 50 Straight STR4 & 7.733 & -0.177 & -0.226 & -23.949 & 0.487 & 0.487 & 25.733 & 23.951 & 0.931 & -0.931 & 1.002 & 0.540 & 0.422 & -0.685 \\
\hline NPR 50 Straight STR4 & 7.678 & -0.040 & -0.259 & -23.760 & 0.464 & 0.483 & 24.499 & 23.761 & 0.970 & -0.970 & 0.962 & 0.626 & 0.096 & -0.633 \\
\hline NPR 50 Straight STR4 & 7.541 & -0.075 & -0.170 & -23.353 & 0.502 & 0.474 & 26.400 & 23.354 & 0.885 & -0.885 & 1.059 & 0.417 & 0.184 & -0.456 \\
\hline NPR 50 Straight STR4 & 7.511 & -0.119 & -0.201 & -23.126 & 0.476 & 0.484 & 24.514 & 23.128 & 0.943 & -0.943 & 0.984 & 0.499 & 0.296 & -0.580 \\
\hline NPR 50 Straight STR4 & 5.941 & -0.039 & -0.186 & -17.555 & 0.359 & 0.383 & 17.654 & 17.556 & 0.994 & -0.994 & 0.939 & 0.607 & 0.127 & -0.621 \\
\hline NPR 50 Straight STR4 & 3.894 & -0.163 & -0.182 & -10.205 & 0.243 & 0.251 & 10.736 & 10.208 & 0.951 & -0.951 & 0.970 & 1.023 & 0.916 & -1.373 \\
\hline NPR 50 Straight STR4 & 2.497 & -0.098 & -0.120 & -5.409 & 0.149 & 0.161 & 5.546 & 5.411 & 0.976 & -0.975 & 0.924 & 1.266 & 1.040 & -1.638 \\
\hline NPR 50 Straight STR4 & 1.496 & -0.028 & -0.077 & -2.158 & 0.084 & 0.096 & 2.140 & 2.159 & 1.009 & -1.008 & 0.865 & 2.033 & 0.743 & -2.164 \\
\hline NPR $5010^{\circ} \mathrm{Gimbal}$ & 6.725 & -1.559 & -0.628 & -28.697 & 0.580 & 0.429 & 29.507 & 28.747 & 0.974 & -0.973 & 1.352 & 1.253 & 3.110 & -3.352 \\
\hline NPR $5010^{\circ} \mathrm{Gimbal}$ & 6.712 & -1.616 & -0.620 & -28.674 & 0.607 & 0.428 & 30.867 & 28.726 & 0.931 & -0.929 & 1.418 & 1.239 & 3.226 & -3.454 \\
\hline NPR $5010^{\circ} \mathrm{Gimbal}$ & 6.742 & -1.713 & -0.582 & -28.586 & 0.576 & 0.430 & 29.309 & 28.643 & 0.977 & -0.975 & 1.339 & 1.167 & 3.428 & -3.621 \\
\hline NPR 50 Slot 3 & 7.524 & -6.531 & 0.387 & -23.170 & 0.592 & 0.475 & 30.830 & 24.076 & 0.781 & -0.752 & 1.245 & -0.958 & 15.742 & -15.768 \\
\hline NPR 50 Slot 3 & 7.511 & -6.460 & 0.344 & -23.153 & 0.602 & 0.474 & 31.377 & 24.040 & 0.766 & -0.738 & 1.270 & -0.852 & 15.589 & -15.610 \\
\hline NPR 50 Slot 3 & 7.480 & -6.357 & 0.398 & -22.975 & 0.604 & 0.472 & 31.468 & 23.842 & 0.758 & -0.730 & 1.280 & -0.993 & 15.466 & -15.495 \\
\hline NPR 50 Slot 3 & 7.337 & -6.418 & 0.430 & -22.540 & 0.586 & 0.472 & 30.080 & 23.440 & 0.779 & -0.749 & 1.242 & -1.092 & 15.894 & -15.927 \\
\hline NPR 50 Slot 3 & 5.858 & -4.932 & 0.356 & -17.373 & 0.467 & 0.377 & 22.886 & 18.063 & 0.789 & -0.759 & 1.238 & -1.172 & 15.849 & -15.888 \\
\hline NPR 50 Slot 3 & 4.166 & -3.290 & 0.255 & -11.316 & 0.332 & 0.268 & 14.957 & 11.788 & 0.788 & -0.757 & 1.238 & -1.291 & 16.211 & -16.257 \\
\hline NPR 50 Slot 3 & 2.370 & -1.505 & 0.152 & -5.295 & 0.183 & 0.153 & 6.666 & 5.507 & 0.826 & -0.794 & 1.199 & -1.644 & 15.868 & -15.945 \\
\hline NPR 50 Slot 3 & 1.471 & -0.503 & 0.028 & -2.031 & 0.098 & 0.095 & 2.466 & 2.092 & 0.848 & -0.823 & 1.036 & -0.797 & 13.923 & -13.944 \\
\hline NPR 50 Slot 4 & 7.582 & -4.023 & 0.084 & -23.750 & 0.569 & 0.479 & 29.682 & 24.088 & 0.812 & -0.800 & 1.188 & -0.202 & 9.614 & -9.616 \\
\hline NPR 50 Slot 4 & 7.555 & -3.678 & 0.202 & -23.582 & 0.559 & 0.477 & 29.145 & 23.868 & 0.819 & -0.809 & 1.171 & -0.490 & 8.864 & -8.877 \\
\hline NPR 50 Slot 4 & 7.525 & -3.963 & 0.214 & -23.594 & 0.566 & 0.475 & 29.522 & 23.925 & 0.810 & -0.799 & 1.192 & -0.519 & 9.536 & -9.549 \\
\hline
\end{tabular}




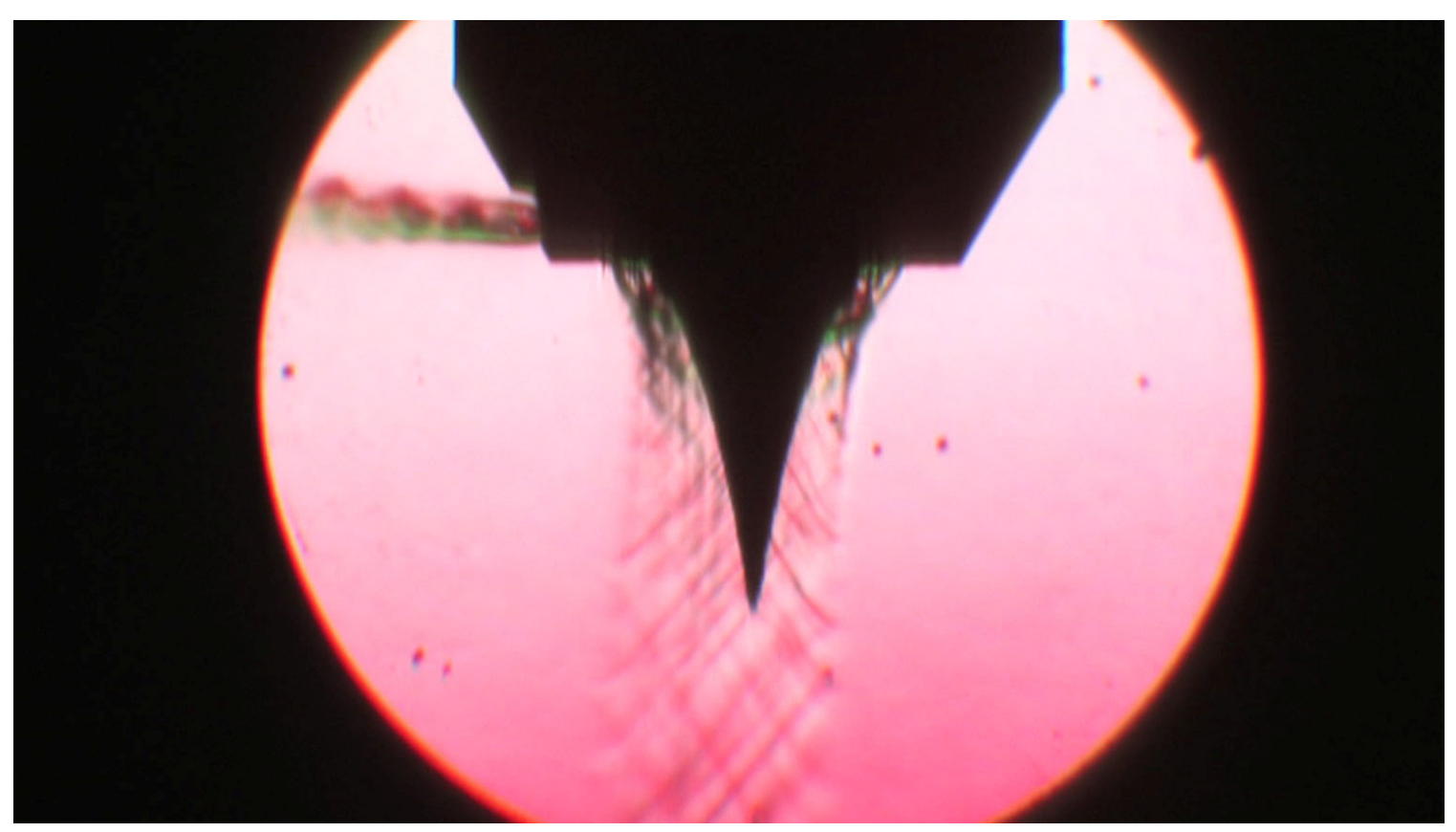

Figure 38: NPR 50 Slot 3.

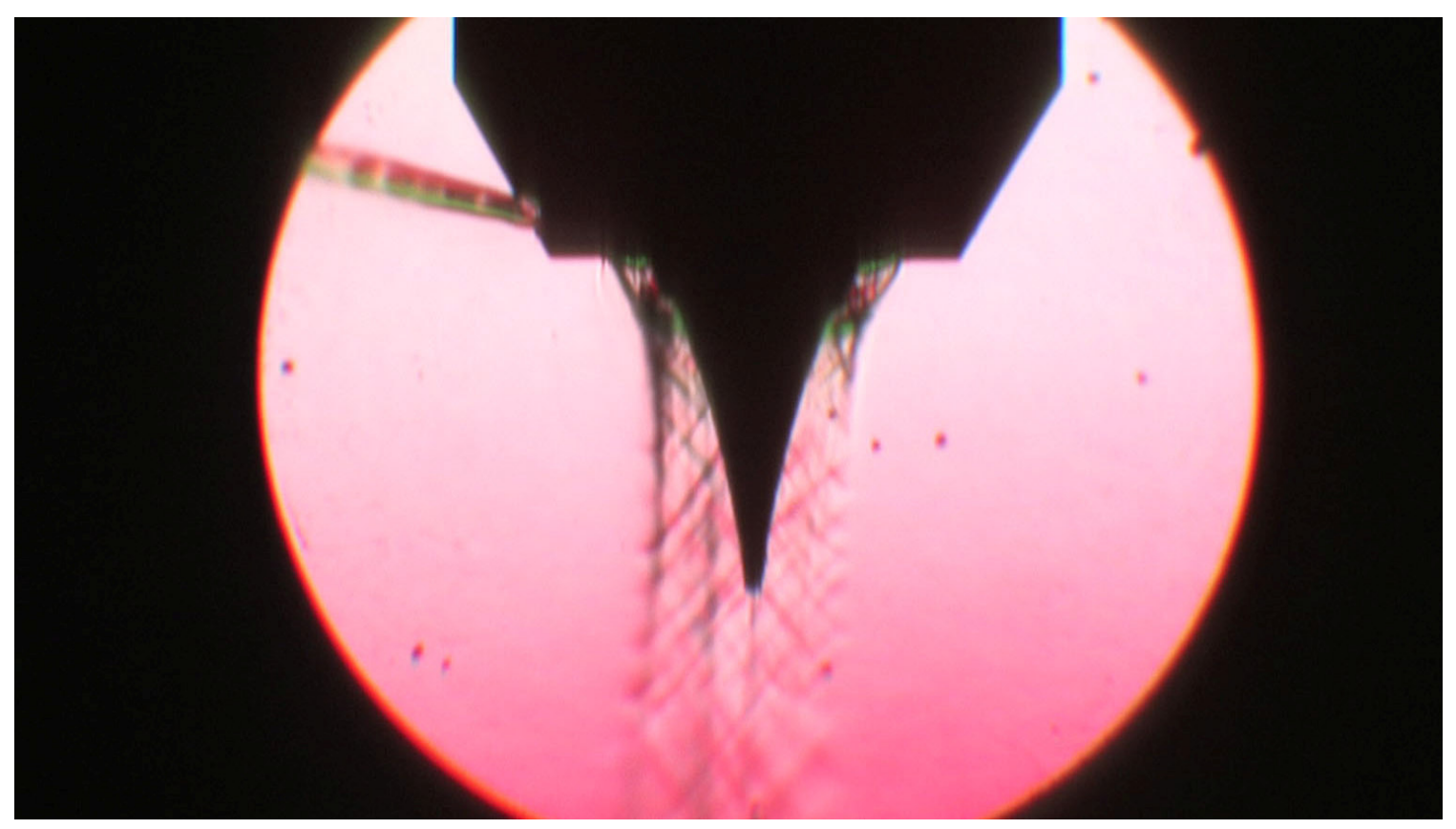

Figure 39: NPR 50 Slot 4. 


\section{Resultant Turn Angle Based on Throat Area}

From the testing of the differing nozzle NPRs and configurations some general conclusions can be realized. The gases exiting the secondary ports in the standard small slot and large slot showed uniform characteristics. The large slot tended to show separation from the fore wall section in the Schlieren photographs. This separation is most likely due to the fact that flow cannot round the sharp lip fast enough to completely fill the volume of the slot. Another apparent tendency was for the flow to exit past the radial axis towards the fore section of the nozzle body.

Shown in Table 9 and Figure 40 is the correlation between the secondary port area and the resultant turn angle. The results agree with the typical nozzle thrust equations where larger thrust is produced by the larger mass flow rate associated with increasing throat area, as well as the corresponding exit area. The resultant turn angle is determined by the angle formed by the net resultant thrust from the aerospike nozzle and the secondary port. With the different nozzle NPR configurations, the thrust produced by the main aerospike flow decreased as the NPRs went from NPR 6 to NPR 50. The increase in NPRs resulted in higher relative turn angles since the secondary port areas stayed constant while the aerospike throat area became smaller. 
Table 9: Slot throat areas and resultant turn angle.

\begin{tabular}{|l|c|l|}
\hline Description & $\begin{array}{c}\text { Actual Throat } \\
\text { Area (in^2) }\end{array}$ & Resultant Turn $\left(^{\circ}\right)$ \\
\hline
\end{tabular}

NPR 6

\begin{tabular}{|l|l|l|l|}
\hline Slot & Baseline slot & 0.0315 & 2.701 \\
\hline Slot 4 & Large Slot & 0.0552 & 4.753 \\
\hline Slot 5 & Small Slot & 0.0281 & 3.003 \\
\hline
\end{tabular}

NPR 20

\begin{tabular}{|c|c|c|c|}
\hline Slot & Baseline slot & 0.0298 & 6.725 \\
\hline Slot 3 & Large Slot & 0.0532 & 11.944 \\
\hline Slot 4 & Small Slot & 0.0276 & 7.462 \\
\hline Slot 5 & Small Slot, $10^{\circ}$ Angle & 0.0256 & 6.908 \\
\hline Slot 6 & Small Slot, $20^{\circ}$ Angle & 0.0242 & 6.571 \\
\hline Slot 8 & Small Slot, $0.075 "$ Axially fore of typical slot & 0.0258 & 6.678 \\
\hline Slot 9 & Small Slot, $0.225 "$ Axially fore of typical slot & 0.0250 & 6.298 \\
\hline Slot 10 & Small Slot, 0.025" Radius & 0.0350 & 9.293 \\
\hline Slot 11 & Small Slot, 0.050" Radius & 0.0457 & 11.367 \\
\hline Slot 12 & Small Slot, 0.075" Radius & 0.0525 & 12.542 \\
\hline Slot 13 & Small Slot, $0.075 "$ Radius on entrance edge only & 0.0496 & 13.703 \\
\hline Slot 14 & Small Slot, $0.075 "$ Radius aft edge only & 0.0324 & 7.86 \\
\hline Slot 15 & Small Slot, $0.075^{\prime \prime}$ Radius, $10^{\circ}$ Angle & 0.0440 & 12.816 \\
\hline Slot 16 & Small Slot, $12.5^{\circ}$ Angle & 0.0246 & 6.721 \\
\hline
\end{tabular}

NPR 50

\begin{tabular}{|l|l|c|c|}
\hline Slot & Baseline Slot & 0.0363 & 8.965 \\
\hline Slot 2 & Baseline Slot & 0.0292 & 9.039 \\
\hline Slot 3 & Large Slot & 0.0619 & 15.7 \\
\hline Slot 4 & Small Slot & 0.0315 & 9.348 \\
\hline
\end{tabular}


Turn Angle vs. Port Throat Area

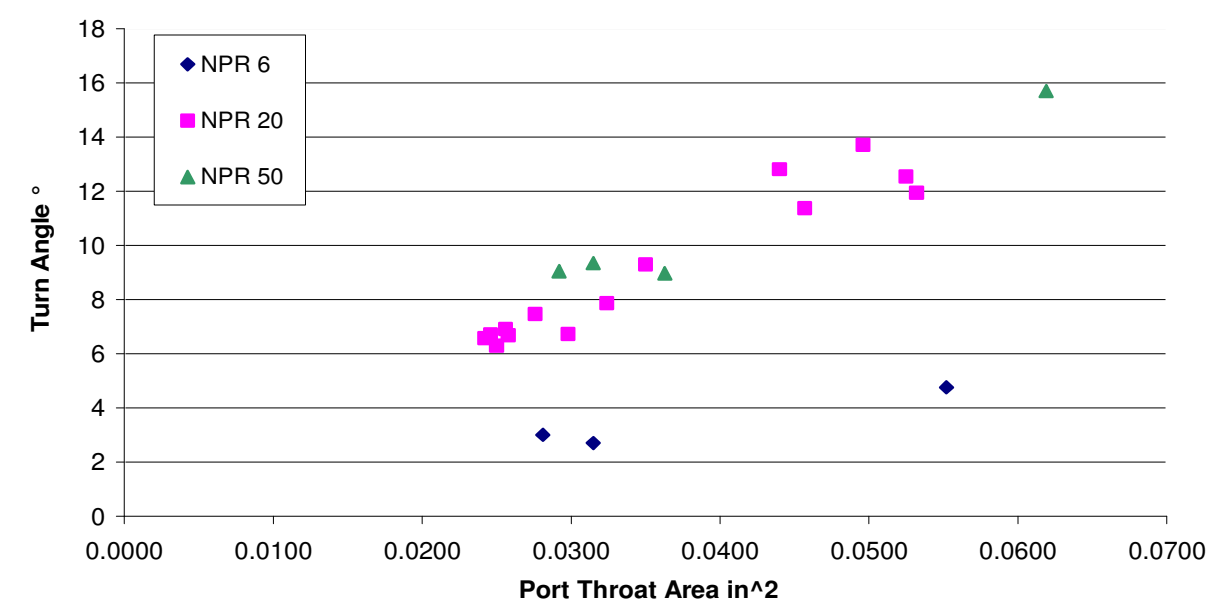

Figure 40: Port throat area vs. turn angle.

NPR 20 slots 5 and 6 were created with angled slots of $10^{\circ}$ and $20^{\circ}$. This approach was used to determine if the flow exiting the secondary port would be affected by angling the slots. As shown in Table 5, angling the slots changes the direction of the flow from the secondary port but does not produce any significant gains in terms of thrust or resultant turn angles. NPR 20 slot 16 was created at a later date with a $12.5^{\circ}$ slot angle and produced nearly radial flow with similar resultant turn angles to slot configurations 5 and 6.

Adding a radius to the inside wall of NPR 20 slots 10 though 13 greatly increases the amount of resultant turn angle produced. Introducing a radius to the entrance of the secondary port, in the small slot configuration opens the throat area of the secondary port by rounding off the edges and allows more flow. The radius also helps smooth out the airflow entering the secondary port and the flow does not reflect off the aft wall of the nozzle and exits perpendicular to the axial axis. The effects of the radius on secondary port thrust and entrance effects became more pronounced as the radius increased. 
During the experiments the supply pressure to the nozzle was also varied, which changed the NPR at which the nozzle operates, these results are shown in Table 3-7. The most significant result was the resultant turn angles are nearly constant through the different NPR adjustments. The constant turn angle throughout the differing NPRs proves that the resultant turn angle depends more on nozzle throat and secondary port areas rather than chamber pressure.

When compared to the previous research conducted in phase I of "Optimal Thrust Vectoring for an Annular Aerospike Nozzle"(1) and "Thrust Vector Optimization of $10^{\circ}$ Gimbaled Finned Aerospike Nozzles"(7), slotted nozzles can out-perform existing techniques based on the resultant turn angles. Turn angles greater than $10^{\circ}$ were routinely achieved throughout testing. The most significant factor is sizing the secondary port area relative to the aerospike throat area. Adding a radius to the inner wall of the slot helps to improve performance.

Although greater turn angles are achieved when compared to previous methods of gimbling and gimbling with fins, there are drawbacks to the slotted configurations. The main drawback to the slotted nozzle design is the flow instability during the test runs. When viewing the schlieren video for the runs, the flow exiting the secondary port would fluctuate and flicker as the nozzle ramped up to a steady-state condition. These seemingly random fluctuations in flow direction at the exit of the secondary port may be problematic in flight. Another disadvantage is the fact that it is extremely difficult to keep the exhaust flow exiting in the radial direction and the required geometries would be difficult and costly to manufacture. 


\section{Axial Chamber Pressure Variation}

Figure 41 shows the pressure recorded along the inner wall of the nozzle body. The results show that there is a slight pressure variation along the axis. The graph below shows that the placement of the secondary port coincides with the higher pressure regions. Also, the pressure at the aft most pressure tap was recorded at approximately 75 psia. The low pressure at this point can be explained by the rapid decrease in pressure as the fluid velocity increases and reaches the choke point at the aerospike throat area(8).

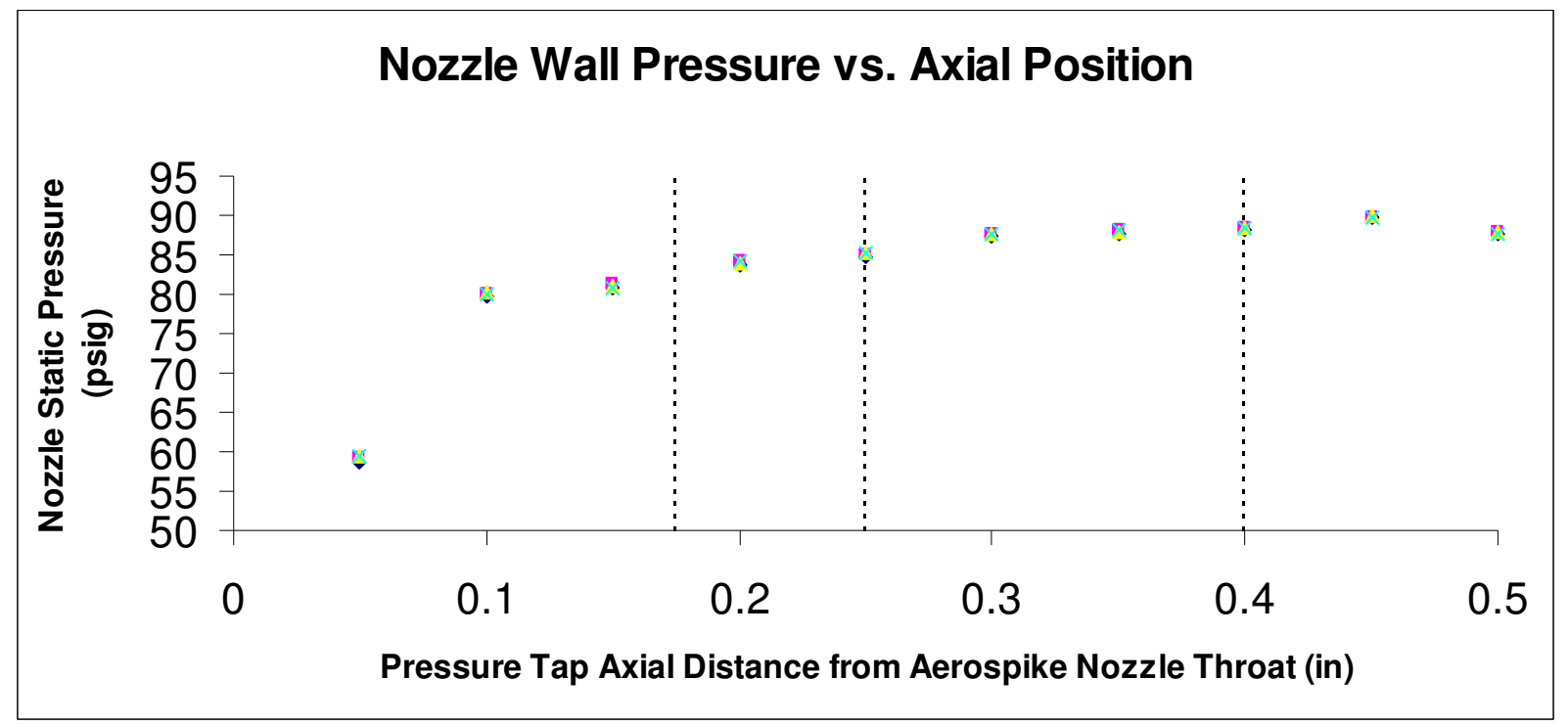

Figure 41: Axial pressure distribution for NPR 20 aerospike nozzle.

\section{Turn Angle versus Chamber Pressure}

Four configurations of the small secondary port geometry nozzles were tested at differing chamber pressures. One nozzle from each design criteria was selected, as well as the NPR 20 Slot 12 geometry, which is the small slot configuration with the $0.075 "$ inlet radius. The servo-actuated ball valve was ranged from the slightest opening to fully open to provide differing supply pressures. Figures $42-45$ show the relationship between 
NPR and the resultant turn angle. The graphs show that the measured resultant turn angles were relatively constant with respect to NPR compared to the calculated values. The calculated turn angles predict that the angle increases with NPR but approaches a horizontal asymptote near NPRs of 10. The calculated values for NPR 20 and NPR 50 nozzles provide a reasonable prediction of what to expect from the experimental results. The critical choked flow pressure $(\mathrm{NPR}=1.894)$ is also included in each graph as a vertical dotted line. The turn angle is independent of chamber pressure and it can be assumed that typical calculated results up to full expansion for NPR 20 and NPR 50 will hold true, which is also confirmed by the measured data. Note that the calculated turn angles were based on measured area from solid models and are subject to error. Due to the width of the slot and the roundness of the pressure chamber it is difficult to get an accurate effective area due to the entrance being parabolic. The method used to determine the area was based on a normal plane to the center axis of the slot. The inability for the rapid prototype process to produce sharp edges also introduces error into the comparison. The nozzles with a radius on the secondary port inlets show better predictability than units without an inlet radius. The calculations performed have not had a uncertainty analysis done to predict the amount of error, but shows an approximate error of $25 \%$ with the exception of a few cases. It should also be noted that the calculations assume one-dimensional isentropic flow, but the actual geometry of the compound nozzle will cause the flow to be more complex. The calculated results show correlation between measured data and analytical calculations, but at lower NPRs the calculations show more error. This is evidenced by dips in the calculated resultant turn angle plots. At lower NPRs, the calculation for thrust shows that the atmospheric 
pressure is much larger than pressure at the exit of the secondary port. The difference in pressure causes the pressure thrust to act against the jet thrust and therefore results in a negative thrust. The negative force resulting from the pressure difference was more pronounced in the NPR 6 Slot 5 and NPR 20 Slot 4 nozzles.

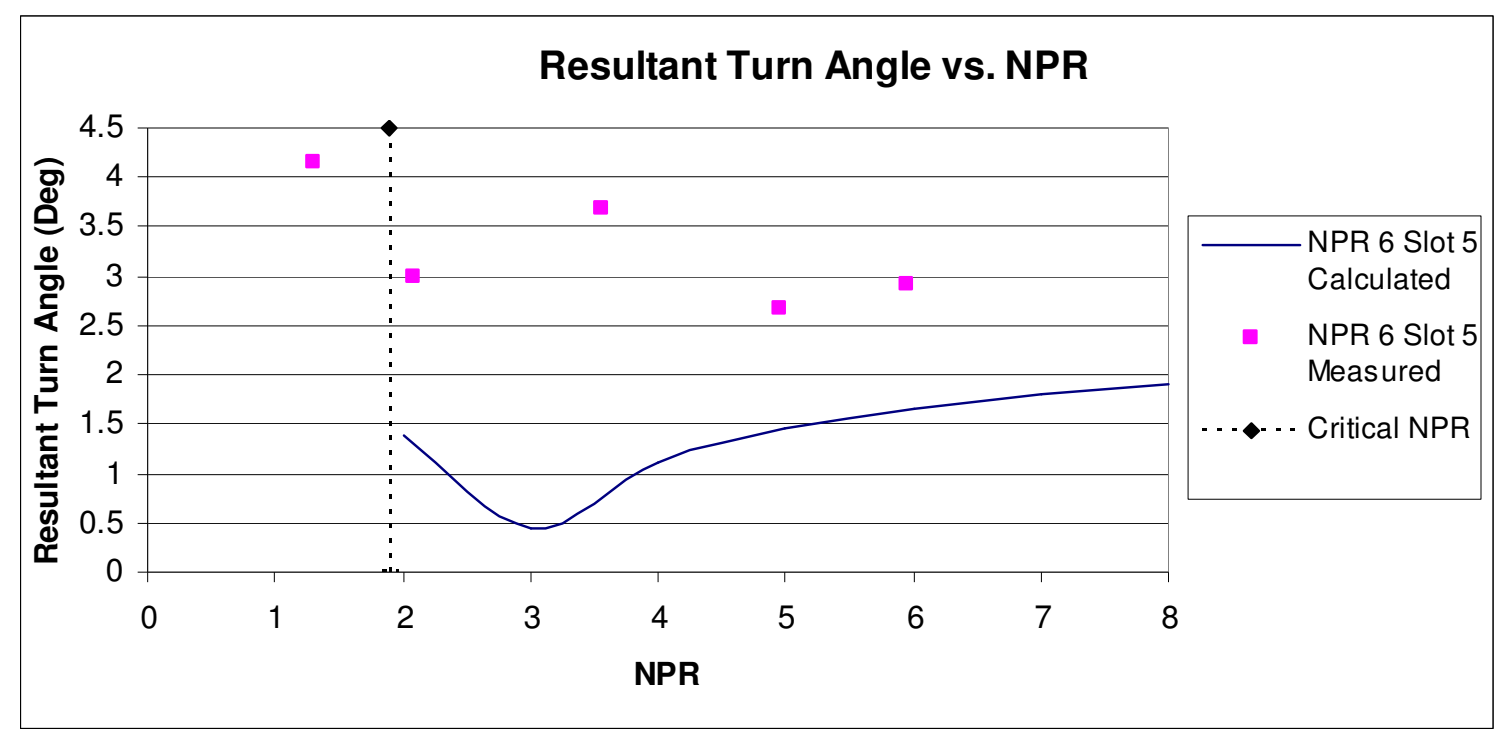

Figure 42: NPR 6 Slot 5 turn angle versus NPR. 


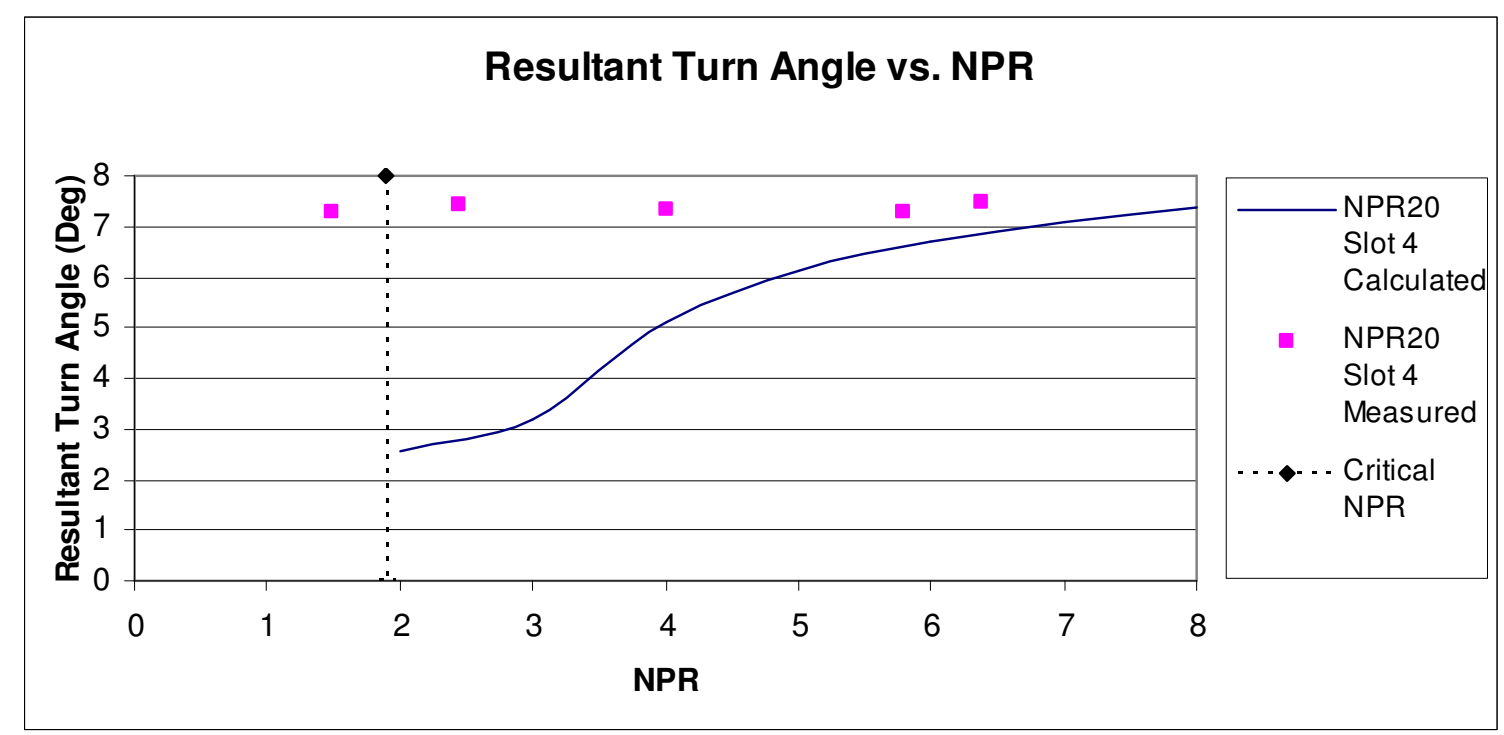

Figure 43: NPR 20 Slot 4 turn angle versus NPR.

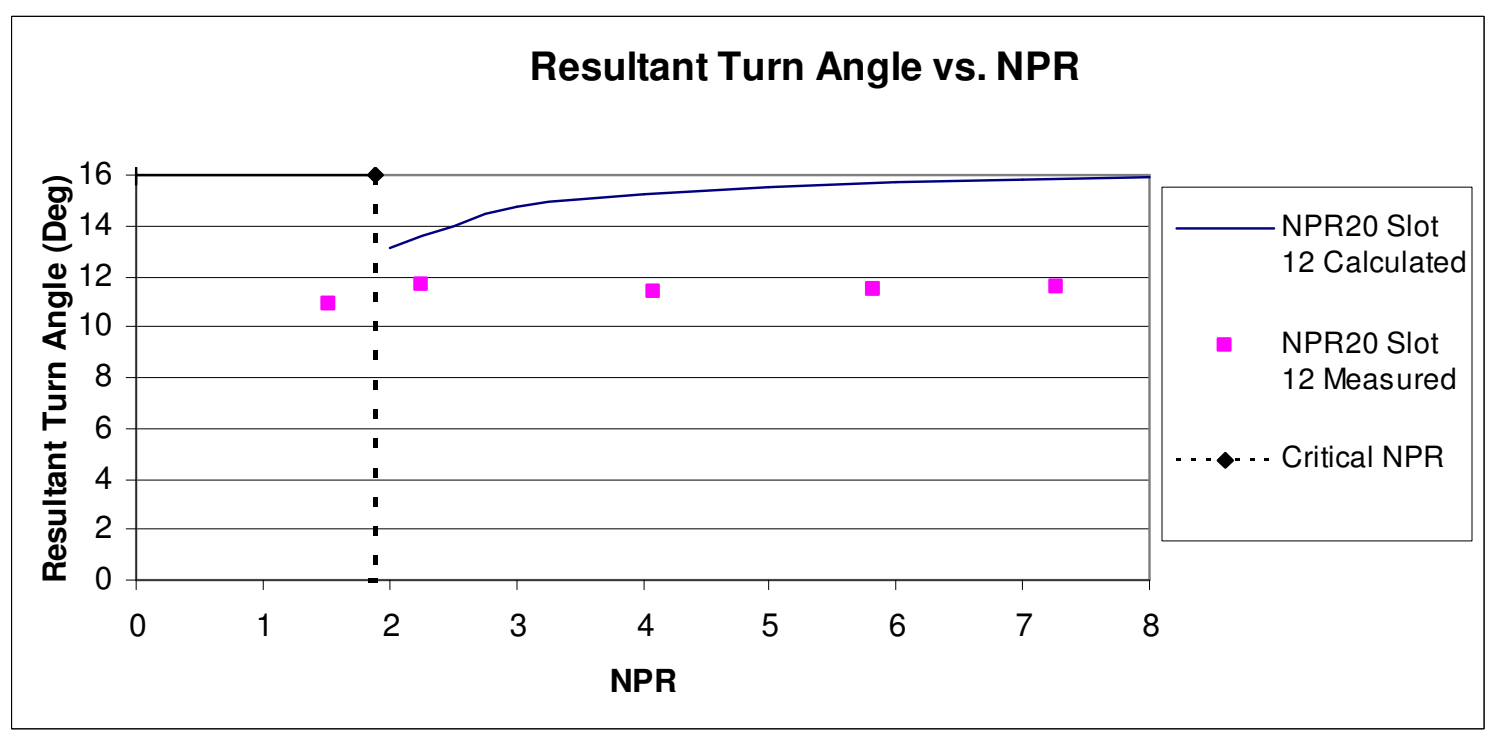

Figure 44: NPR 20 Slot 12 turn angle versus NPR. 


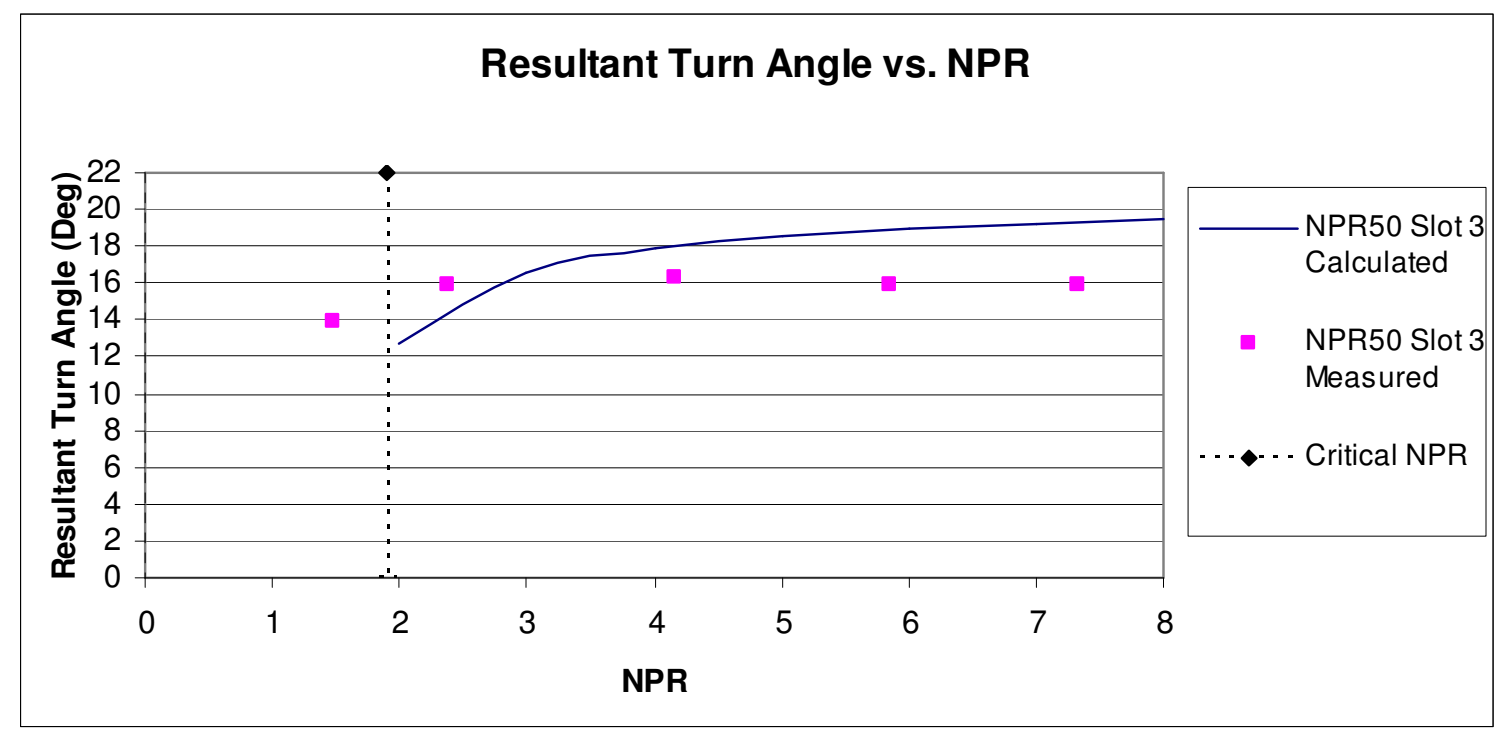

Figure 45: NPR 50 Slot 3 turn angle versus NPR.

A further comparison for all the slotted configurations with radial secondary ports was also conducted. The calculated values were compared to the measured values, and the results graphed in Figures 43-46. The measured data compared to the calculated values shows that the best predictability results from the small slot configurations especially with added inlet radii. 


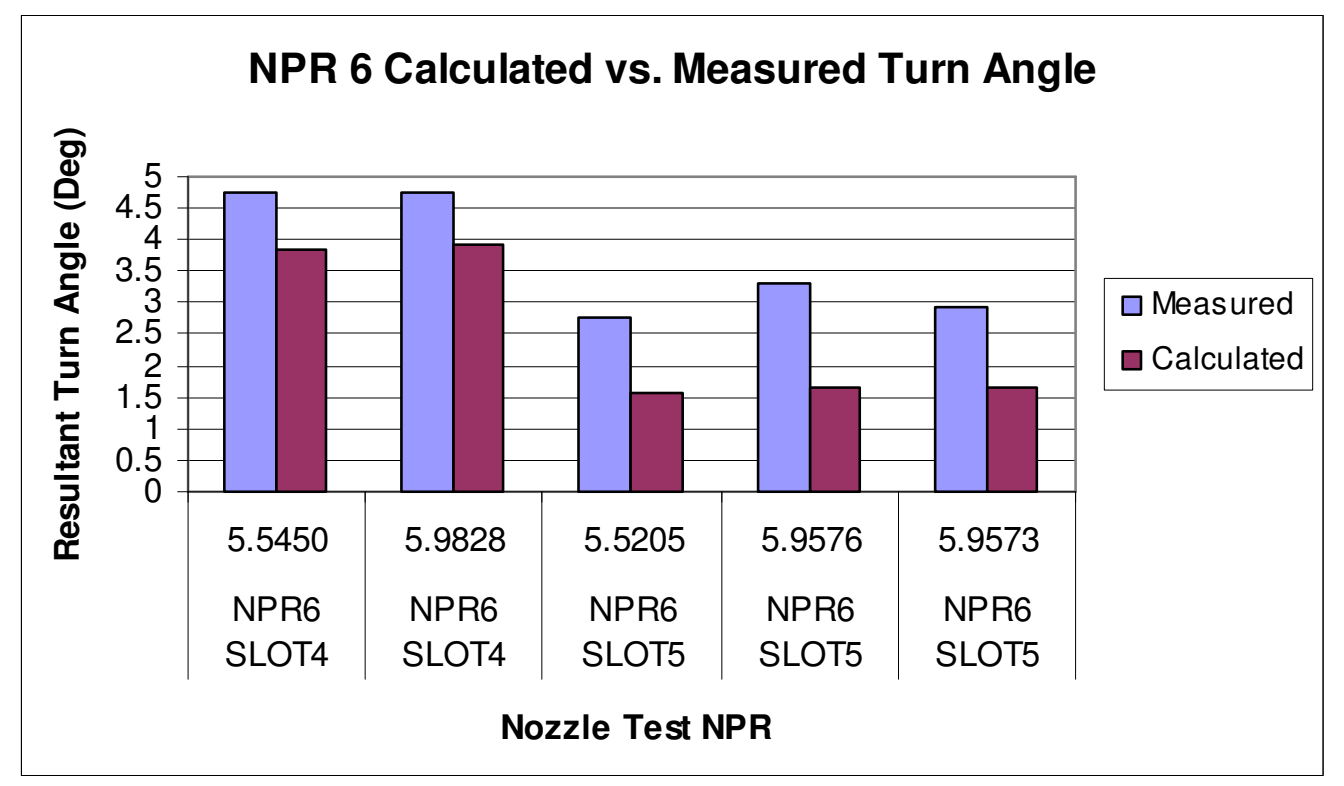

Figure 46: NPR 6 slotted nozzles, measured and calculated values.

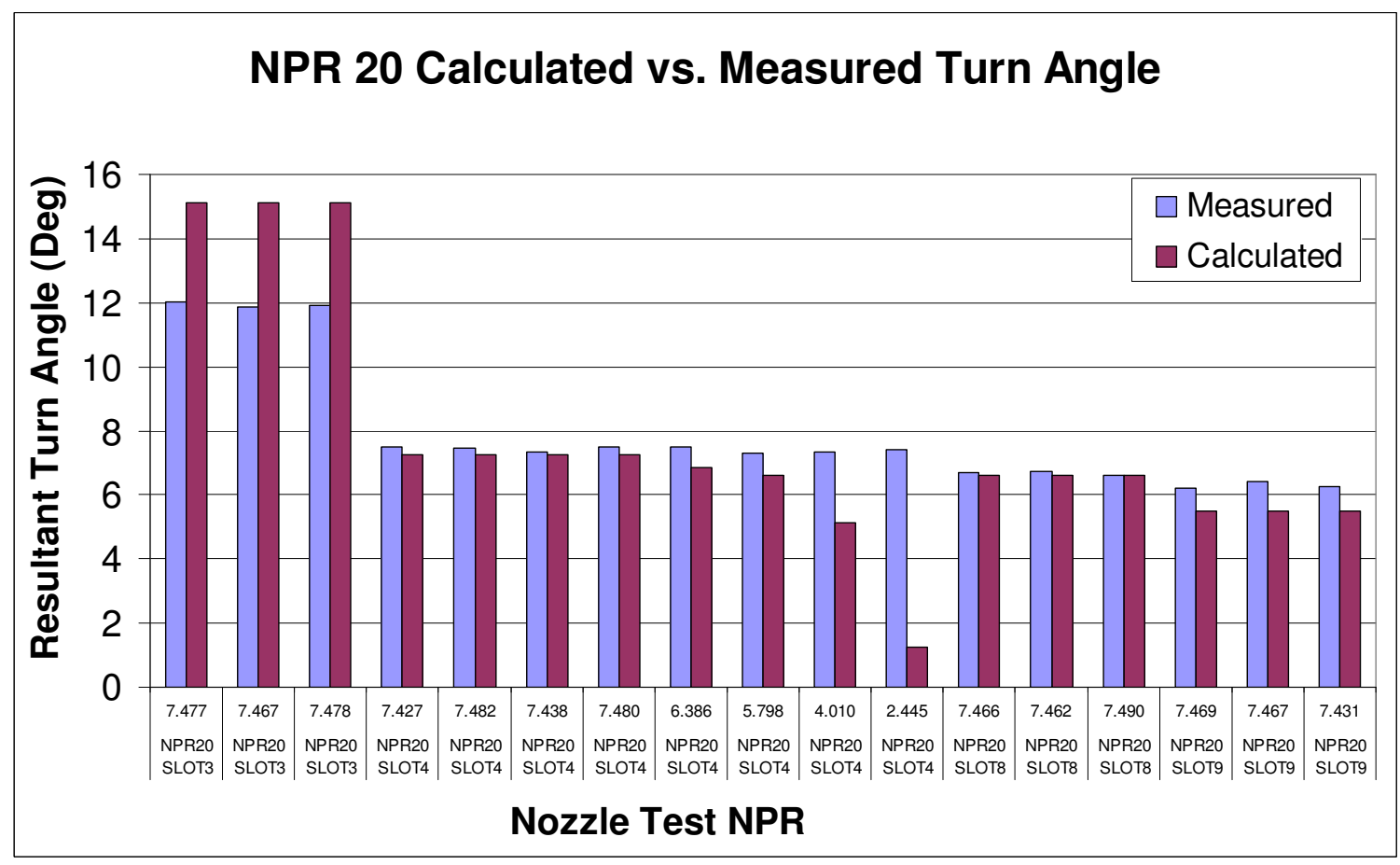

Figure 47: NPR 20 slotted nozzles, measured and calculated values. 


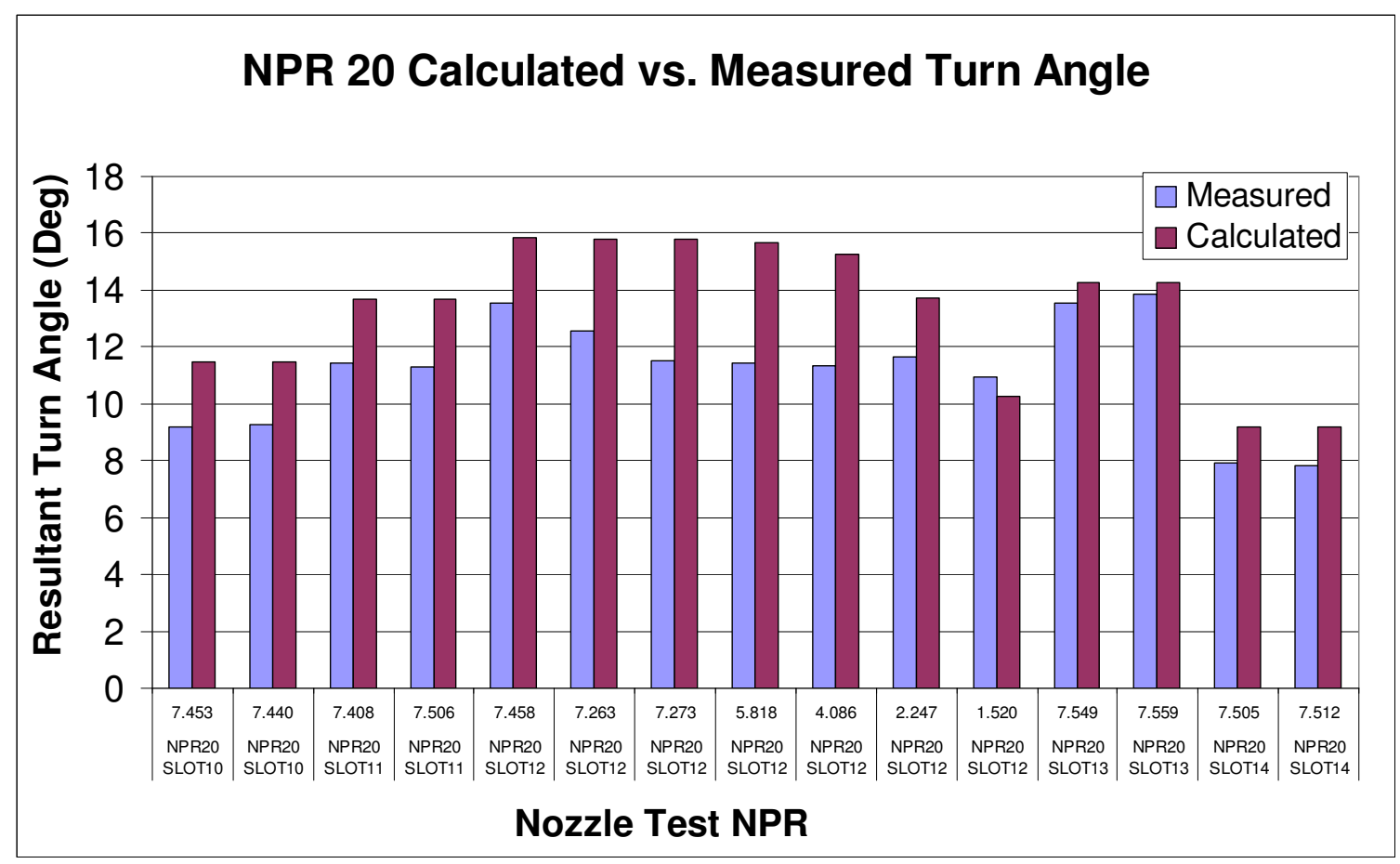

Figure 48: NPR 20 slotted nozzles, measured and calculated values continued.

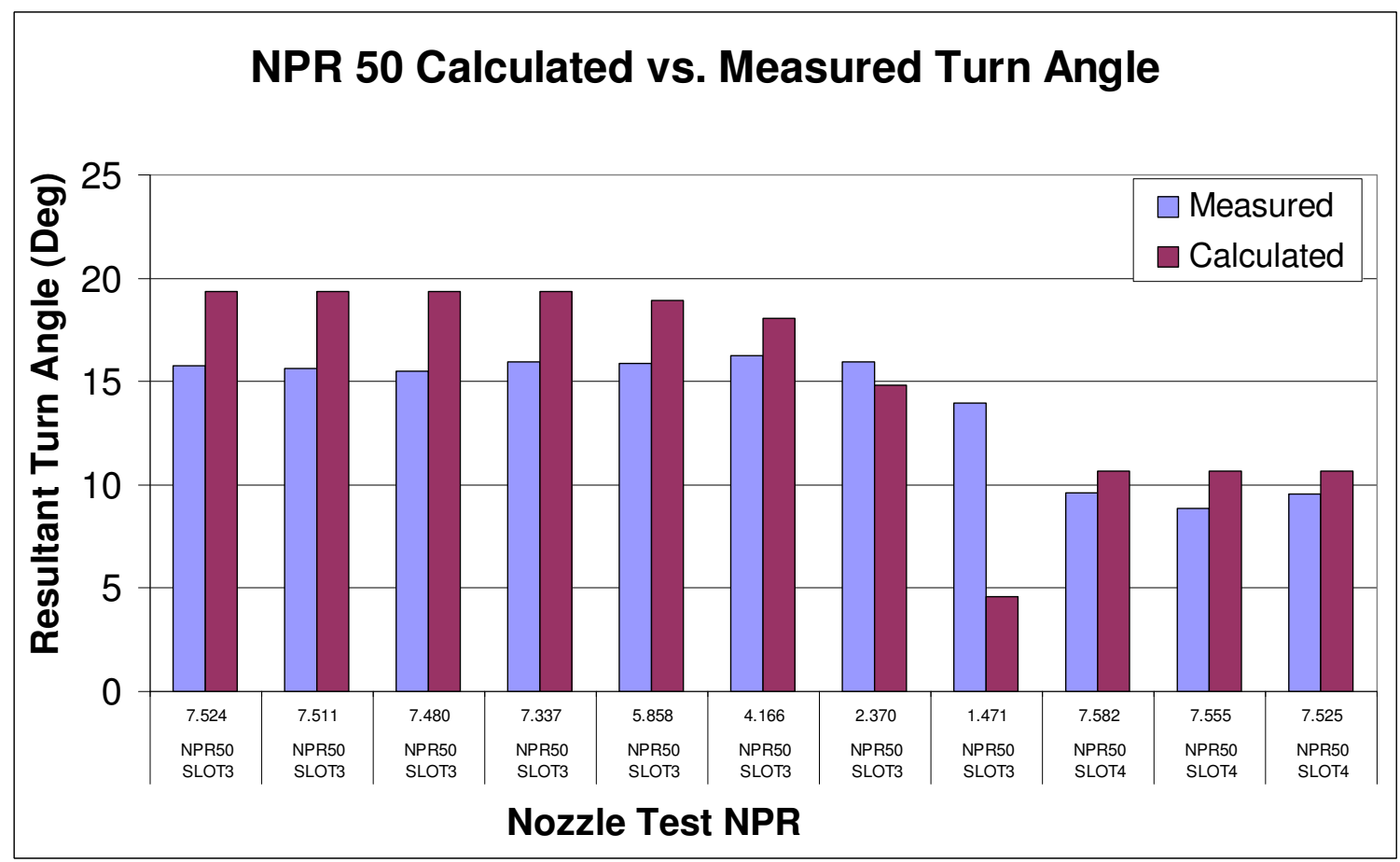

Figure 49: NPR 50 slotted nozzles, measured and calculated values. 
Figures 50-51 show the predicted values for the NPR 20 and NPR 50 nozzles up to their designed NPRs. The NPR 6 nozzles are not shown since the test facility is able to operate the nozzles at their intended design point.

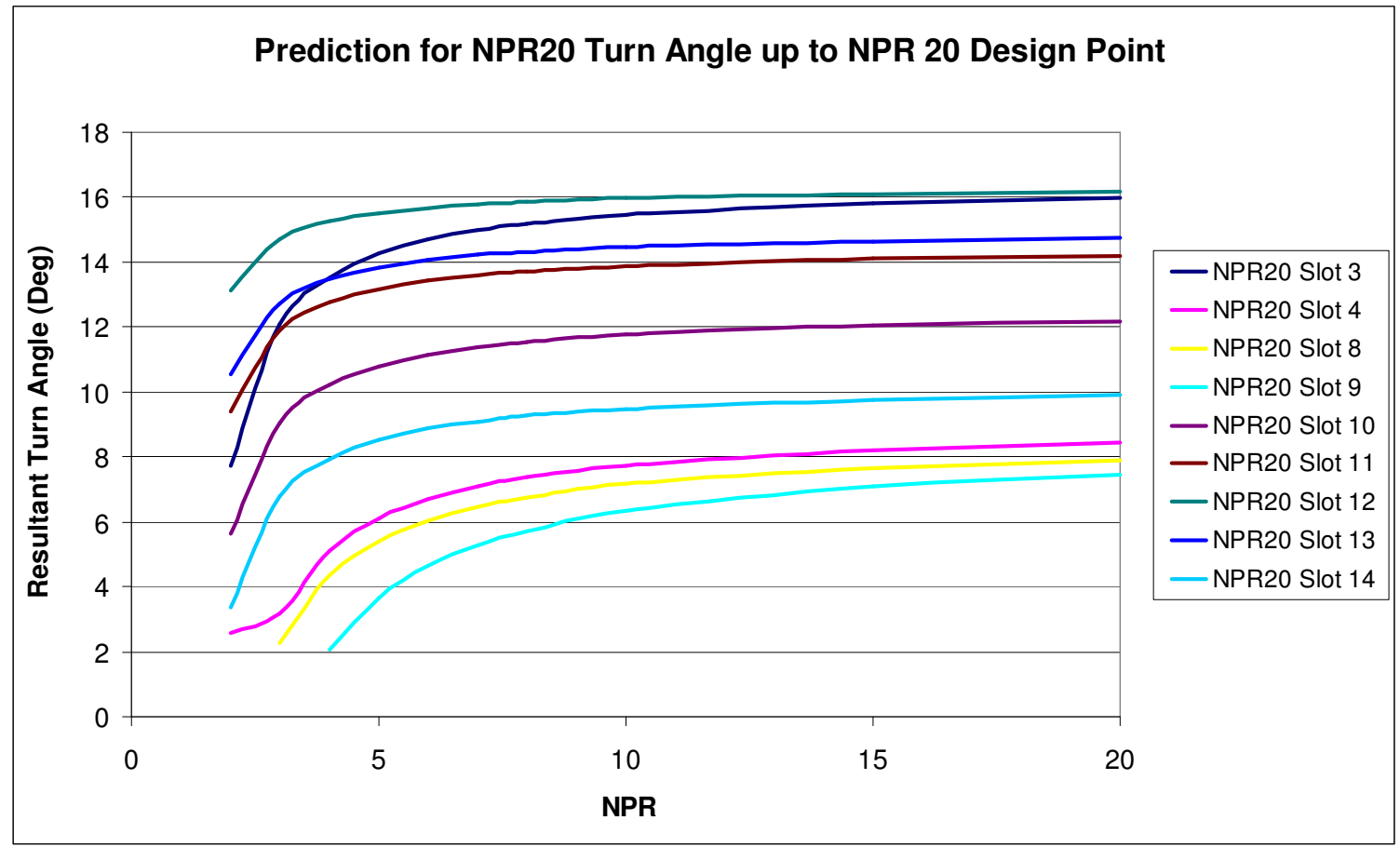

Figure 50: Predicted values based on NPR for NPR 20 nozzles. 


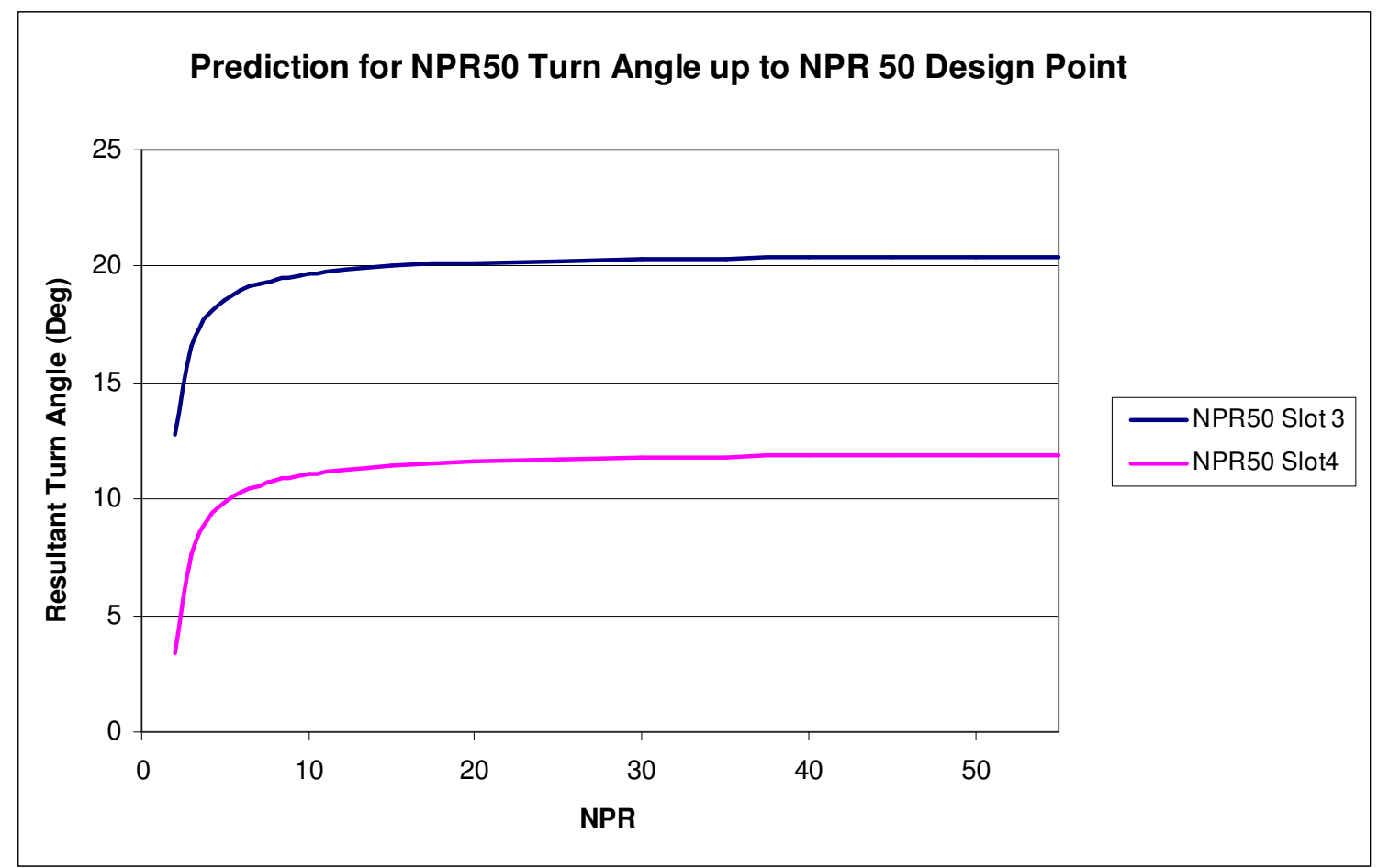

Figure 51: Predicted values based on NPR for NPR 50 nozzles. 


\section{Conclusion}

The slotted compound nozzle provides significant advantages over other conventional thrust vectoring techniques. The slotted configuration exceeds turn angles seen in most previously researched methods $(1,7)$. Although a completely gimbled nozzle can provide significant resultant turn angles, the gimbled nozzle comes at a cost of complication in implementation. With the compound nozzle configuration, $15^{\circ}$ of turn angle was possible. The only drawback of the compound slotted nozzle seems to be the observed flow direction and the occasional flow instability observed exiting the slot. The results of the Schlieren visualization showed the angles to be misaligned from the desired radial direction. Further development efforts are needed in order to straighten out the flow. The addition of radii to the inlet seemed to help flow direction and stability. The entrance side of the slot seemed to benefit the most from a radius placed around the edge.

In general it was observed that the throat and exit areas of the secondary port play a role in how much side thrust can be generated. As the throat area increases, more mass flow through the slot is observed, and larger resultant turn angles are generated. There is a limitation on how large an area can be implemented before the entire slot fails to fill, although the large slot configurations were not tested with a radius. Further optimization between the slot area and aerospike throat area could be implemented to find the perfect balance.

The measured turn angles seemed to be largely independent of NPR. This intuitively makes sense since both aerospike thrust and slot thrust changes linearly with pressure, thus the resultant angle would remain constant. Scaled testing or theoretical calculations would be satisfactory in predicting the performance of future designs. 


\section{Bibliography}

1. Carpenter, T., Murray, W. "Optimal Thrust Vectoring for an Annular Aerospike Nozzle,” Proposal No. 04 STTR-II T2.02-9951, 2004.

2. Besnard, Eric and Garvey, John. 'Development and Flight-Testing of Liquid Propellant of Aerospike Engines", Proceedings of the $40^{\text {th }}$ annual AIAA/ASME/SAE/ASEE Joint Propulsion Conference and Exhibit, AIAA Fort Lauderdale, FL, 2004, AIAA paper 2004-3354.

3. Nyberg, Donald Gerrit, Groudle, Thomas Adrian, Smith, Richard Doyle. (2009) U.S. Patent No. 7,565,797. Washington, DC: U.S. Patent and Trademark Office.

4. Bovankovich, Mark. "Analysis of a Multicomponent Thrust Measurement Stand." BS. California Polytechnic State University. 1992. San Luis Obispo, CA.

5. Hall, Perry E.. "Validation and Performance of a Dual Flow Thrust Stand." MS. California Polytechnic State University. 1994. San Luis Obispo, Ca.

6. Lee, Che-Ching and Thompson, Donald D. "Fortran Program for Plug Nozzle Design.” NASA TM X-53019, July 1964.

7. Rohlik, N. "Thrust Vector Optimization of $10^{\circ}$ Gimbaled Finned Aerospike Nozzles", MS. Mechanical Engineering Department, California Polytechnic State University. San Luis Obispo, 2008

8. Sutton, G.P. and Biblarz, O. "Rocket Propulsion Elements", $7^{\text {th }}$ Ed., John Wiley \& Sons, New York, 2001.

9. Vaccarezza, Stephen Emilio. "A Color Schlieren Performance Analysis of a Thrust Vectored Nozzle with Postexit Vanes." MS. California Polytechnic State University. 1993. San Luis Obispo, CA.

10. Rossi, Richard Alan. "Undeflected Dual Flow Thrust Vectoring Nozzle Performance." MS. California Polytechnic State University. 1994. San Luis Obispo, CA.

11. Clauson, Tanda Lauree. "Performance Comparison of Dual and Single Flow Thrust Vector Nozzles." MS. California Polytechnic State University. 1996. San Luis Obispo, CA.

12. Zucrow, M.J., Hoffman, J.D. "Gas Dynamics: Volume 1," John Wiley \& Sons, New York, 1976. 